\title{
Going the Extra (Synaptic) Mile: Excitotoxicity as the Road Toward Neurodegenerative Diseases
}

\section{OPEN ACCESS}

Edited by:

Balázs Pál,

University of Debrecen, Hungary

Reviewed by:

Christine R. Rose,

Heinrich Heine University of

Düsseldorf, Germany

Lucia Wittner,

Research Centre for Natural Sciences

(MTA), Hungary

${ }^{*}$ Correspondence:

Sandra H. Vaz

svaz@medicina.ulisboa.pt

${ }^{\dagger}$ These authors share first authorship

Specialty section:

This article was submitted to Cellular Neurophysiology, a section of the journal Frontiers in Cellular

Neuroscience

Received: 18 December 2019 Accepted: 26 March 2020 Published: 24 April 2020

Citation:

Armada-Moreira A, Gomes Jl,

Pina CC, Savchak OK

Gonçalves-Ribeiro J, Rei N, Pinto S, Morais TP, Martins RS, Ribeiro FF,

Sebastião AM, Crunelli V and Vaz SH (2020) Going the Extra (Synaptic)

Mile: Excitotoxicity as the Road

Toward Neurodegenerative Diseases.

Front. Cell. Neurosci. 14:90.

doi: 10.3389/fncel.2020.00090

\author{
Adam Armada-Moreira ${ }^{1,2,3 t}$, Joana I. Gomes ${ }^{1,2 t}$, Carolina Campos Pina ${ }^{1,2}$, \\ Oksana K. Savchak ${ }^{1,2}$, Joana Gonçalves-Ribeiro ${ }^{1,2}$, Nádia Rei $i^{1,2}$, Sara Pinto ${ }^{1,2}$, \\ Tatiana P. Morais ${ }^{4}$, Robertta Silva Martins ${ }^{5}$, Filipa F. Ribeiro ${ }^{1,2}$, Ana M. Sebastião ${ }^{1,2}$, \\ Vincenzo Crunelli ${ }^{4,6}$ and Sandra H. Vaz ${ }^{1,2 *}$
}

'Instituto de Farmacologia e Neurociências, Faculdade de Medicina da Universidade de Lisboa, Lisbon, Portugal, ${ }^{2}$ Instituto de Medicina Molecular João Lobo Antunes, Faculdade de Medicina da Universidade de Lisboa, Lisbon, Portugal, ${ }^{3}$ Interdisciplinary Nanoscience Center (iNANO), Aarhus University, Aarhus, Denmark, ${ }^{4}$ Neuroscience Division, School of Bioscience, Cardiff University, Cardiff, United Kingdom, ${ }^{5}$ Laboratório de Neurofarmacologia, Instituto Biomédico, Universidade Federal Fluminense, Niterói, Brazil, ${ }^{6}$ Department of Physiology and Biochemistry, Faculty of Medicine and Surgery, University of Malta, Msida, Malta

Excitotoxicity is a phenomenon that describes the toxic actions of excitatory neurotransmitters, primarily glutamate, where the exacerbated or prolonged activation of glutamate receptors starts a cascade of neurotoxicity that ultimately leads to the loss of neuronal function and cell death. In this process, the shift between normal physiological function and excitotoxicity is largely controlled by astrocytes since they can control the levels of glutamate on the synaptic cleft. This control is achieved through glutamate clearance from the synaptic cleft and its underlying recycling through the glutamate-glutamine cycle. The molecular mechanism that triggers excitotoxicity involves alterations in glutamate and calcium metabolism, dysfunction of glutamate transporters, and malfunction of glutamate receptors, particularly $\mathrm{N}$-methyl-D-aspartic acid receptors (NMDAR). On the other hand, excitotoxicity can be regarded as a consequence of other cellular phenomena, such as mitochondrial dysfunction, physical neuronal damage, and oxidative stress. Regardless, it is known that the excessive activation of NMDAR results in the sustained influx of calcium into neurons and leads to several deleterious consequences, including mitochondrial dysfunction, reactive oxygen species (ROS) overproduction, impairment of calcium buffering, the release of pro-apoptotic factors, among others, that inevitably contribute to neuronal loss. A large body of evidence implicates NMDAR-mediated excitotoxicity as a central mechanism in the pathogenesis of many neurodegenerative diseases, including amyotrophic lateral sclerosis (ALS), Alzheimer's disease (AD), and epilepsy. In this review article, we explore different causes and consequences of excitotoxicity, discuss the involvement of NMDAR-mediated

\footnotetext{
Abbreviations: AD, Alzheimer's Disease; ALS, amyotrophic lateral sclerosis; AMPAR, $\alpha$-amino-3-hydroxy-5-methylisoxazole4-propionate receptors; AQP4, aquaporin 4; $\mathrm{A} \beta$, amyloid- $\beta$ peptide; $\mathrm{BDNF}$, brain-derived neurotrophic factor; CREB, cAMP-regulatory element binding protein; CypD, cyclophilin D; EAAT, excitatory amino acid transporters; eNMDAR, extrasynaptic NMDAR; GABA, $\gamma$-aminobutyric acid; GABAR, GABA receptors; iGluR, ionotropic glutamate receptors; KAR, kainate receptors; Kir4.1, input rectifier channels for potassium; mGluR, metabotropic glutamate receptors; NMDAR, N-methyl-D-aspartic acid receptors; NO, nitric oxide; NOS, NO synthase; ROS, reactive oxygen species; sNMDAR, synaptic NMDAR; SOD, superoxide dismutase; TLE, temporal lobe epilepsy; TNF- $\alpha$, tumor necrosis factor- $\alpha$.
} 
excitotoxicity and its downstream effects on several neurodegenerative disorders, and identify possible strategies to study new aspects of these diseases that may lead to the discovery of new therapeutic approaches. With the understanding that excitotoxicity is a common denominator in neurodegenerative diseases and other disorders, a new perspective on therapy can be considered, where the targets are not specific symptoms, but the underlying cellular phenomena of the disease.

Keywords: excitotoxicity, astrocytes, NMDA receptors, calcium signaling, neurodegenerative diseases, oxidative stress

\section{EXCITOTOXICITY: WHAT IS IT, WHERE DOES IT COME FROM, HOW DOES IT LIVE?}

\section{The Good, the Bad, and the Ugly: General Definition and Summary of Consequences}

When looking into the glutamatergic system within the central nervous system, one can see three sides of the same biological phenomenon. First, there is The Good: the glutamatergic system is essential for brain functioning. Indeed, with $40 \%$ of glutamatergic synapses in the central nervous system (Fairman and Amara, 1999), glutamate is essential for neuronal communication, as well as for higher-level functions, such as learning and memory. Then, there is The Bad: since glutamate plays such an important role in the brain, dysregulation of the glutamatergic system has long been implicated as a key step in the pathophysiology of neuronal death (Bano et al., 2005). Finally, there is The Ugly: excitotoxicity. This phenomenon, an important aspect of glutamatergic dysregulation, describes the toxic actions of excitatory neurotransmitters, mainly glutamate, that ultimately lead to neuronal death (Connolly and Prehn, 2015). While glutamate does not directly kill neurons, the exacerbated or prolonged activation of glutamate receptors starts a cascade of neurotoxicity (Lipton, 2008; Vincent and Mulle, 2009), which includes cationic influx, mitochondrial dysfunction, energetic and oxidative stress, and overproduction of reactive oxygen species (ROS; Connolly and Prehn, 2015; Prentice et al., 2015). Here, we review the main factors involved in excitotoxicity, as summarized in Figure 1, and their role in neurodegenerative diseases and epilepsy.

\section{If These Walls Could Talk... About Excitotoxicity: Historic Review}

The term "excitotoxicity" makes its debut in 1969 in a study by Olney where, for the first time, cell death was observed as a consequence of exposure to glutamate or aspartate (Olney, 1969). This type of excitotoxicity can be divided into three steps. It starts with the induction, which begins with the overactivation of ionotropic glutamate receptors (iGluR), such as N-methyl-D-aspartic acid receptors (NMDAR), $\alpha$ amino-3-hydroxy-5-methylisoxazole-4-propionate receptors (AMPAR) and kainate receptors (KAR). NMDAR display a high permeability to both sodium and calcium (McBain and Mayer, 1994), while AMPAR and KAR activation contributes mainly to sodium influx. This ionic influx is followed by water influx, leading to cell swelling and mitochondrial dysfunction. The final step of induction is the activation of metabotropic glutamate receptors (mGluR), activating pathways regulated by diacylglycerol and inositol 1,4,5-triphosphate (Zivin and Choi, 1991). Amplification and expression are the following stages. These consist of exacerbated metabolic activity, further disruption of ion gradients, elevated electrical neuronal activity, and mitochondria dysfunction (Zivin and Choi, 1991).

Other than this classification system for excitotoxicity, this phenomenon can be further categorized as strong or weak excitotoxicity (Albin and Greenamyre, 1992). Strong excitotoxicity refers to the classical phenomenon described by Olney (1969), where excitotoxicity is elicited by direct exposure to glutamate or another excitotoxic compound. In strong excitotoxicity, the calcium influx is prolonged, there is depolarization of both cell and mitochondria membranes, excessive consumption of $\mathrm{NAD}(\mathrm{P}) \mathrm{H}$, and an established bioenergetic failure. Furthermore, cell death is generally brought on by necrosis (Castilho et al., 1998; Connolly and Prehn, 2015). On the other hand, weak excitotoxicity results from a prolonged alteration of glutamate receptor function, possibly impacting membrane potential and cellular metabolism and increasing cellular sensitivity to the toxic actions of glutamate (Albin and Greenamyre, 1992). In this scenario, neurons are transiently able to restore calcium homeostasis, membrane potential, and internal ATP and $\mathrm{NAD}(\mathrm{P}) \mathrm{H}$ pools (Ward et al., 2000; Weisová et al., 2009). These neurons can then undergo delayed apoptosis, characterized by delayed calcium dysregulation, nuclear compression, and cellular contraction (Ankarcrona et al., 1995; Bonfoco et al., 1995; Ward et al., 2007; D'Orsi et al., 2012). This is accompanied by a loss of membrane potential, ATP depletion, and overproduction of ROS (Luetjens et al., 2000; Vesce et al., 2004).

\section{A Glutamatergic Mind: Glutamate in Physiological and Excitotoxic Conditions}

In central nervous system synapses, glutamate clearance is achieved by diffusion and transporter uptake, mainly into neighboring glial cells (van den Berg and Garfinkel, 1971; Benjamin and Quastel, 1972; Hertz et al., 1999), and is practically independent of enzymatic breakdown (Watkins and Evans, 1981).

It should however be noted that glutamatergic synapses are complex-their morphological characteristics (number of 


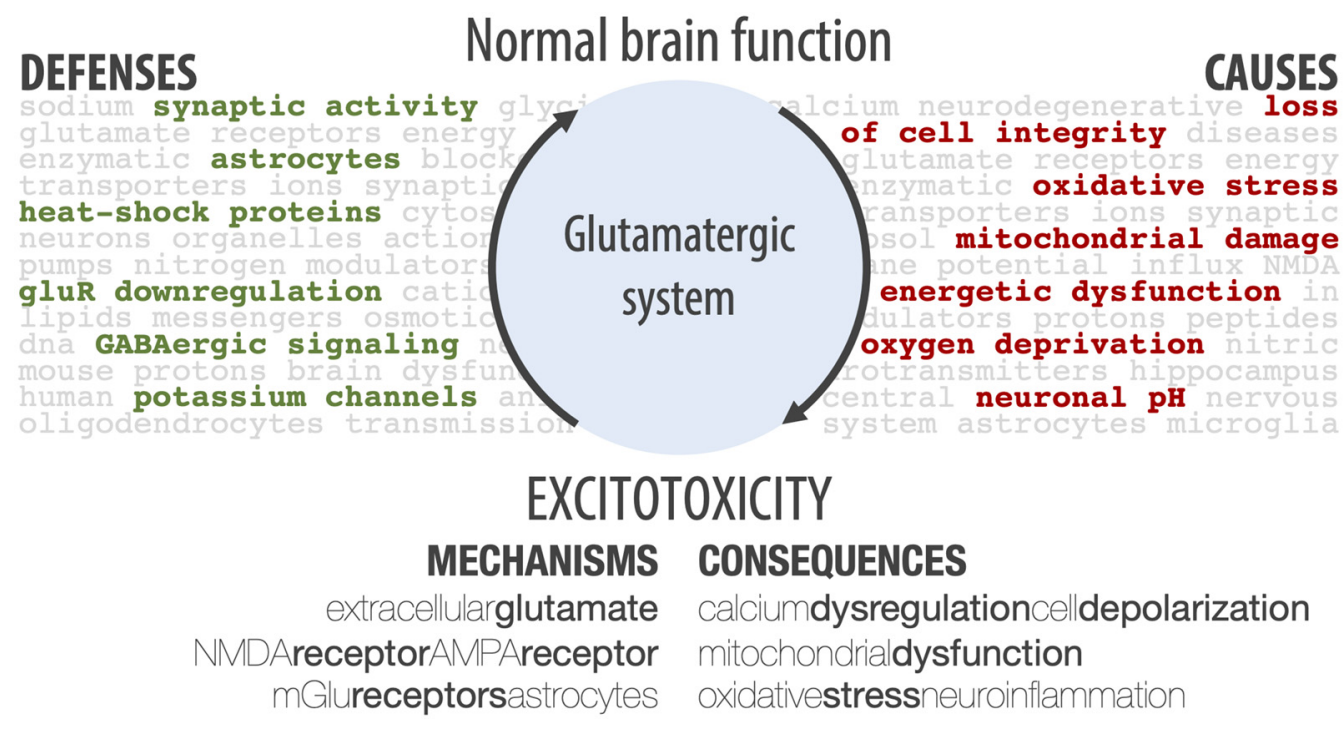

FIGURE 1 | Schematic summary of different aspects of excitotoxicity, including the main cellular defenses against it, the main causes, the players involved in its mechanisms, and general cellular consequences. The shift from normal brain function to an excitotoxic state is brought about by the main causes, and this shift is avoided by the main cellular defenses. If the defenses fail, excitotoxicity is amplified by different mechanisms, causing cellular consequences.

release sites, the existence of dendritic spines, etc.) can differ greatly and synapses in different neural circuitries exhibit different time courses of synaptic communication (Jonas, 2000). Furthermore, the exact time course of glutamate dynamics can be altered by the microanatomical synaptic properties (synaptic contact size, complexity of synaptic morphology, glial wrapping, etc.) and by the density of glutamate transporters (Jonas, 2000).

Even taking all this into account, during a synaptic event, the peak concentration of glutamate in the synapse can be estimated to be $1.1 \mathrm{mM}(1.0-1.5 \mathrm{mM})$, with a decay time constant of $1.2 \mathrm{~ms}$ (0.70-2.0 ms; Clements et al., 1992), while in extrasynaptic locations, the peak concentration can reach $190 \mu \mathrm{M}$ (Dzubay and Jahr, 1999). On the opposite side, the baseline concentration of synaptic glutamate (with no synaptic event occurring) is thought to vary between $25 \mathrm{nM}$ (Herman and Jahr, 2007) and $600 \mathrm{nM}$ (Mark et al., 2001), depending on the study. This basal concentration is unaltered by synaptic activity, being controlled solely by glutamate transporters (Herman and Jahr, 2007). Furthermore, this basal concentration does not activate glutamate receptors (Trussell and Fischbach, 1989; Patneau and Mayer, 1990; Conn and Pin, 1997) nor interferes with neuronal excitability (Herman and Jahr, 2007).

In excitotoxicity, the time course of glutamate dynamics can be affected in several different manners. The synaptic concentration of glutamate can rise above its usual peak concentration (above $1.1 \mathrm{mM}$ ), although this value might plateau due to complete depletion of presynaptic glutamate, or this peak concentration can be maintained for an excessive amount of time, which is translated to an increase in the decay time, or even the baseline concentration of glutamate may be increased, regardless of depolarization-induced release. Regarding this last scenario, it is known that neuronal excitotoxic injury occurs with baseline concentrations of glutamate of $2-5 \mu \mathrm{M}$ (Mark et al., 2001).

\section{Glutamate and the Depolarization Factory: Glutamate Receptors in Excitotoxicity}

Glutamatergic neurotransmission is performed through iGluR and mGluR. The iGluR are ligand-gated ion channels permeable to various cations, namely sodium, potassium, and calcium, that produce excitatory glutamate-evoked currents, while mGluR are $\mathrm{G}$ protein-coupled receptors that control cellular processes via $\mathrm{G}$ protein signaling cascades (Reiner and Levitz, 2018). The main characteristics of these receptors are summarized in Table $\mathbf{1}$ and reviewed in detail in this section.

iGluR can be divided into three functional classes such as NMDAR, AMPAR, and KAR (Hansen et al., 2017). While all iGluR is in the first line of the excitotoxic response, NMDAR has been pinpointed as the main culprit in glutamateinduced neurotoxicity, due to their permeability to calcium ions. NMDAR exhibits a voltage-dependent magnesium-blockade, high permeability to calcium, and requires simultaneous binding of glutamate and a co-agonist, such as glycine and D-serine, for activation (Guo et al., 2017). NMDAR are tetrameric structures composed of GluN1, GluN2A-D and GluN3A-B subunits that form a central ion channel pore. Diversity in NMDAR subunits and assembly results in different receptor subtypes with distinct functional properties, including different channel kinetics, channel opening probability, and conductance. Therefore, these differences in subunit composition can impact both synaptic plasticity and neuronal function. Previous literature reported that GluN2A-containing receptors present faster kinetics, while GluN2B-containing receptors present slower opening, closing, and glutamate unbinding, indicating that NMDAR containing GluN2A open more reliably and with faster kinetics than 
NMDAR containing GluN2B subunits (Erreger et al., 2005). These data suggest that NMDAR containing GluN2A is more likely to sense rapid glutamate transients in the synapse and open with a high probability, while NMDAR containing GluN2B seems to be set to sense basal levels of glutamate and open with much lower probability. Moreover, it is known that NMDAR subunit composition also determines single-channel conductance and blockage by magnesium ions (Kuner and Schoepfer, 1996; Brimecombe et al., 1997; Cull-Candy et al., 2001), where both GluN2A- or GluN2B-containing receptors display a high ionic conductance and stronger magnesium block. In mature neurons, GluN2A subunits are predominantly synaptic (sNMDAR), whereas GluN2B-containing receptors are mostly extrasynaptic (eNMDAR; Rönicke et al., 2011). In rat hippocampal slices, the amount of eNMDAR has been estimated to be $36 \%$ of that of sNMDAR (Harris and Pettit, 2007) and it is known that D-serine mainly binds to sNMDAR, while glycine preferentially binds to eNMDAR (Papouin et al., 2012). Furthermore, previous studies reported a neuroprotective role for SNMDAR and a neurotoxic role for eNMDAR by receptor-mediated influx of calcium (Hardingham et al., 2002; Hardingham and Bading, 2010; Samson et al., 2016). Moreover, it has been proposed that the activation of NMDAR containing GluN2A subunits stimulates signaling cascades associated with neuroprotection and regulates survival, while stimulation of NMDAR containing GluN2B subunits leads to the activation of excitotoxic pathways, leading to neuronal death (Zhou et al., 2013). sNMDAR (mainly enriched with GluN2A subunits) activation promotes neuroprotection via changes in gene expression that have multiple effects within the cell. Stimulation of sNMDAR is known to result in the enhancement of antioxidant defenses, promoting the transcription of pro-survival factors, including cAMP-regulatory element-binding protein (CREB; Hardingham and Bading, 2010), that results in the transcription of brain-derived neurotrophic factor (BDNF), essential for neuronal survival. SNMDAR activity is also implicated in the generation of anti-apoptotic effects, including the inactivation of pro-death transcription factors, such as forkhead box protein O and p53 (Dick and Bading, 2010). In contrast, stimulation of eNMDAR (mainly enriched with GluN2B subunits) preferentially induces pro-death effects, such as the shut-off of CREB pathway, blocking BDNF expression (Hardingham et al., 2002); the inactivation of extracellular signalregulated kinases 1 and 2, which are necessary for BDNF function on spines (Hardingham et al., 2002); activation of forkhead box protein $\mathrm{O}$ and calpains, with consequent cleavage of the striatal enriched tyrosine phosphatase, which prevents this phosphatase from inhibiting p38 mitogen-activated protein kinase; and oxidative stress with subsequent neurodegeneration (Hardingham et al., 2002; Hardingham and Bading, 2010). Hence, while sNMDAR has a neuroprotective role, eNMDAR preferentially initiates cell death pathways (Hardingham and Bading, 2010). It is known that low levels of eNMDAR activity have no effects on neuronal survival, while high levels of eNMDAR stimulation enhance cell death pathways and exacerbate neurodegenerative processes, consequently reducing neuronal survival (Hardingham and Bading, 2010). eNMDAR 
can also be activated by mechanical stimuli and aspartate. Indeed, the GluN2B subunit has been reported to play a role in the mechanosensitive activation of NMDAR (Maneshi et al., 2017). On the other hand, although with lower affinity than glutamate, aspartate can bind and activate NMDAR (Chen et al., 2005). Aspartate levels are severely increased following traumatic brain injury (Palmer et al., 1994; Amorini et al., 2017) and, when present in excessive levels extrasynaptically, are associated with excitotoxicity (Choi et al., 1989). In summary, while sNMDAR signaling is associated with the suppression of pro-apoptotic transcription factors (Dick and Bading, 2010), eNMDAR stimulation increases the activity of pro-apoptotic factors, leading to oxidative stress and cell death (Hardingham et al., 2002; Hardingham and Bading, 2010; Parsons and Raymond, 2014). The activation of these pro-apoptotic factors can affect gene activity regulation of BDNF and vascular endothelial growth factor (Hardingham et al., 2002), essential for the maintenance of synaptic connectivity and architecture (Bading, 2013). Hence, the excessive intracellular calcium levels resulting from the excessive eNMDAR stimulation lead to excitotoxic cell death and contributes to neuronal injury.

Intriguingly, there are conflicting pieces of evidence regarding NMDAR involvement in excitotoxicity. Some studies state that NMDAR has a dichotomic effect in excitotoxicity, where activation of sNMDAR counteracts excitotoxicity and activation of eNMDAR is the main contributor to the excitotoxic cascade (Jia et al., 2015). Other authors propose that NMDAR-induced excitotoxicity requires overactivation of both sNMDAR and eNMDAR (Zhou et al., 2013, 2015). Finally, other studies even suggest neurotoxicity could be solely dependent on sNMDAR activity, since silencing sNMDAR can act as a neuroprotective approach against NMDA-induced excitotoxicity, while inhibiting eNMDAR does not have any protective effect, questioning the role of these receptors in neurotoxicity (Papouin et al., 2012).

AMPAR are tetrameric ionotropic glutamate receptors formed by GluA1-4 subunits. These receptors can be either hetero- or homotetramers and, depending on subunit composition, display different calcium permeability (Pál, 2018), with the GluA2 subunit controlling AMPAR calcium permeability. Assemblies of highly calcium-permeable AMPAR have been implicated in excitotoxicity. Moreover, the GluA2 subunit can also be subjected to RNA editing, with the conversion of a glutamine codon into an arginine one, and AMPAR is calcium-permeable if they contain the unedited GluA2 subunit or if they lack the GluA2 subunit (Wright and Vissel, 2012). Given their high calcium permeability, AMPAR lacking GluA2 is thought to contribute to excitotoxic cell death (Wright and Vissel, 2012).

KAR is composed of GluR5-7 and KA1-2 subunits. KAR properties are similar to AMPAR in that they allow ion flux directly following glutamate exposure, and are mostly impermeable to calcium. Although AMPAR is localized mostly in the postsynaptic membrane, several studies have shown that KAR may be localized in both pre- and post-synaptically (Chittajallu et al., 1996; Castillo et al., 1997). Post-synaptically, KAR, and AMPAR have a similar function in alleviating the magnesium block in NMDAR. This phenomenon leads to an exacerbation of NMDAR activation under glutamate excess.

mGluR are probably the most diverse receptor family of the central nervous system (CNS). The mGluR1 and mGluR5 subtypes are located in the peri- and extrasynaptic neuronal regions (Ferraguti et al., 2008). They are coupled to $\mathrm{G}_{\mathrm{q}}$ protein and exert their actions via the inositol trisphosphate/calcium signal pathway, being consequently able to stimulate calcium release from neuronal stores, thus triggering delayed cell death (Pál, 2018).

\section{The Gatekeepers of Homeostasis: Astrocytes}

In the forebrain, it has been shown that astrocytes are responsible for about $90 \%$ of the glutamate clearance from the synaptic cleft. During synaptic transmission, only approximately $20 \%$ of synaptically-released glutamate reaches the postsynaptic glutamate receptors, while the remainder can reach the extrasynaptic space (Kojima et al., 1999). Due to the significant role of astrocytes in glutamate re-uptake, impairment of astrocytic glutamate transporters leaves neurons highly susceptible to excitotoxicity (Rothstein et al., 1996). During an acute insult, astrocytes can prevent excitotoxicity by removing extracellular glutamate with high-affinity sodiumdependent glutamate transporters also known as excitatory amino acid transporters (EAAT). These proteins can clear glutamate from the extracellular space into cells, where it can be metabolized or recycled. Several subtypes of EAAT have already been pharmacologically identified. These transporters were divided into four subtypes in rats (GLAST, GLT-1, EAAC1, and EAAT4) and five in humans (EAAT1-5), and can be found in neurons (EAAT3 or EAAC1 and EAAT4) and astrocytes (EAAT1 or GLAST and EAAT2 or GLT-1; Danbolt, 2001; Crino et al., 2002; Beart and O'Shea, 2007; Sarac et al., 2009; Gonçalves-Ribeiro et al., 2019). Additionally, although glutamate transporters activity may come mostly from (if not exclusively) from astrocytes, the role of glutamate transporters in neurons still needs to be further explored. Indeed, neuronal glutamate transporters knockout does not influence in terms of preventing excitotoxicity, since mice with this knockout show no differences in survival, weight gain, and seizure activity compared to wildtype. On the other hand, synaptosomes prepared from these knockout mice showed a reduction of glutamate activity by $40 \%$ (Petr et al., 2015), suggesting that the role of neuronal glutamate transporters is yet to be revealed.

Furthermore, astrocytes are responsible for the maintenance of glutamate homeostasis by sustaining its synthesis, uptake and release via the glutamate-glutamine cycle (van den Berg and Garfinkel, 1971; Benjamin and Quastel, 1972; Ottersen et al., 1992). Through this cycle, synaptically released glutamate is predominantly taken up into astrocytes, where it is amidated to glutamine by the astrocyte-specific enzyme glutamine synthetase (Norenberg and Martinez-Hernandez, 1979). Glutamine is then released to the synapse and uptake by adjacent neurons, where it is converted to glutamate and $\gamma$-aminobutyric acid (GABA), which are then repackaged into vesicles and again released in the 
synapse as neurotransmitters (Allen, 2014; Rodríguez-Arellano et al., 2016).

In a different perspective, astrocytes are hypothesized to be the main effectors of glycolysis to produce lactate that is then transferred to neurons through the astrocyte-neuron lactate shuttle. This metabolic link between neurons and astrocytes is because neurons are highly energy-demanding cells but are unable to perform the citric acid cycle without an external supply of lactate, due to the lack of the essential enzyme pyruvate carboxylase (Schousboe et al., 1997; Magistretti and Allaman, 2015). Since astrocytic glutamate re-uptake is electrogenic, for each glutamate molecule entrance, three sodium ions enter the cell, activating the sodium/potassium ATPase. This, in turn, activates the glycolysis pathway in the astrocytes, stimulating the production of the lactate by either increasing glucose uptake or intracellular glycogen breakdown. Produced lactate is later released into the intracellular space by the monocarboxylate transporter 1 expressed in the astrocytes and received by neurons through the monocarboxylate transporter 2 (Stobart and Anderson, 2013). It is later used by the neuron as the carbon source in the Krebs cycle for oxidative phosphorylation. Besides lactate, astrocytes also release citrate, involved in the regulation of neuronal excitability by chelating zinc ions, thus inhibiting NMDAR (Westergaard et al., 1995; Schousboe et al., 1997). Furthermore, although recent literature suggests that neurons are primarily responsible for the synthesis and release of $\mathrm{D}$-serine (Wolosker et al., 2016), several independent studies strongly support that astrocytes are the main source of D-serine, essential for NMDAR function (Henneberger et al., 2010; Bergersen et al., 2012; Martineau et al., 2013; Sultan et al., 2015).

\section{THE BUTTERFLY EFFECT: DETAILED LOOK INTO EXCITOTOXICITY-INDUCED DYSFUNCTIONS}

\section{One Ion to Rule Them all: The Central Role of Calcium to Propagate Glutamate Toxicity}

One of the first consequences of excessive activation of glutamate receptors, namely NMDAR, is a sustained influx of calcium into the neuron (Mehta et al., 2013). Calcium has long been identified as a key player in glutamate neurotoxicity, as summarized in Figure 2. Specifically, early studies proved that scavenging extracellular calcium would decrease excitotoxicityinduced neuronal degeneration, while removal of other cations would not (Berdichevsky et al., 1983; Choi et al., 1988). This influx synergizes with the release of calcium from intracellular stores, such as the mitochondria and the endoplasmic reticulum, due to membrane damage caused by the disruption of ionic gradients (Mehta et al., 2013).

Together, these phenomena lead to a striking increase in the intracellular calcium concentration, which can activate enzymes that degrade proteins, lipids, and nucleic acids (Berliocchi et al., 2005), as well as enzymes involved in arachidonic acid pathways, such as phospholipase A2, cyclooxygenase2 , and lipoxygenases. These latter enzymes, when activated, lead to the production of arachidonic acid and its conversion into prostaglandins, leukotrienes, and thromboxanes with the concomitant production of ROS (Freeman and Crapo, 1982; Pazdernik et al., 1992; Murphy et al., 1994). Among these molecules, prostaglandin E2 has been shown to have a dual role in excitotoxicity: at low concentration (nanomolar range), prostaglandin E2 presents a neuroprotective effect (Akaike et al., 1994); at higher concentrations (micro- to millimolar), as seen in the calcium-induced arachidonic acid cascade, prostaglandin E2 contributes to neurotoxicity and cell death (Hewett et al., 2000). Additionally, calcium-induced activation of phospholipase A2 inhibits GABA receptors (GABAR), thus preventing neuronal hyperpolarization and further contributing to excitotoxicity (Hamano et al., 1996).

Finally, the calcium dysregulation also activates ATP-dependent ion pumps, to counteract the cationic influx, such as the sodium/potassium and calcium ATPases, which will drain all available ATP, creating a low-energy neuronal state (Connolly et al., 2014; Surin et al., 2014).

\section{Eternal Dysfunction for the Mitochondrial Minds: Mitochondrial Damage}

Another large contributor to glutamate neurotoxicity are mitochondria (Figure 2), which are essential in bioenergetic homeostasis and calcium signaling regulation (Mehta et al., 2013). Indeed, following the excitotoxicity-induced calcium influx, mitochondria capture cytosolic calcium via the mitochondrial calcium uniporter, attempting to maintain a low cytosolical calcium concentration (Qiu et al., 2013). While this process temporarily buffers the intracellular calcium concentration, the excessive cationic uptake eventually leads to the depolarization of the mitochondrial membrane, impairing ATP production and anti-oxidant mitochondrial functions (Nicholls and Budd, 2000; Kushnareva et al., 2005) and leaving neurons in a low-energy and oxidative state with high production of ROS (Mehta et al., 2013). Following this cascade, mitochondrial dysfunction contributes to apoptotic cell death, activating both caspases (Lipton, 2008) and calpains (Caldeira et al., 2014).

\section{The Wizard of ROS: Oxidative Stress}

The excessive activation of glutamate receptors also leads to an imbalance between ROS and their opposing antioxidant forces (Bondy and LeBel, 1993), a phenomenon named oxidative stress. In an excitotoxic scenario, oxidative stress is brought about by a higher intracellular concentration of ROS, which is directly associated with glutamate neurotoxicity (Nicholls, 2004). ROS are then mediators of enzyme inactivation, lipidic peroxidation and consequent membrane damage, DNA alterations, and apoptosis (Floyd, 1999; Lucca et al., 2009).

The excitotoxic production of ROS is related to the activation of the pro-oxidant enzymes xanthine oxidase and NADPH oxidase (Prentice et al., 2015) and mitochondrial dysfunction. Interestingly, NADPH oxidase, and not mitochondria, has been identified as the major source of ROS following glutamate exposure (Brennan et al., 2009). 


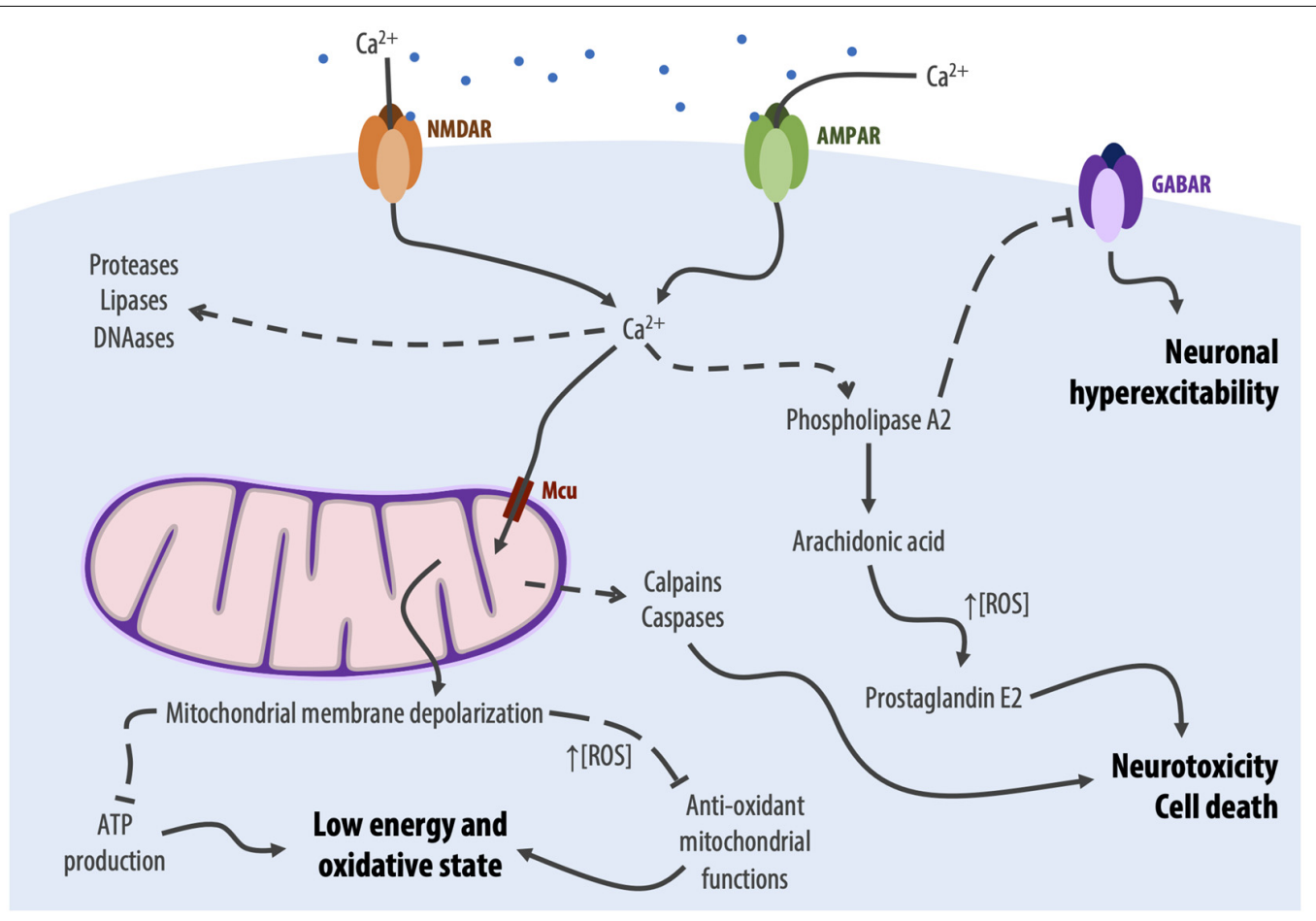

FIGURE 2 | Graphical depiction of the main calcium-dependent processes involved in excitotoxicity, leading to oxidative stress and cell death. Dotted lines with end arrows represent activation, dotted lines with T ends represent inhibition. Mcu, mitochondrial calcium uniporter.

Additionally, studies have demonstrated that glutamate binding to NMDAR results in the production of nitric oxide (NO) as a consequence of nitric oxide synthase (NOS) activation by calcium influx, which is spatially linked to NMDAR via the postsynaptic density protein of $95 \mathrm{kDa}$ (Aarts et al., 2002; Zhou et al., 2010; Jones, 2011). It has also been observed that an increase in NO concentration can trigger biochemical pathways that contribute to neuronal death and cognitive impairment (Díaz et al., 2010), since NO can react with the superoxide anion forming peroxynitrite, known to lead to the formation of 3-nitrotyrosine (Butterfield and Kanski, 2001). NO is then responsible for protein degradation by nitration and oxidation, lipid peroxidation, and DNA damage (Jia et al., 2015). Protein nitration results in the dysfunction of several proteins such as superoxide dismutase (SOD), actin, and tyrosine hydroxylase, and can interfere with cell signaling pathways mediated by tyrosine phosphorylation (Butterfield and Stadtman, 1997), contributing to the intracellular signaling dysregulation.

\section{WE NEED TO TALK ABOUT EXCITOTOXICITY: EXCITOTOXICITY AS A CONSEQUENCE OF OTHER PHENOMENA}

A possible trigger for excitotoxicity is the physical damage of a neuron. In physiological conditions, the extracellular glutamate concentration is around $0.01 \%$ of the intracellular concentration, not reaching the threshold for post-synaptic neuronal activation which maintains the glutamate pools in an inactive state (Mehta et al., 2013). However, this percentage can quickly increase if a damaged neuron releases all its glutamate content into the extracellular space, leading to excitotoxicity in neighboring neurons (Mehta et al., 2013).

Oxidative stress is one of the main consequences of glutamate-induced neurotoxicity. However, it is not possible to define a unidirectional cause/effect relationship between the two phenomena, since oxidative stress and excessive intracellular ROS can also induce excitotoxicity by stimulating extracellular glutamate release (Pellegrini-Giampietro et al., 1990) and releasing calcium from mitochondria into the cytosol (Richter and Kass, 1991). In another perspective, it has already been shown that astrocytic glutamine synthetase is especially susceptible to ROS-induced inactivation, which compromises the whole glutamate-glutamine cycle and contributes to an increase in extracellular glutamate concentration and consequent excitotoxicity (Schor, 1988). Additionally, the presence of ROS has been shown to decrease glutamate transporter activity, impairing synaptic clearance of glutamate further contributing to the increase in extracellular glutamate concentration (Anderson and Swanson, 2000).

Oxygen deprivation can also induce excitotoxicity through different mechanisms. In a straight forward manner, hypoxicischemic states directly stimulate glutamate release, increasing the extracellular glutamate concentration to neurotoxic levels (Prentice et al., 2015). Additionally, oxygen deprivation leads to energetic stress by impairing mitochondrial oxidative 
phosphorylation and, consequently, blocking ATP production (Doyle et al., 2008). This blockage leads to the depletion of intracellular ATP, which prevents the reuptake of glutamate, creating an excitotoxic concentration of extracellular glutamate (Rossi et al., 2000).

In a different perspective, while mitochondrial damage is one of the main consequences of excitotoxicity, mitochondria can also be originators of excitotoxicity. Mitochondrial toxins, for instance, can cause energetic impairment, preventing ATP production (Dong et al., 2009). Over time, cellular ATP pools are then depleted, with a concomitant decline in the activity of the sodium/potassium ATPase, which will depolarize the neuronal membrane (Mehta et al., 2013). By itself, this depolarization can render neurons more prone to firing action potentials (Dutta and Trapp, 2011). It, however, also affects NMDAR by removing their voltage-dependent magnesium-block, lowering their activation threshold so that non-excitotoxic glutamate concentrations become capable of inducing an excitotoxic response (Stavrovskaya and Kristal, 2005).

Finally, the physiological brain $\mathrm{pH}$ is estimated to be $\mathrm{pH}$ 7.2-7.3 in rats (Siemkowicz and Hansen, 1981), and pH 7.33 in humans (Mutch and Hansen, 1984). However, some diseases or disorders can drastically alter the $\mathrm{CNS} \mathrm{pH}$, inducing either acidosis or alkalosis. For instance, anaerobic conditions of ischemia promote the alteration of the metabolism of the cells from aerobic oxidation of glucose to anaerobic glycolysis. This alteration in metabolism produces lactate and protons, which is responsible for acidosis ( $\mathrm{Li}$ et al., 2016). Interestingly, a curious phenomenon occurs in acidosis. While severe acidosis $(\mathrm{pH}<6.4)$ contributes to excitotoxicity through a loss of ionic gradients (Kraig et al., 1987) and activation of acid-sensing ion channels, which intensifies excitotoxicity by providing another entry for calcium (Waldmann et al., 1997; Cheng et al., 2018; Qiang et al., 2018), mild acidosis ( $\mathrm{pH}$ 6.5-7.0) appears to partly prevent excitotoxicity (Simon et al., 1993), as well as glutamate-induced neuronal death (Tombaugh and Sapolsky, 1990). This phenomenon occurs due to the inhibitory effects of protons on NMDAR activation (Tang et al., 1990). On the other end of the spectrum, alkalosis $(\mathrm{pH}>8.0)$ seems to induce neurotoxicity. When compared to acidosis, alkalosis produces a more severe dysfunction that is more difficult to counteract. Indeed, cortical GABAergic neurons appear to be more susceptible to alkalosis than to acidosis (Zhang et al., 2013). And, considering the inhibitory effect of protons on NMDAR, it is possible to conclude that alkalosis leads to an increase in NMDAR activation. Thus, alkalosis contributes to excitotoxicity by both directly stimulating NMDAR, but also by disrupting inhibitory neurotransmission.

\section{SAVING PRIVATE NEURON: CELLULAR DEFENSES AGAINST EXCITOTOXICITY}

During excitotoxicity, neurons mobilize a variety of defenses to decrease the damaging effects of this process, among which are potassium channels, GABA signaling, acid-sensing ion channels, adenosine, and NO (Sapolsky, 2001).
Potassium channels are responsible for limiting and rectifying neuronal excitability during action potentials. The smallconductance calcium-dependent potassium channels (Sah, 1996) are highly calcium-dependent and are quite sensitive to transient increases of cytosolic calcium (Blatz and Magleby, 1987). The small-conductance channels mediate the shift of the excitotoxic calcium mobilization into a protective, hyperpolarizing signal (Madison and Nicoll, 1984; Lancaster and Adams, 1986; Sah, 1996; Honrath et al., 2017). Other key potassium channels are the ATP-dependent potassium channels, whose conductance is enhanced by ATP depletion (Politi and Rogawski, 1991; Riepe et al., 1992), particularly following excitotoxic insults (Trapp and Ballanyi, 1995). At presynaptic sites, ATP-dependent potassium channel activation also inhibits glutamate release (Bancila et al., 2004).

NMDAR-mediated calcium influx also increases sodium/potassium ATPase activity, leading to decreased excitability by stabilizing the resting membrane potential (Marcaida et al., 1996).

Another defense mechanism against excitotoxicity involves the inhibitory neurotransmitter GABA and GABAergic signaling (Bradford, 1995). Also, taurine released from glial cells during insults (Magnusson et al., 1991; Torp et al., 1991), similarly to GABA, also decreases presynaptic neuronal excitability by increasing chloride influx (Huxtable, 1992) through $\mathrm{GABA}_{\mathrm{A}} \mathrm{R}$ (O’Byrne and Tipton, 2000; Winkler et al., 2019). Moreover, neuronal networks were shown to offer a fast-acting GluN2Adependent neuroprotective signaling mechanism, which uses the innate capacity of surrounding neuronal networks to quench excitation, through the recruitment of $G_{A B A} R$ (Samson et al., 2016).

Glutamate receptor number can be also decreased by calciummediated activation of calpains. Activation of these proteases can result in the proteolysis of both NMDAR and AMPAR (Bi et al., 1996, 1998a,b). Moreover, calcium-dependent activation of calcineurin and calmodulin can inhibit voltage-gated and NMDAR-gated calcium currents, respectively (Vyklický, 1993; Lieberman and Mody, 1994; Ehlers et al., 1996).

During necrotic insults, energy depletion gives rise to adenosine. Adenosine inhibits presynaptic glutamate release, an action that is accomplished through $A_{1}$ adenosine receptors linked by $\mathrm{G}$ proteins to both calcium and potassium channels and decreases postsynaptic calcium currents in response to glutamate (Phillis and Wu, 1981; Cunha, 2005). On the other hand, a downstream consequence of glutamatergic excitotoxicity is the generation of NO, which acts intracellularly to inhibit NMDAR activity by nitrosylation (Lipton et al., 1993).

Another response of neurons to cell stress is the expression of heat-shock proteins, which protect against misfolding, conferring resistance to necrotic injury (Yenari et al., 1999). Neurons can also up-regulate and increase the activity of antioxidant agents following necrotic insults, which includes Mn- and Cu/Zn-SOD (Ohtsuki et al., 1993; Fukuhara et al., 1994; Matsuyama et al., 1994), glutathione peroxidase, and catalase (Goss et al., 1997).

Also, recent evidence has shown that synaptic activity can protect primary rat hippocampal neurons against mitochondrial 
oxidative stress and mitochondrial dysfunction derived from acute excitotoxicity, since synaptic activity can induce the transcriptional repression of the mitochondrial calcium uniporter, leading to a reduction in excitotoxicity associated with mitochondrial calcium overload (Depp et al., 2018).

\section{A BRIEF HISTORY OF ALS: AMYOTROPHIC LATERAL SCLEROSIS}

Amyotrophic Lateral Sclerosis (ALS) is a fatal and progressive neurodegenerative disease, characterized by the degeneration of both upper (motor cortex) and lower (spinal cord) motor neurons that result in motor dysfunction and, ultimately, death. While primary symptoms of ALS are associated with motor dysfunction, other areas of the brain may undergo degeneration, with $40-60 \%$ of patients showing evidence of different levels of cognitive impairment (Witgert et al., 2010; Ferrari et al., 2011). Although $90 \%$ of ALS cases are sporadic with no known cause, in the $10 \%$ of familial cases, more than 30 genes have already been implicated (Chen et al., 2013), with mutations in $\mathrm{Cu} / \mathrm{Zn}-\mathrm{SOD} 1$, transactive response DNA-binding protein, fused in sarcoma, chromosome 9 open reading frame 72 , and several others (Ajroud-Driss and Siddique, 2015).

Despite numerous studies demonstrating the involvement of several altered signaling pathways, the pathogenetic mechanisms behind ALS are still unclear. Indeed, it seems that, in ALS, neurodegeneration is the product of a combination of different concomitant mechanisms. Understanding the cause of motor neuron degeneration is critical for unraveling ALS pathogenesis and there are mainly two hypotheses to explain the origin of the disease (Kiernan et al., 2011). The first one is the dying-forward hypothesis, which proposes an anterograde degeneration of motor neurons via glutamate excitotoxicity from the cortex. The second one is the dying-back hypothesis, which suggests that ALS may start distally at the nerve terminal or the neuromuscular junction, progressing towards the cell body. Despite the numerous hypotheses proposed, alterations in excitatory neurotransmission appear to have a key role in disease progression, mediated by increased susceptibility to excitotoxicity, as schematically depicted in Figure 3 (Bae et al., 2013). Physiological studies have demonstrated cortical hyperexcitability in patients with both sporadic and familial ALS before the onset of symptoms (Vucic and Kiernan, 2013). In addition to cortical hyperexcitability, peripheral axons also present changes in their excitability in ALS patients (Vucic and Kiernan, 2006). Changes in neuronal activity can also lead to morphological alterations. In the $\mathrm{SOD} 1^{\mathrm{G} 93 \mathrm{~A}}$ mouse model, upper motor neurons display reductions in dendritic length and spine density, suggesting a homeostatic response to heightened pre-synaptic activity or even a stressed state of these neurons (Fogarty et al., 2016; Saba et al., 2016). It is however still unclear whether hyperexcitability is one of the causes of motor neuron degeneration or a compensatory mechanism resulting from motor neuron degeneration.

One of the first proposed mechanisms underpinning neurodegeneration in ALS was glutamate-mediated excitotoxicity (Bendotti and Carrì, 2004). One suggested way in which glutamate excitotoxicity may occur is through a decrease in the levels of the transporters responsible for the removal of glutamate from the synaptic cleft. In ALS, a likely trigger for neuroinflammation is the motor neuronal and astrocytic release of misfolded proteins, like aberrant SOD1, and other toxic molecules. This release stimulates the activation of microglia, unleashing pro-inflammatory and neurotoxic actions (Appel et al., 2011; Zhao et al., 2013; Brites and Vaz, 2014; Pinto et al., 2017), which dysregulate the communication between motor neurons and glial cells, compromising neuronal homeostasis. Microglia are considered the immune cells of the brain and may adopt different polarized activated phenotypes, with the M1 and M2 being the most accepted. The classical M1 phenotype is associated with the release of pro-inflammatory molecules and activation of receptors, and the M2 phenotype is related to the secretion of anti-inflammatory mediators and growth factors. However, recent studies point to the coexistence of different heterogeneous states and mixed phenotypes (Tang et al., 1990; Pinto et al., 2017). In ALS, microglia function changes along with disease progression, displaying the M2 anti-inflammatory phenotype at early stages and switching to the $\mathrm{M} 1$ activated subtype as the disease progresses (Zhao et al., 2013; Gravel et al., 2016). Activated microglia contribute and enhance motor neuron death, and can even acquire a distinct and impaired phenotype at the end-stage that accelerates disease progression (Nikodemova et al., 2014; Pinto et al., 2017). In addition to neuroinflammation, glial cells also play a role in glutamate-mediated excitotoxicity. Specifically, astrocytemediated downregulation of EAAT2, leading to a decrease in glutamate uptake and subsequent potentiation of excitotoxic effects, has been reported in both ALS patients and SOD1G93A mice (Howland et al., 2002), as well as in the TDP-43 rat model (Tong et al., 2013), correlating with regions of motor neuron loss (Sasaki et al., 2000). Thus, a decrease in the level of these transporters may lead to the accumulation of glutamate in the extracellular space, resulting in postsynaptic glutamate receptor overstimulation and consequent excitotoxic effects (Lin et al., 1998; Zarei et al., 2015). Furthermore, not only have astrocytes in ALS been reported to release lower levels of neurotrophic factors, but they have been shown to release neurotoxic factors that play a role in furthering neurodegeneration (Komine and Yamanaka, 2015; Cunha et al., 2018; Gomes et al., 2019). Moreover, it has been shown that, in ALS patients carrying SOD1 gene mutations, there is a decrease in motor neuron levels of calcium-binding proteins, which-by decreasing calcium buffering in the cytoplasm-may exacerbate excitotoxicity (Bernard-Marissal et al., 2012; Mattson, 2013). In the SOD1 G93A mouse model, overexpression of EAAT2 delays disease onset but not death (Guo et al., 2003) and fails to prevent loss of phrenic nerve motor neurons or rescue respiratory function (Li et al., 2015). Several pathways have been implicated in the modulation of EAAT2 levels, such as tumor necrosis factor- $\alpha$ (TNF- $\alpha)$ and downstream nuclear factor к-B signaling (Boycott et al., 2008). Recently, membralin, an endoplasmic reticulum membrane protein, was also shown to have a role in EAAT2-mediated glutamate excitotoxicity in ALS. Membralin levels are reduced in human ALS spinal cord and SOD1 ${ }^{\mathrm{G} 93 \mathrm{~A}}$ 


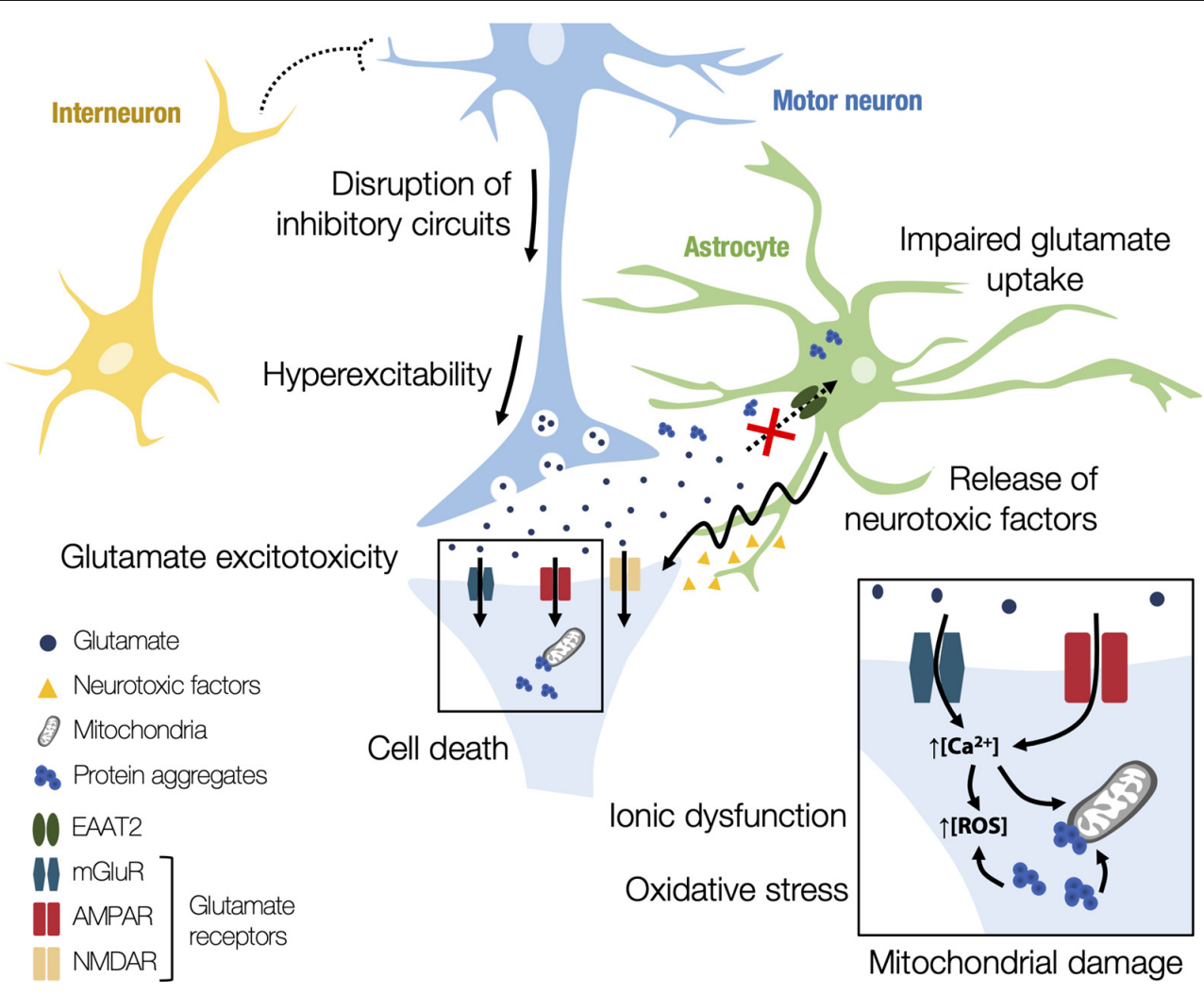

FIGURE 3 | Schematic representation of the alterations in excitatory neurotransmission in amyotrophic lateral sclerosis (ALS). Different pathophysiological mechanisms have been proposed to explain excitotoxicity in ALS. Interneuron alterations are observed in early disease stages, with a loss of cortical and spinal interneurons, leading to the disruption of inhibitory circuits. Consequently, there is an excitation-inhibition imbalance, increasing subsequent excitability and glutamate release to the synaptic cleft. Glutamate-mediated excitotoxicity may happen through an astrocyte-mediated downregulation of excitatory amino acid transporter 2 (EAAT2), which decreases the glutamate uptake from the synaptic cleft and potentiates the excitotoxic effects. Astrocytes in ALS also release neurotoxic factors that trigger changes to motor neuron glutamate receptors and render them susceptible to excitotoxicity, furthering neurodegeneration. Moreover, the excessive firing and the dysregulated calcium influx through atypical glutamate receptors results in an ionic dysfunction in motor neurons. The excessive entry of calcium into motor neurons results in mitochondrial overload and in the generation of reactive oxygen species (ROS), which ultimately causes oxidative stress. The presence of protein aggregates in mitochondria can also lead to alterations in normal cell metabolism, increasing the susceptibility to glutamatergic overstimulation as well as the activation of apoptotic pathways.

mouse models and its deletion suppresses EAAT2 expression through a TNF- $\alpha /$ TNF receptor 1 /nuclear factor $\kappa-B$ pathway. Overexpression of membralin in astrocytes was shown to increase EAAT2 expression and improve motor neuron survival (Jiang et al., 2019).

However, defects in the clearance of glutamate do not seem to be the only origin of excessive extracellular glutamate. In the SOD $1^{\mathrm{G} 93 \mathrm{~A}}$ mouse model, activation of Group I mGluR or the GABA/glycine heterotransporter abnormally increases the release of glutamate (Raiteri et al., 2003; Giribaldi et al., 2013; Milanese et al., 2015). Recently, Bonifacino and colleagues (Bonifacino et al., 2019) demonstrated that mGluR are overexpressed in the spinal cord of SOD $1^{\mathrm{G} 93 \mathrm{~A}}$ mice at pre-symptomatic stages and that their function is altered early on in the disease, suggesting that it can represent a cause rather than a consequence of disease progression. Group I mGluR may be potential targets for preventing excitotoxicity in ALS since it has been shown that treatment with an antagonist attenuated cell death, delayed the onset of motor symptoms, and slightly prolonged survival in $\mathrm{SOD} 1^{\mathrm{G} 93 \mathrm{~A}}$ mice (Rossi et al., 2008).

Moreover, calcium permeability of AMPAR is largely determined by the presence of the GluA2 subunit and it has been shown that mutant SOD1 astrocytes secrete factors that lower the expression of this subunit in motor neurons, consequently leading to AMPAR-mediated excitotoxicity and cell death (Van Damme et al., 2005, 2007). Moreover, fused in sarcoma-ALS astrocytes trigger changes to motor neuron AMPAR that render them susceptible to excitotoxicity (Kia et al., 2018) and patients with the chromosome 9 open reading frame 72 mutations appear to have increased vulnerability to AMPAR-mediated excitotoxicity (Selvaraj et al., 2018).

Besides glutamate-mediated excitotoxicity, excitotoxicity may arise from an altered regulation by interneurons. Interneurons are one of the main regulators of neuronal signaling and the majority in the cortex is inhibitory, using GABA or glycine as a neurotransmitter. In healthy individuals, a subthreshold stimulus of the motor cortex generally leads to the activation of 
inhibitory GABAergic interneurons, thus reducing subsequent excitability, in a process called short intracortical inhibition (Wagle-Shukla et al., 2009). In ALS patients, however, cortical inhibition is impaired, with a reduced or complete absence of short intracortical inhibition. Importantly, the reduction of short intracortical inhibition was shown to be an adverse prognostic factor in ALS (Shibuya et al., 2016). Several post-mortem reports indicate a loss of cortical and spinal interneurons, in addition to motor neuron losses (Stephens et al., 2006). These observations are seen in different mouse models that also exhibit interneuron alterations in early disease stages. The wobbler mouse model displays hippocampal hyperexcitability, together with a reduced number of interneurons (Thielsen et al., 2013). Also, in the SOD $1^{\mathrm{G} 93 \mathrm{~A}}$ mouse model, decreases in calretinin interneurons and subsequent increases in parvalbumin interneurons in motor and somatosensory cortex may be compensatory changes to improve excitation-inhibition balance (Chung et al., 2005; Minciacchi et al., 2009). In the spinal cord of the SOD1 ${ }^{\mathrm{G} 93 A}$ mice, interneurons degenerate before the loss of motor neurons (Martin et al., 2007). Further studies on a mutant SOD1 zebrafish model revealed that interneurons are the first to exhibit neuronal stress and, once more, that the reduction of inhibitory currents or interneurons preceded any defects in motor neurons (McGown et al., 2013).

Another known mechanism involved in ALS neurodegeneration is oxidative stress. The major enzyme involved in the prevention of oxidative damage is the $\mathrm{Cu} / \mathrm{Zn}$-SOD1 enzyme. Congruently, mutations in the SOD1 gene-resulting in either a decrease/loss or a dominant gain of function-have been found to contribute to cytotoxicity. In line with this, a study demonstrated that the cerebrospinal fluid, serum, and urine samples of ALS patients had increased levels of free radicals and concomitant oxidative stress (Zarei et al., 2015). Another source of oxidative damage in mitochondrial dysfunction. The existence of alterations is normal cell metabolism due to misfolded mutant SOD1 deposits in mitochondria has been reported in both ALS patients and mouse models. Furthermore, dysfunctions in energy, alterations in the triggering of apoptotic signals, disruptions in mitochondrial transport along axons, and atypical production of ATP and ROS have been also associated with ALS (Pasinelli et al., 2000; Mattiazzi et al., 2002; Menzies et al., 2002; Damiano et al., 2006). Moreover, the presence of mutant SOD1 in mitochondria can lead to an increase of the motor neurons sensitization to glutamatergic (over)-stimulation and therefore to excitotoxicity. Also, the inflammation and associated microglial activation, both hallmarks of ALS, may contribute to increasing the motor neurons' susceptibility to excitotoxicity.

\section{THE OLD MAN AND THE ALZHEIMER'S DISEASE}

Alzheimer's Disease (AD) is an age-dependent neurodegenerative disease, considered the most common form of dementia worldwide (Alzheimer's Association, 2009). $\mathrm{AD}$ is firstly manifested by the loss of episodic memory and later loss of executive functions like language, attention, and reasoning (LaFerla et al., 2007). AD is commonly characterized by the presence of senile plaques, large extracellular aggregates of fibrillary amyloid- $\beta$ peptide $(\mathrm{A} \beta)$, originated by the abnormal cleavage of amyloid precursor protein where the sequential cleavage of amyloid precursor protein by $\beta$ - and $\gamma$-secretase produces the neurotoxic A $\beta$ peptide (Scheuner et al., 1996; Ertekin-Taner, 2007). The presence of intracellular neurofibrillary tangles of hyperphosphorylated tau protein is also a characteristic of AD (Grundke-Iqbal et al., 1986; Ferrer, 2012). Many pieces of evidence suggest that $A \beta_{1-42}$ oligomers are the most toxic $A \beta$ species, exerting their pathological actions by disrupting glutamatergic transmission, mainly by acting on NMDAR and mGluR (Walsh et al., 2002). A $\beta$ can also increase glutamate release from both neurons (Brito-Moreira et al., 2011) and astrocytes (Talantova et al., 2013), resulting in abnormally high extracellular glutamate levels capable of activating eNMDAR and, thus, leading to the activation of pro-death pathways and consequent excitotoxicity. Hence, the harmful effects of $\mathrm{A} \beta$ in $\mathrm{AD}$ may be mediated by the excessive activation of eNMDAR containing predominantly GluN2B subunits (Li et al., 2011). Also, it has been demonstrated that the presence of $A \beta$ can induce a sustained calcium influx via NMDAR (Texidó et al., 2011), which can trigger a cascade of events leading to mitochondrial and synaptic dysfunction, excitotoxicity, production of ROS, and neuronal death (Ferreira et al., 2012), as depicted in Figure 4.

An imbalance between SNMDAR and eNMDAR activity was observed in brain samples from $\mathrm{AD}$ patients, which can contribute to the $A \beta$-triggered neurotoxicity observed in this disease. In parallel, it is also known that stimulation of eNMDAR plays a critical role in AD. Recent studies performed in rat acute hippocampal slices under $A \beta$ exposure and in $A \beta$-injected mice support the idea that enhancement of sNMDAR activity, together with the inhibition of eNMDAR, has protective effects against $\mathrm{A} \beta$-induced neurotoxicity (Huang et al., 2017). eNMDAR stimulation is also associated with the inactivation of extracellular signal-regulated kinase/mitogenactivated protein kinase signaling (Mulholland et al., 2008), which is crucial for memory consolidation and synaptic plasticity, suggesting that eNMDAR activation leads to the impairment of the molecular mechanisms underlying memory and learning processes (Schafe et al., 2000). In the presence of $A \beta$, the exacerbated calcium influx via eNMDAR is also associated with excessive activation of calpains, which are calciumdependent proteases involved in multiple cellular functions, including proliferation, differentiation, and modulation of synaptic function (Wu and Lynch, 2006). The overactivation of calpains in $\mathrm{AD}$ is associated with functional changes in several proteins involved in neuronal transmission, such as BDNF. Previous reports have shown that $\mathrm{A} \beta$ impairs BDNF function in a calpain-dependent manner (Jerónimo-Santos et al., 2015), whereas inhibition of eNMDAR can prevent $A \beta$-triggered impairment of BDNF action in long-term synaptic potentiation (Tanqueiro et al., 2018).

Under physiological conditions, mitochondrial calcium signaling stimulates oxidative phosphorylation and ATP synthesis. In $\mathrm{AD}$, as a consequence of the exacerbated calcium 


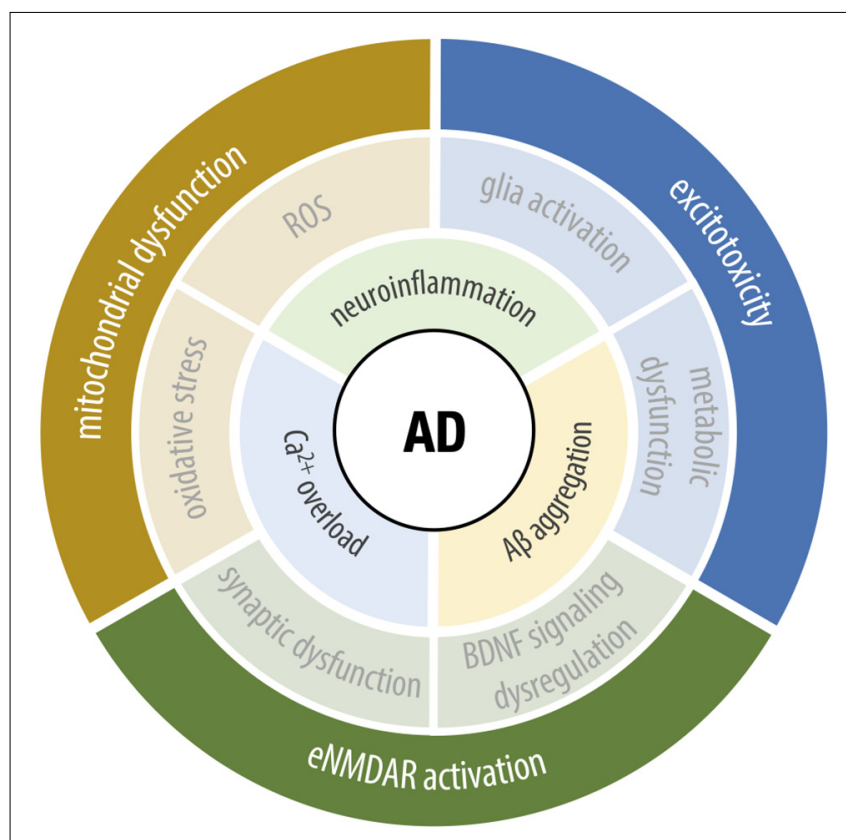

FIGURE 4 | Underlying cellular mechanisms of Alzheimer's disease (AD). The upstream key hallmarks of $A D$ range from ionic dysfunction to the impairment of several cellular processes, including $\mathrm{Ca}^{2+}$-signaling dysregulation, abnormal $A \beta$ production and aggregation and neuroinflammation. The crosstalk between the mentioned factors, leads to the pathological phenotype, involving mitochondrial dysfunction, excitotoxicity, and extrasynaptic NMDA receptor (eNMDAR) activation. As the symptomatic circle closes, the dysfunction of one leads to further activation of the others, altogether contributing to neurodegeneration and cognitive deficits, characteristics of the disease.

levels derived from eNMDAR activation, mitochondria form a non-specific pore in their internal membrane, termed mitochondrial permeability transition pore (Leung et al., 2008). With the pore opening, protons can cross this membrane, leading to the loss of mitochondrial membrane potential and dysregulation of $\mathrm{pH}$ gradient. Consequently, this affects ATP synthesis by oxidative phosphorylation, resulting in ionic and metabolic impairment, inevitably leading to cell death. Moreover, this decrease in mitochondrial bioenergetic capacity and consequent impairment of oxidative phosphorylation is associated with free radical production and subsequent oxidative damage. There are evidences of cyclophilin $\mathrm{D}(\mathrm{CypD})$, an integral part of the mitochondrial permeability transition pore (Leung et al., 2008), playing a critical role in $A \beta$-induced mitochondrial and synaptic injury (Du et al., 2008, 2011). Neuronal CypD is linked to $\mathrm{A} \beta$-mediated ROS production, whereas $\mathrm{CypD}$-deficient neurons appear to be resistant to $A \beta$-mediated inactivation of protein kinase A/CREB signaling, thus revealing that the absence of CypD can prevent $\mathrm{A} \beta$-induced mitochondrial and synaptic dysfunction (Du et al., 2014). Additionally, mitochondrial dysfunction in $\mathrm{AD}$ includes respiration deficits, increased generation and accumulation of free radicals, and impaired energy metabolism (Hensley et al., 1994; Manczak et al., 2006; Yao et al., 2009; Calkins et al., 2011). Changes in mitochondrial dynamics, including decreased transport, increased fission, and, eventually, loss of mitochondrial function, are also observed in AD (Hensley et al., 1994; Manczak et al., 2006; Yao et al., 2009; Calkins et al., 2011).

Dysfunctional mitochondria are considered the main generator of ROS and consequent oxidative stress in $\mathrm{AD}$, where oxidative stress can alter protein kinase A/CREB signaling, a signaling pathway necessary for neuronal survival (Wang et al., 2014). Indeed, several reports indicate that alterations in brain glucose metabolism in $\mathrm{AD}$ patients contribute to synaptic dysfunction and neuronal loss (Kennedy et al., 1995; Ishii et al., 1997). ROS, as well as reactive nitrogen species, are associated with the formation of protein carbonyls and 3-nitrotyrosine, which correlates with the level of protein oxidation within a cell. The determination of protein carbonyls levels and tyrosine nitration is considered viable measures of oxidative damage, where tyrosine nitration is one specific form of protein oxidation that is associated with AD (Castegna et al., 2003), which culminates in the loss of protein function, cellular dysfunction and, ultimately, cell death (Butterfield and Stadtman, 1997; Butterfield et al., 2006).

In $\mathrm{AD}$, glial cell activation and consequent pro-inflammatory response is associated with an increased expression of NOS, an enzyme responsible for NO production. Indeed, inducible NOS, one of the NOS isoforms, has been found in activated astrocytes and microglia, suggesting a critical role of this enzyme in pathological conditions (Diaz et al., 2011). Also, inducible NOS has been described as the main culprit behind the NO increase to neurotoxic levels, whereas its inhibition was found to be a useful target for neuronal protection against $\mathrm{A} \beta$-mediated toxicity (Diaz et al., 2011). Furthermore, a recent report found that, in adult rats injected with $A \beta_{25-35}$, a neurotoxic $A \beta$ fragment, there is an increase in inducible NOS expression and consequent upsurge of NO levels, which was prevented by the administration of a highly selective cannabinoid receptor 1 agonist, ACEA (Patricio-Martínez et al., 2019). Additionally, animals injected with ACEA and $A \beta_{25-35}$ presented an improvement in learning and memory when compared with animals injected with $A \beta_{25-35}$ alone (Patricio-Martínez et al., 2019), suggesting the involvement of the cannabinoid receptor 1 in neuroprotective mechanisms in $\mathrm{AD}$.

Growing evidence has identified reactive astrocytes as a key player in glutamate-mediated excitotoxicity, since astrogliosis results in the loss of astrocytic physiological function and consequent impairment of neuronal synaptic transmission. This phenomenon is common in $\mathrm{AD}$, where $\mathrm{A} \beta$ induces functional, morphological, and metabolic astrocytic dysfunction (Angelova and Abramov, 2014; Brawek and Garaschuk, 2014). Specifically, a downregulation of astrocytic glutamate transporters has been shown in both animal models and $\mathrm{AD}$ human brain samples, impairing glutamate uptake and causing excitatory overload in the synaptic cleft. Moreover, in astrocytic cell culture, A $\beta$ reduces the expression of GLT-1 through a mechanism that involves the calcineurin/nuclear factor of activated $\mathrm{T}$ cells pathway (Abdul et al., 2009) and oxidative stress (Scimemi et al., 2013). This reduction of GLT-1 expression in astrocytes results in increased glutamate levels at the synapse, which, by acting on eNMDAR, contributes to the progression of $\mathrm{AD}$ pathology in 
the human brain (Simpson et al., 2010). Additionally, a study performed in postmortem human samples suggests that the preservation of GLT-1 expression in reactive astrocytes could act as a neuroprotective mechanism against $\mathrm{AD}$ neuropathological changes (Kobayashi et al., 2018).

Astrocytic glutamate uptake is not only essential for synaptic glutamate clearance, but also the activation of the astrocytic glycolysis cycle. The impaired glutamate uptake will then lead to glycolysis deficiency. In this scenario, neurons not only suffer the consequences of the excessive extracellular glutamate but also of metabolic insufficiency as the astrocytes fail to fulfill the necessary energetic needs. In the hippocampus, glycogen-derived lactate is responsible for memory formation and long-term synaptic potentiation (Newman et al., 2011). Inhibition of lactate production and neuronal delivery weakens synaptic plasticity and memory formation, by impairment of the Krebs cycle and cell signaling dysregulation (Barros, 2013; Schurr, 2014; Dienel, 2017). Indeed, when Long-Evans rats with induced astrocytic metabolic impairment were treated with downstream glycolytic metabolites, such as pyruvate or $\beta$-hydroxybutyrate, memory improvement and consolidation were observed (Descalzi et al., 2019). This may suggest that astrocytic metabolic impairment is responsible for memory loss and cognitive impairment, even in the premature stages of $\mathrm{AD}$ (Merlini et al., 2011).

Metabolic dysfunction is a very early sign of disease onset. Some studies suggest that glucose hypometabolism is a hallmark of $\mathrm{AD}$ that can be detected long before any significant $\mathrm{A} \beta$ plaques and neurofibrillary tangles (Mosconi et al., 2009; Chen and Zhong, 2013). As the first aggregates occur with concomitant astrocytic dysfunction, signaling for glycolysis starts to drop and leads to the onset of energetic failure, causing metabolic starvation and consequent excitotoxicity. So far, it has been difficult to determine the causal relationship between astrocytic glutamate uptake dysregulation and metabolic disturbance. Nevertheless, the contribution of the metabolic processes in the pathological excitotoxicity is undeniable.

The role of neuroinflammation in the chemically induced $\mathrm{AD}$ animal models has been proven significant for the neurodegenerative profile and assumed to be a crucial factor in disease progression (Liu and Hong, 2003; Reynolds et al., 2007; Taylor et al., 2013). In the early stages of AD, activated microglia express both neurodegenerative (M1) and neuroprotective (M2) phenotypes (Edwards et al., 2006). The M2 phenotype exhibits a great capacity for $A \beta$ and tau protein aggregates clearance through phagocytosis. During disease progression, however, the M2 phenotype appears to undergo polarization into an M1 phenotype, resulting in the overproduction of neurotoxic factors. Indeed, in all stages of $\mathrm{AD}$, significant aggregation of M1 microglia has been observed surrounding neurofibrillary tangles (Sheffield et al., 2000; Yao and Zu, 2020). M1 microglia not only release neurotoxic factors but have also been shown to downregulate or even block neuroprotective mechanisms involved in phagocytosis of $A \beta$ (Yamamoto et al., 2008). This inhibition is mainly due to the impairment of the $A \beta$ receptor complex, complement receptor 3 , and insulin-degrading enzyme expression (Koenigsknecht-Talboo and Landreth, 2005). Among neurotoxic factors released by microglia, microglial glutamate release can stimulate excitotoxicity (Barger et al., 2007), while the release of pro-inflammatory cytokines such as interferon $\gamma$ and TNF $\alpha$ impair the uptake and internal degradation of extracellular glutamate (Hu et al., 2000; Yamamoto et al., 2008). In AD, reactive astrocytes are also able to release pro-inflammatory cytokines, such as, $\mathrm{TNF} \alpha$ and interleukin $1-\beta$, which, while not directly cytotoxic, can impair astrocytic glutamate uptake and to enhance NMDAR-induced calcium release, contributing to $\mathrm{AD}$ progression. Moreover, it is known that inhibitors of these inflammatory mediators attenuate both synaptic and cognitive deficits in $A \beta$-treated mice, suggesting that these inflammatory responses mediated by astrocytes have negative effects upon synaptic plasticity mechanisms (Ralay Ranaivo et al., 2006).

Though not often discussed, the cystine-glutamate (Xc-) antiporter system is essential for cysteine homeostasis and considered only a secondary mechanism in the glutamate release and uptake. However, its contribution to pathological states such as glutamate excitotoxicity should not be ignored. The Xcantiporter system is highly expressed in microglia and astrocytes. It is a sodium-independent anionic amino acid transporter with high specificity for negative species of cysteine and glutamate (Sato et al., 2002). It is also electroneutral, instead of electrogenic as most common EAAT systems (Lo et al., 2008). This antiporter is a heterodimer (Lutgen et al., 2014), composed of heavy $4 \mathrm{~F} 2$ chain and a specific light chain, named $\mathrm{xCT}$, linked by a disulfide bridge (Lewerenz et al., 2012). It uptakes cystine in exchange for releasing glutamate in the molar ratio 1:1 (Sato et al., 1999). Although less discussed, the Xc- system significantly increases extracellular and, more specifically, synaptic levels of glutamate, releasing up to $60 \%$ of all extracellular glutamate in the striatum (Baker et al., 2002). This antiporter can release up to $0.6 \mu \mathrm{M} / \mathrm{s}$ of glutamate into the extracellular space (Warr et al., 1999), which is then uptaken by GLT-1 (Baker et al., 2002; Bridges et al., 2012). Depending on the influx and overall capacity to uptake glutamate, this release can either activate or desensitize the NMDAR (Warr et al., 1999). The cystineglutamate antiporter was reported to exhibit neuroprotective effects in neurodegenerative diseases, as it is linked to the production of glutathione and the rise of antioxidant cellular capacity (Bridges et al., 2012). This protective effect is observed in $\mathrm{AD}$ models, where the Xc- system uptakes cystine, showing great potential at lowering $\mathrm{A} \beta$-induced toxicity, oxidative stress, and later apoptosis. However, when activated either by oxidative stress, TNF- $\alpha$, or amyloid precursor protein, this antiporter can release cytotoxic amounts of glutamate (Barger and Basile, 2001; Sato et al., 2001). Not only is this antiporter involved in the release of glutamate, contributing to excitotoxicity, but it has also been shown to block microglial neuroprotective functions in $\mathrm{AD}$. Indeed, activated microglia in both $\mathrm{AD}$ patients and in $\mathrm{AD}$ mouse models show an increased expression of this antiporter and, specifically, the xCT protein (Bridges et al., 2012). In mice, transgenic depletion of the Slcal1 gene ( $\mathrm{xCT}^{-/-}$ mice) impaired microglial polarization into the neurotoxic phenotype and reduced up to $70 \%$ pathological glutamate release in cultured microglial cells (Mesci et al., 2015). Upon blockade of either NMDAR or the Xc- system, microglia act in a neuroprotective way when exposed to $A \beta$ and attenuate neuronal 
death. However, when neurons were cultured with microglia depleted of lipid-associated apolipoprotein E expression, the neuroprotective phenotype was lost (Qin et al., 2006), implying that the neuroprotective phenotype of microglia in $\mathrm{AD}$ is related to apolipoprotein $\mathrm{E}$. In neuron-microglia co-cultures, the activation of the Xc- system by the $\mathrm{A} \beta$ deposits not only exacerbates excitotoxicity, but also lowers the neuronal threshold for glutamate toxicity, allowing non-toxic concentrations of glutamate to exert excitotoxic actions (Qin et al., 2006). Although very sparse in current literature, the neuroprotective role of the $\mathrm{Xc}$ - system in vivo showed similar effects, where the activation of microglial cells by $A \beta$ can cause both phenotypes, the neurotoxic being mostly related to glutamate release and increased neuronal susceptibility to excitotoxicity, and the neuroprotective related to expression of apolipoprotein $\mathrm{E}$ and glutathione (Bannai and Tateishi, 1986; Qin et al., 2006; Shih et al., 2006).

As stated before, another AD hallmark is hypoglycemia. Removal of glucose in mixed astrocyte-neuron cell cultures leads to a glycemic neuronal injury and death (Thorn et al., 2015). However, the neuronal death observed in glucose deprivation conditions is not connected to energy failure but most likely tied to glutamate accumulation in the synaptic cleft (Jackman et al., 2012). Astrocytes express significant levels of the cystineglutamate antiporter and are also the main metabolic factories and energy suppliers for neurons. As these processes are tightly linked, the dysfunction of one is likely to mediate the function of the other system, for the benefit or damage. Upon glucose deprivation in cultured astrocytes, $\mathrm{xCT}$ protein expression rose in a time-dependent matter (Thorn et al., 2015).

In the triple transgenic $\mathrm{AD}$ mouse model (3xTg-AD), astrocytic glutamine synthetase expression was found to be decreased in the hippocampus, suggesting a critical role of astrocytes in $\mathrm{AD}$-related disruption of glutamate homeostasis, which may affect the efficiency of glutamatergic transmission, contributing to the cognitive deficits of the disease (Olabarria et al., 2011). Also, it is known that glutamine synthetase activity is sensitive to oxidation and may be impaired by oxidative stress in AD (Smith et al., 1991; Hensley et al., 1994, 1995).
In the $3 \mathrm{xTg}-\mathrm{AD}$ mouse model, $\mathrm{A} \beta$ near to astrocytes leads to the extrasynaptic release of glutamate and consequent eNMDAR activation (Talantova et al., 2013), which contributes to synaptic dysfunction and neuronal death. Furthermore, there are also evidences that eNMDAR activity can trigger the generation of toxic A $\beta$ (Talantova et al., 2013), which suggests a key role of eNMDAR and astrocytic glutamate release in mediating $\mathrm{A} \beta$ neurotoxicity.

As mentioned before, astrocytes are responsible for the supply of D-serine to neurons (Henneberger et al., 2010). Indeed, recent evidences reveal that serine racemase, the enzyme responsible for $\mathrm{D}$-serine synthesis is strongly expressed in reactive astrocytes in both human $\mathrm{AD}$ samples and $\mathrm{AD}$ rat models (Balu et al., 2019). Moreover, changes in intracellular signaling cascades, consistent with excitotoxicity and decreased neuronal survival were found (Balu et al., 2019). Hence, these findings support a model where $\mathrm{D}$-serine released from reactive astrocytes could bind to extrasynaptic GluN2B-containing NMDAR, triggering the activation of excitotoxic signaling pathways and consequent neuronal damage and death. It has however been shown that, in AD-like conditions, the selective blockade of eNMDAR together with the administration of a D-serine-like NMDAR co-agonist significantly improved spatial and related forms of learning and memory (Huang et al., 2017). Moreover, there are evidences that blocking eNMDAR provides neuroprotection against $A \beta$ triggered deficits, together with the enhancement of sNMDAR activity (Huang et al., 2017). In conclusion, while it is known that D-serine is mainly a co-agonist of sNMDAR, the role of $\mathrm{D}$-serine as a mediator of neuronal excitotoxicity cannot be excluded.

In line with what was described above, many studies support the active involvement of glial cells, in particular astrocytes, in early stages of $\mathrm{AD}$ pathogenesis, where $\mathrm{A} \beta$ can dysregulate astrocytic calcium signaling both in vitro and in vivo (Haughey and Mattson, 2003; Kuchibhotla et al., 2009), which can result in the excessive release of glutamate and other gliotransmitters, enhancing extrasynaptic glutamatergic signaling and consequent excitotoxicity in $\mathrm{AD}$, as summarized in Figure 5.

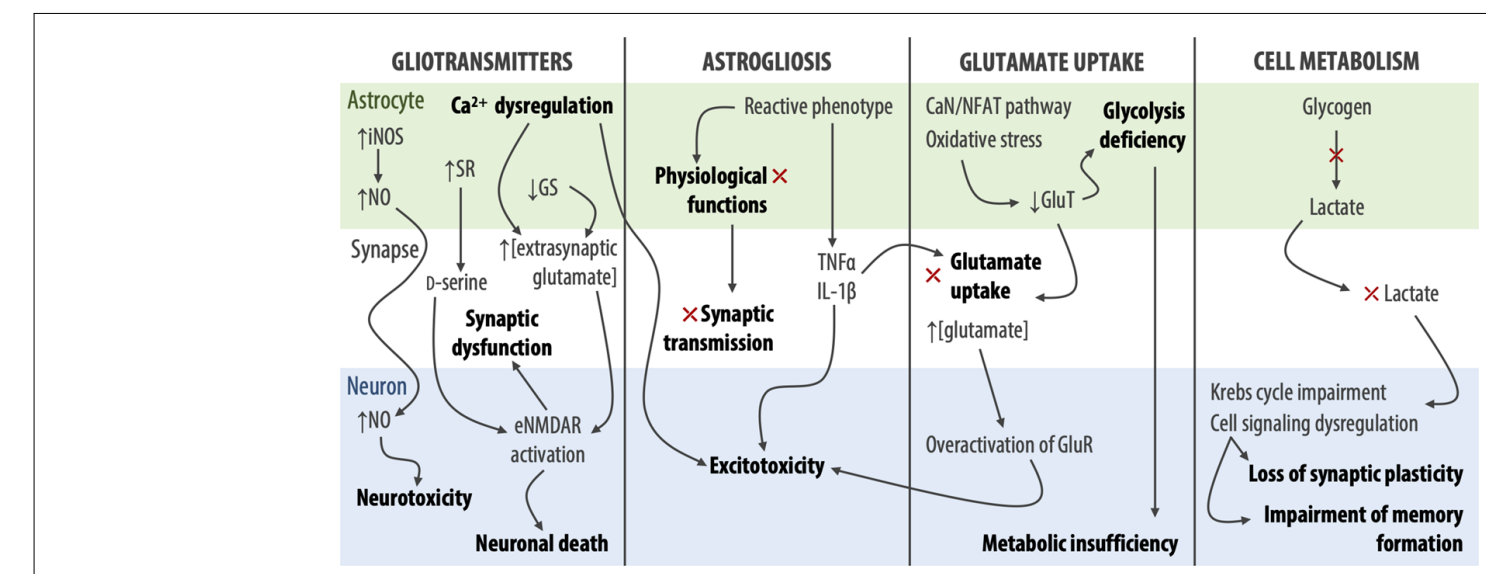

FIGURE 5 | A $\beta$-induced astrocytic dysfunctions leading to excitotoxicity and AD pathogenesis. iNOS, inducible nitric oxide synthase; NO, nitric oxide; SR, serine racemase; GS, glutamine synthetase; CaN/NFAT_calcineurin/nuclear factor of activated T cells; GluT, glutamate transporters; GluR, glutamate receptors. 


\section{THE PHANTOM OF THE BRAIN: EPILEPSY}

Epilepsy is one of the most common neurological disorders, estimated to affect more than 70 million people worldwide (Singh and Trevick, 2016). Epilepsy can be regarded as a family of disorders which comprise several diseases and conditions and can be defined by: (i) the unprovoked occurrence of at least two seizures more than $24 \mathrm{~h}$ apart; (ii) one unprovoked seizure and further seizure probability of at least $60 \%$; or (iii) diagnosis of an epilepsy syndrome. There are multiple types of seizures, which are characterized in accordance with their onset, physical manifestation, and level of consciousness, differing in the corresponding pathophysiological mechanisms (Fisher et al., 2017). Nevertheless, all epileptic seizures involve persistent changes in synaptic events such as neurotransmitter release, and receptor and transporter activity, and are underpinned by an abnormal excessive or synchronous neuronal firing activity, typically resulting from an imbalance between excitatory and inhibitory processes mediated by the neurotransmitters glutamate and GABA, respectively. Excessive neuronal firing is accompanied by increased extracellular levels of glutamate, leading to excitotoxicity (Soukupová et al., 2014), one of the primary sources of neuronal damage in epilepsy. The processes by which excitotoxicity results in neuronal damage and/or death have previously been described and, in this section, we will focus on the underlying pathophysiological mechanisms of different types of epilepsy and how they correlate with excitotoxicity. The main findings discussed here are summarized in Figure 6.

\section{Temporal Side Story: Temporal Lobe Epilepsy}

Temporal lobe epilepsy (TLE) is the most common form of epilepsy, affecting up to 40 million people worldwide (Hubbard et al., 2016; Peterson and Binder, 2019). TLE is characterized by the occurrence of focal seizures that may impair individuals and is often associated with treatment resistance, where approximately $30 \%$ of patients taking antiepileptic drugs present drug resistance that prevents them from living seizure-free (Sarac et al., 2009; Hubbard et al., 2016; Peterson and Binder, 2019).

The increase in local excitation and cytotoxicity in the epileptogenic focus of TLE is linked to an increase in extracellular glutamate levels (Proper et al., 2002; Sarac et al., 2009; Albrecht and Zielinska, 2017). Changes in glutamate levels have been reported in the hippocampus of epileptic patients before, during, and after seizures, which may occur due to increased glutamate release or its impaired reuptake (Proper et al., 2002; Hoogland et al., 2004; Hubbard et al., 2016).

As mentioned before, glutamate uptake is a major determinant of extracellular glutamate levels and evidence shows that the alteration of glutamate concentrations in epilepsy may result from aberrant EAAT expression or function (Crino et al., 2002; Proper et al., 2002). Indeed, an increase in EAAT3 expression in the hippocampus of both patients and animal models with TLE has been observed (Crino et al., 2002). This enhanced expression may lead to the increased glutamate release during seizures by increasing intracellular

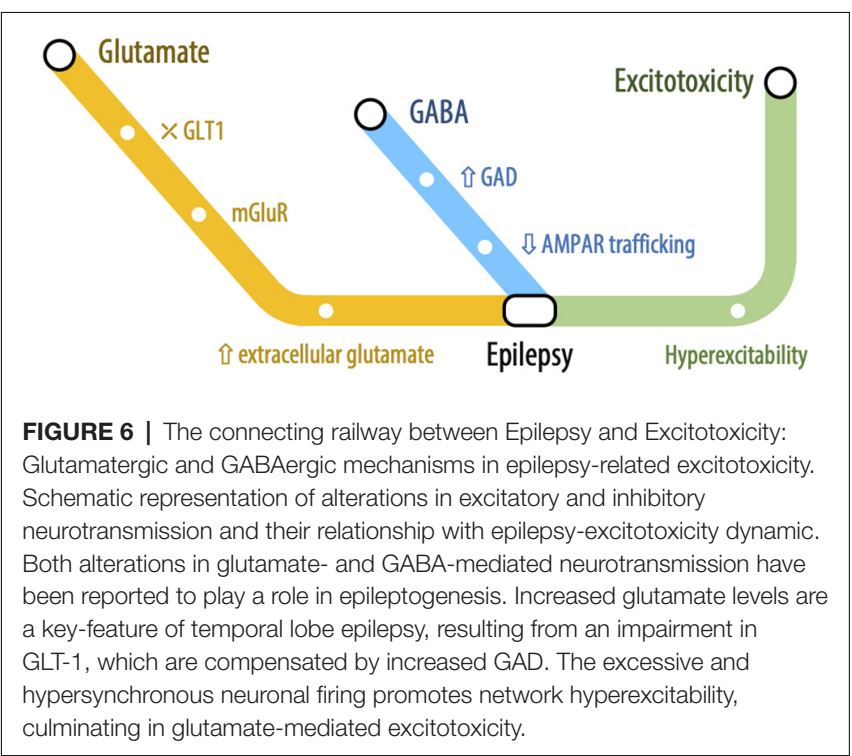

glutamate, which will be stored in vesicles and synaptically released by the classical calcium-dependent pathway (During and Spencer, 1993; Crino et al., 2002). Another mechanism by which increased glutamate release may occur is EAAT3 reversal due to the alteration of cellular excitability promoted during epileptogenesis (Rossi et al., 2000). However, the increase in EAAT3 expression may be a compensatory mechanism, leading to the improvement of GABAergic inhibitory transmission, as shown in the granular cells of the dentate gyrus of TLE animal models, which had increased glutamate decarboxylase expression and GABA release (Sloviter et al., 1996; Crino et al., 2002).

Additionally, reactive astrocytes with morphological and functional alterations may be important in epileptogenesis since they contribute to the increase of neuronal excitability. In TLE, this astrocyte-induced excitotoxicity occurs by dysregulation of glutamate astrocytic transporters (EAAT1 or GLAST and EAAT2 or GLT-1), which are responsible for maintaining extracellular glutamate homeostasis (Hubbard et al., 2016; Peterson and Binder, 2019). Different studies have shown that there is a reduction in EAAT1 and EAAT2 expression in the sclerotic hippocampus of TLE patients at RNA or protein levels (Proper et al., 2002; Rakhade and Loeb, 2008). Furthermore, modifications in GLT-1 function and expression contribute to TLE hyperexcitability and seizure generation (Hubbard et al., 2016; Peterson and Binder, 2019). Different studies have already shown that knockout animal models for GLT-1 exhibit severe spontaneous seizures that can lead to early postnatal death (Tanaka et al., 1997; Hubbard et al., 2016; Peterson and Binder, 2019), and that GLT-1 overexpression may generate pilocarpineinduced epileptogenesis resistant mice (Kong et al., 2012; Sha et al., 2017). In fact, in the intrahippocampal kainic acid mouse model of TLE, a down-regulation of hippocampal astrocytic GLT-1 has been reported, coinciding with the increased excitability (Peterson and Binder, 2019). Also, there seems to be a temporal regulation of GLT-1 expression during epileptic 
seizures, with an increase in GLT-1 levels 1-4 days after seizure and a reduction 4-7 days after a seizure (Hubbard et al., 2016; Peterson and Binder, 2019). This difference in GLT-1 expression after epileptic seizures can arise from changes in the membrane anchor and trafficking system, since, upon glutamate release, GLT-1 can be trafficked to synaptic and non-synaptic regions to ensure glutamate clearance (Murphy-Royal et al., 2015). Different drugs can ameliorate epilepsy intensity by targeting GLT-1. Among these drugs, antibiotics such as $\beta$-lactam and ceftriaxone show antiepileptic effects and can increase GLT-1 levels (Rothstein et al., 2005; Zeng et al., 2010), and, in a pilocarpine-induced TLE model, a GLT-1 activator was able to promote an increase in GLT-1 expression and reduction of spontaneous seizures frequency by $50 \%$ (Kong et al., 2014; Sha et al., 2017). However, GLT-1 internalization and degradation are still observed, suggesting that these are the causes of GLT-1 deficiency and the limiting factors for the use of these drugs in the treatment of TLE (Susarla and Robinson, 2008). Thus, some studies have shown that besides increasing GLT-1 expression, it would be necessary to use inhibitors of proteins responsible for its degradation. Studies have been performed with a Hsp90B inhibitor (17AAG), which is one of the proteins that recruit GLT-1 for degradation (Whitesell and Lindquist, 2005). Not only was this drug able to increase GLT-1 expression, it also maintained GLT-1 protein levels more effectively than ceftriaxone and exhibited a remarkable seizure suppression effect in the TLE model (Sha et al., 2017).

Besides glutamate homeostasis, astrocytes can also modulate water flow and potassium homeostasis in the extracellular space (Devinsky et al., 2013). Potassium concentration is regulated by astrocytes through its uptake by the sodium/potassium ATPase, sodium/potassium/chloride cotransporters, and input rectifier channels for potassium (Kir 4.1; Ransom et al., 2000; D’Ambrosio et al., 2002; Kofuji and Newman, 2004; Nikolic et al., 2019). Increased potassium concentration in the extracellular space can generate sustained neuronal depolarization and neuronal hyperexcitability (Walz, 2000; Devinsky et al., 2013; Nikolic et al., 2019), and evidence in the literature suggests an association between the uncontrolled increase of extracellular potassium levels and epilepsy, both in humans and in animal models (Steinhäuser et al., 2016).

In recent years, studies have shown an association between the glial water channel aquaporin-4 (AQP4) and Kir 4.1, forming an astrocytic protein complex responsible for removing potassium from the extracellular space, being an important mechanism in establishing a hyperpolarized neuronal membrane potential which may play an important role in epilepsy (Aronica et al., 2000; Das et al., 2012; Devinsky et al., 2013). Indeed, reduced expression of Kir 4.1 has been described in the hippocampus of patients with TLE (Das et al., 2012), where astrocytes showed deficits in potassium and glutamate uptake similar to those found in Kir 4.1 knockout animal models (Djukic et al., 2007; Chever et al., 2010; Nikolic et al., 2019). Furthermore, AQP4 knockout animals are also more susceptible to seizures and epilepsy (Dudek and Rogawski, 2005; Devinsky et al., 2013) and, in kainate-induced epileptic animal models, a reduction in AQP4 expression was also reported (Lee et al., 2012; Devinsky et al., 2013). Similarly, patients with TLE who have hippocampal sclerosis show a decrease or loss of AQP4 expression, suggesting the involvement of these channels in early epileptogenesis (Amiry-Moghaddam et al., 2003; Eid et al., 2005; Seifert et al., 2010). Taken together, these findings show that, in addition to the glutamate transporters, the control of potassium homeostasis and water flow is involved in neuronal excitability and TLE, even though further studies are needed to better elucidate their underlying mechanisms for controlling neuronal excitability.

Not only is ion homeostasis, such as sodium and potassium, altered in various forms of epilepsy, but cell metabolism has also been shown to be deeply affected in the epileptic brain. For instance, it is well known that there is a high energy demand during seizures, accompanied by high glucose consumption by neural networks. However, cerebral glucose hypometabolism is a feature of interictal phases in different forms of epilepsy, in regions that encompass but are generally larger than the region of seizure onset (Goffin et al., 2008; Pittau et al., 2014). The exact mechanisms underpinning such alterations are not clear, but mitochondrial dysfunction, linked with deficient glycolysis, remains a plausible hypothesis. Indeed, glutamate is known to promote astrocytic glycolysis (Bittner et al., 2011; Yan et al., 2017), a process in which glucose is converted into lactate. In epilepsy, where extracellular glutamate levels are increased, this process is most likely heightened when in comparison with control conditions. Thus, this results in a rapid depletion of glucose and a quick increase in lactate levels, indicating that, following seizure activity, in which there is a high consumption of glucose, neurons likely rely mostly on astrocyte-derived lactate. The lactate surplus is released into the extracellular space, creating a gradient between astrocytes and neurons (Mächler et al., 2016). Accompanying these alterations, the expression of astroglial monocarboxylate transporters, which lead to an efflux of monocarboxylates in astrocytes, has been reported to be increased in animal models of TLE (Liu et al., 2014), further suggesting that this astroglial-neuronal metabolic coupling pathway is affected in epilepsy. This pathway is vital for several brain functions, including for long-term memory formation (Suzuki et al., 2011), which might indicate a compromise of several neural functions, as a consequence of disrupted energy homeostasis. Due to the accumulating evidence of metabolic disruption in epilepsy, treatment strategies targetting cell metabolism have been gaining more attention, including the revival of the ketogenic diet (Walczyk and Wick, 2017). Pyruvate has been proposed as a possible treatment for epilepsy on account of being an anaplerotic mitochondrial fuel and because of its protective features, including acting as a potent ROS scavenger and normalizing cytosolic redox state. This molecule also facilitates brain-to-blood glutamate flux, preventing neuronal excitability (Popova et al., 2017). Finally, since blood glutamate can be converted into 2-ketoglutarate in the presence of pyruvate, mediated by glutamate-pyruvate transaminase (Gottlieb et al., 2003), treatment with pyruvate can be a protective measure against excitotoxicity (Carvalho et al., 2011).

In addition to alterations in cell metabolism in epilepsy, which include the hypermetabolism and hypometabolism during ictal and interictal phases, respectively, intracellular ATP levels are 
also affected. Indeed, depletion of intracellular ATP has been reported in seizures (Wasterlain et al., 2010), and considering that the major source of ATP in the mitochondria, the possibility of mitochondrial dysfunction in epilepsy has gained considerable attention. While it is known that mitochondrial dysfunction is involved in seizure-related neuronal death (Kovac et al., 2013), it has also been associated with increased ROS and NO production during seizures (Frantseva et al., 2000; Jarrett et al., 2008), which is related with the activation of glutamate receptors and depolarization of the mitochondrial membrane. As the major sources of ATP are glycolysis and mitochondrial respiration, alterations in the rate of these processes in epilepsy will also impact ATP production which, reciprocally, influences mitochondrial activity. Mitochondrial dysfunction has been profoundly linked with neuronal damage and death (Rose et al., 2017), and this organelle is particularly relevant for calcium homeostasis. Mitochondria serve as a key regulator of cytosolic calcium, via the mitochondrial calcium uniporter and, in its turn, the influx of calcium into the mitochondria can activate the respiratory chain as well as promote the production of ATP. During seizure activity, in which neurons are exposed to high concentrations of glutamate, the subsequent activation of NMDAR induces calcium oscillations and a subsequent depolarization of the mitochondrial membrane (Kovac et al., 2012), which can be a trigger for neuronal death (Vergun et al., 1999). In rats where epileptic status was induced by L-allylglycine and bicuculline, the influx of calcium into neurons led to mitochondrial calcium overload, resulting in cell death (Griffiths et al., 1983; De Stefani et al., 2011). This issue has been overcome in the pilocarpine model of epilepsy by the inhibition of the mitochondrial calcium uniporter system, which decreased neuronal death, suggesting this system plays a role in seizure activity (Wang et al., 2015). Also, increasing ATP production by providing a substrate such as a pyruvate has been demonstrated to prevent neuronal death (Kovac et al., 2012). It should be noted that not only mitochondrial alterations can be observed but also in the endoplasmic reticulum, another intracellular pool of calcium. Indeed, debilitation of endoplasmic reticulum calcium with thapsigargin results in decreased neuronal excitation triggered by bicuculline in cultures (Sokal et al., 2000) as well as in slices, where (RS)-3,5-dihydroxyphenylglycine and pilocarpineinduced ictal discharges were shown to be dependent on the endoplasmic reticulum calcium pool (Rutecki et al., 2002). Although very few studies have focused on the contribution of endoplasmic reticulum calcium stores toward seizure activity, it has been demonstrated that depleting intracellular endoplasmic reticulum calcium stores can counteract neuronal excitability (Sokal et al., 2000).

Another major consequence of intracellular calcium accumulation and mitochondrial dysregulation is the exacerbated production of ROS, which is an essential mechanism in excitotoxicity-induced neuronal injury (Patel et al., 1996). Indeed, oxidative stress has been implicated in both immediate and later excitotoxic neuronal damage and increased ROS production has been reported in the ictal and interictal phases of epilepsy (Liang et al., 2000). Furthermore, this increase is also known to inhibit mitochondrial complex 1 activity and decrease mitochondrial membrane potential (Ryan et al., 2012; Rowley et al., 2015).

Additionally, calcium influx also leads to NOS activation and consequent $\mathrm{NO}$ overproduction, which is known to be increased in the cerebral cortex of rodents and epilepsy patients (Mülsch et al., 1994; González-Hernández et al., 2000) and has been suggested to contribute to seizure-induced neuronal death. It has also been demonstrated that NO-mediated activation of the type 1 ryanodine receptor is crucial for seizure-induced neuronal death and that antagonists of this receptor have a neuroprotective effect, emerging as suitable candidates for ameliorating conditions following seizures (Mikami et al., 2016). Supporting this fact, it has been described that non-selectively blocking NOS can potentiate rubidium chloride anti-convulsive effects (Rahimi et al., 2019). Thus, given the onset of metabolic and mitochondrial alterations as a consequence of excitotoxicity in seizure activity and their relevance for neuronal damage, there has been a growing interest in the use of antioxidants and other neuroprotective drugs that prevent neuronal damage following seizures (Petkova et al., 2014; Mishra et al., 2015; Williams et al., 2015; Pauletti et al., 2019).

\section{CURTAIN CALL: CONCLUSIONS}

Excitotoxicity relies on multiple pathways that are involved in several regulatory cell mechanisms. Studies reviewed here suggest that, although the glutamatergic system is essential for brain functioning, its dysregulation is implicated as a key step in the pathophysiology of neuronal impairment, which is closely associated with excitotoxicity. This dysregulation may occur at the receptor, transporter, or metabolic levels, leading to different types of cellular responses that ultimately culminate in oxidative stress and neuronal death. Several neurodegenerative diseases display excitotoxic events or characteristics, and possibly this chronic mild excitotoxicity contributes, among other factors, to the neuronal death observed in these pathophysiological conditions. Thus, it is urgent to discover new therapeutic targets that counteract the excitotoxicity mediated by glutamatergic system, with a positive impact on neurological diseases such as ALS, AD, and TLE.

\section{AUTHOR CONTRIBUTIONS}

AA-M, JG, CP, OS, JG-R, NR, SP, TM, RM, and FR wrote the manuscript. AA-M designed the illustrations. AS and $\mathrm{VC}$ revised the manuscript. SV wrote, designed, and revised the manuscript.

\section{FUNDING}

This work was funded by Fundação para a Ciência e Tecnologia (FCT), Portugal (PTDC/BTM-SAL/32147/2017, $\mathrm{PD} / \mathrm{BD} / 114278 / 2016, \mathrm{IMM} / \mathrm{BI} / 2-2020$ ), and by FCT/Ministério da Ciência, Tecnologia e Ensino Superior (MCTES) through Fundos do Orçamento de Estado (UID/BIM/50005/2019). TM was funded by the European Union's Horizon 2020 research and innovation programme under the Marie Skłodowska/Curie grant agreement No. 722053. 


\section{REFERENCES}

Aarts, M., Liu, Y., Liu, L., Besshoh, S., Arundine, M., Gurd, J. W., et al. (2002). Treatment of ischemic brain damage by perturbing NMDA receptor- PSD-95 protein interactions. Science 298, 846-850. doi: 10.1126/science.1072873

Abdul, H. M., Sama, M. A., Furman, J. L., Mathis, D. M., Beckett, T. L., Weidner, A. M., et al. (2009). Cognitive decline in Alzheimer's disease is associated with selective changes in calcineurin/NFAT signaling. J. Neurosci. 29, 12957-12969. doi: 10.1523/JNEUROSCI.1064-09.2009

Ajroud-Driss, S., and Siddique, T. (2015). Sporadic and hereditary amyotrophic lateral sclerosis (ALS). Biochim. Biophys. Acta 1852, 679-684. doi: 10.1016/j. bbadis.2014.08.010

Akaike, A., Kaneko, S., Tamura, Y., Nakata, N., Shiomi, H., Ushikubi, F., et al. (1994). Prostaglandin E2 protects cultured cortical neurons against N-methylD-aspartate receptor-mediated glutamate cytotoxicity. Brain Res. 663, 237-243. doi: 10.1016/0006-8993(94)91268-8

Albin, R. L., and Greenamyre, J. T. (1992). Alternative excitotoxic hypotheses. Neurology 42, 733-738. doi: 10.1212/wnl.42.4.733

Albrecht, J., and Zielinska, M. (2017). Mechanisms of excessive extracellular glutamate accumulation in temporal lobe epilepsy. Neurochem. Res. 42, 1724-1734. doi: 10.1007/s11064-016-2105-8

Allen, N. J. (2014). Astrocyte regulation of synaptic behavior. Annu. Rev. Cell Dev. Biol. 30, 439-463. doi: 10.1146/annurev-cellbio-100913-013053

Alzheimer's Association. (2009). 2009 Alzheimer's disease facts and figures. Alzheimers Dement. 5, 234-270. doi: 10.1016/j.jalz.2009.03.001

Amiry-Moghaddam, M., Otsuka, T., Hurn, P. D., Traystman, R. J., Haug, F.-M., Froehner, S. C., et al. (2003). An $\alpha$-syntrophin-dependent pool of AQP4 in astroglial end-feet confers bidirectional water flow between blood and brain. Proc. Natl. Acad. Sci. U S A 100, 2106-2111. doi: 10.1073/pnas.0437 946100

Amorini, A. M., Lazzarino, G., Di Pietro, V., Signoretti, S., Lazzarino, G., Belli, A., et al. (2017). Severity of experimental traumatic brain injury modulates changes in concentrations of cerebral free amino acids. J. Cell. Mol. Med. 21, 530-542. doi: $10.1111 /$ jcmm. 12998

Anderson, C. M., and Swanson, R. A. (2000). Astrocyte glutamate transport: review of properties, regulation, and physiological functions. Glia 32, 1-14. doi: 10.1002/1098-1136(200010)32:1<1::aid-glia10>3.0.co;2-w

Angelova, P. R., and Abramov, A. Y. (2014). Interaction of neurons and astrocytes underlies the mechanism of $\mathrm{A} \beta$-induced neurotoxicity. Biochem. Soc. Trans. 42, 1286-1290. doi: 10.1042/bst20140153

Ankarcrona, M., Dypbukt, J. M., Bonfoco, E., Zhivotovsky, B., Orrenius, S., Lipton, S. A., et al. (1995). Glutamate-induced neuronal death: a succession of necrosis or apoptosis depending on mitochondrial function. Neuron 15, 961-973. doi: 10.1016/0896-6273(95)90186-8

Appel, S. H., Zhao, W., Beers, D. R., and Henkel, J. S. (2011). The microglialmotoneuron dialogue in ALS. Acta Myol. 30, 4-8.

Aronica, E., van Vliet, E. A., Mayboroda, O. A., Troost, D., da Silva, F. H., and Gorter, J. A. (2000). Upregulation of metabotropic glutamate receptor subtype mGluR3 and mGluR5 in reactive astrocytes in a rat model of mesial temporal lobe epilepsy. Eur. J. Neurosci. 12, 2333-2344. doi: 10.1046/j.1460-9568.2000. 00131.x

Bading, H. (2013). Nuclear calcium signalling in the regulation of brain function. Nat. Rev. Neurosci. 14, 593-608. doi: 10.1038/nrn3531

Bae, J. S., Simon, N. G., Menon, P., Vucic, S., and Kiernan, M. C. (2013). The puzzling case of hyperexcitability in amyotrophic lateral sclerosis. J. Clin. Neurol. 9, 65-74. doi: 10.3988/jcn.2013.9.2.65

Baker, D. A., Xi, Z. X., Shen, H., Swanson, C. J., and Kalivas, P. W. (2002). The origin and neuronal function of in vivo nonsynaptic glutamate. J. Neurosci. 22, 9134-9141. doi: 10.1523/JNEUROSCI.22-20-09134.2002

Balu, D. T., Pantazopoulos, H., Huang, C. C. Y., Muszynski, K., Harvey, T. L., Uno, Y., et al. (2019). Neurotoxic astrocytes express the D-serine synthesizing enzyme, serine racemase, in Alzheimer's disease. Neurobiol. Dis. 130:104511. doi: 10.1016/j.nbd.2019.104511

Bancila, V., Nikonenko, I., Dunant, Y., and Bloc, A. (2004). Zinc inhibits glutamate release via activation of pre-synaptic KATP channels and reduces ischaemic damage in rat hippocampus. J. Neurochem. 90, 1243-1250. doi: 10.1111/j.14714159.2004.02587.x
Bannai, S., and Tateishi, N. (1986). Role of membrane transport in metabolism and function of glutathione in mammals. J. Membr. Biol. 89, 1-8. doi: 10.1007/bf01870891

Bano, D., Young, K. W., Guerin, C. J., Lefeuvre, R., Rothwell, N. J., Naldini, L., et al. (2005). Cleavage of the plasma membrane $\mathrm{Na}^{+} / \mathrm{Ca}^{2+}$ exchanger in excitotoxicity. Cell 120, 275-285. doi: 10.1016/j.cell.2004.11.049

Barger, S. W., and Basile, A. S. (2001). Activation of microglia by secreted amyloid precursor protein evokes release of glutamate by cystine exchange and attenuates synaptic function. J. Neurochem. 76, 846-854. doi: 10.1046/j.14714159.2001.00075.x

Barger, S. W., Goodwin, M. E., Porter, M. M., and Beggs, M. L. (2007). Glutamate release from activated microglia requires the oxidative burst and lipid peroxidation. J. Neurochem. 101, 1205-1213. doi: 10.1111/j.1471-4159. 2007.04487.x

Barros, L. F. (2013). Metabolic signaling by lactate in the brain. Trends Neurosci. 36, 396-404. doi: 10.1016/j.tins.2013.04.002

Beart, P. M., and O'Shea, R. D. (2007). Transporters for L-glutamate: an update on their molecular pharmacology and pathological involvement. Br. J. Pharmacol. 150, 5-17. doi: 10.1038/sj.bjp.0706949

Bendotti, C., and Carrì, M. T. (2004). Lessons from models of SOD1-linked familial ALS. Trends Mol. Med. 10, 393-400. doi: 10.1016/j.molmed.2004. 06.009

Benjamin, A. M., and Quastel, J. H. (1972). Locations of amino acids in brain slices from the rat. Tetrodotoxin-sensitive release of amino acids. Biochem. J. 128 631-646. doi: 10.1042/bj1300901c

Berdichevsky, E., Riveros, N., Sánchez-Armáss, S., and Orrego, F. (1983). Kainate, $\mathrm{N}$-methylaspartate and other excitatory amino acids increase calcium influx into rat brain cortex cells in vitro. Neurosci. Lett. 36, 75-80. doi: 10.1016/03043940(83)90489-5

Bergersen, L. H., Morland, C., Ormel, L., Rinholm, J. E., Larsson, M., Wold, J. F. H., et al. (2012). Immunogold detection of L-glutamate and D-serine in small synaptic-like microvesicles in adult hippocampal astrocytes. Cereb. Cortex 22, 1690-1697. doi: 10.1093/cercor/bhr254

Berliocchi, L., Bano, D., and Nicotera, P. (2005). $\mathrm{Ca}^{2+}$ signals and death programmes in neurons. Philos. Trans. R. Soc. Lond. B. Biol. Sci. 360, 2255-2258. doi: 10.1098/rstb.2005.1765

Bernard-Marissal, N., Moumen, A., Sunyach, C., Pellegrino, C., Dudley, K., Henderson, C. E., et al. (2012). Reduced calreticulin levels link endoplasmic reticulum stress and Fas-triggered cell death in motoneurons vulnerable to ALS. J. Neurosci. 32, 4901-4912. doi: 10.1523/JNEUROSCI.5431-11.2012

Bi, X., Chang, V., Molnar, E., McIlhinney, R. A. J., and Baudry, M. (1996). The C-terminal domain of glutamate receptor subunit 1 is a target for calpain-mediated proteolysis. Neuroscience 73, 903-906. doi: 10.1016/03064522(96)00157-1

Bi, X., Chen, J., and Baudry, M. (1998a). Calpain-mediated proteolysis of GluR1 subunits in organotypic hippocampal cultures following kainic acid treatment. Brain Res. 781, 355-357. doi: 10.1016/s0006-8993(97)01365-6

Bi, X., Rong, Y., Chen, J., Dang, S., Wang, Z., and Baudry, M. (1998b). Calpainmediated regulation of NMDA receptor structure and function. Brain Res. 790, 245-253. doi: 10.1016/s0006-8993(98)00067-5

Bittner, C. X., Valdebenito, R., Ruminot, I., Loaiza, A., Larenas, V., SoteloHitschfeld, T., et al. (2011). Fast and reversible stimulation of astrocytic glycolysis by $\mathrm{K}^{+}$and a delayed and persistent effect of glutamate. J. Neurosci. 31, 4709-4713. doi: 10.1523/JNEUROSCI.5311-10.2011

Blatz, A. L., and Magleby, K. L. (1987). Calcium-activated potassium channels. Trends Neurosci. 10, 463-467. doi: 10.1016/0166-2236(87)90101-9

Bondy, S. C., and LeBel, C. P. (1993). The relationship between excitotoxicity and oxidative stress in the central nervous system. Free Radic. Biol. Med. 14 633-642. doi: 10.1016/0891-5849(93)90144-j

Bonfoco, E., Krainc, D., Ankarcrona, M., Nicotera, P., and Lipton, S. A. (1995). Apoptosis and necrosis: two distinct events induced, respectively, by mild and intense insults with $\mathrm{N}$-methyl-D-aspartate or nitric oxide/superoxide in cortical cell cultures. Proc. Natl. Acad. Sci. U S A 92, 7162-7166. doi: $10.1073 /$ pnas.92.16.7162

Bonifacino, T., Rebosio, C., Provenzano, F., Torazza, C., Balbi, M., Milanese, M., et al. (2019). Enhanced function and overexpression of metabotropic glutamate receptors 1 and 5 in the spinal cord of the SOD1G93A mouse model of 
amyotrophic lateral sclerosis during disease progression. Int. J. Mol. Sci. 20:E4552. doi: 10.3390/ijms20184552

Boycott, H. E., Wilkinson, J. A., Boyle, J. P., Pearson, H. A., and Peers, C. (2008). Differential involvement of TNF $\alpha$ in hypoxic suppression of astrocyte glutamate transporters. Glia 56, 998-1004. doi: 10.1002/glia.20673

Bradford, H. F. (1995). Glutamate, GABA and epilepsy. Prog. Neurobiol. 47, 477-511. doi: 10.1016/0301-0082(95)00030-5

Brawek, B., and Garaschuk, O. (2014). Network-wide dysregulation of calcium homeostasis in Alzheimer's disease. Cell Tissue Res. 357, 427-438. doi: 10.1007/s00441-014-1798-8

Brennan, A. M., Suh, S. W., Won, S. J., Narasimhan, P., Kauppinen, T. M., Lee, H., et al. (2009). NADPH oxidase is the primary source of superoxide induced by NMDA receptor activation. Nat. Neurosci. 12, 857-863. doi: 10.1038/nn.2334

Bridges, R., Lutgen, V., Lobner, D., and Baker, D. A. (2012). Thinking outside the cleft to understand synaptic activity: contribution of the cystine-glutamate antiporter (System $\mathrm{X}_{\mathrm{c}}^{-}$) to normal and pathological glutamatergic signaling. Pharmacol. Rev. 64, 780-802. doi: 10.1124/pr.110.003889

Brimecombe, J. C., Boeckman, F. A., and Aizenman, E. (1997). Functional consequences of NR2 subunit composition in single recombinant N-methylD-aspartate receptors. Proc. Natl. Acad. Sci. U S A 94, 11019-11024. doi: 10.1073/pnas.94.20.11019

Brites, D., and Vaz, A. R. (2014). Microglia centered pathogenesis in ALS: insights in cell interconnectivity. Front. Cell. Neurosci. 8:117. doi: 10.3389/fncel.2014. 00117

Brito-Moreira, J., Paula-Lima, A. C., Bomfim, T. R., Oliveira, F. B., Sepúlveda, F. J., De Mello, F. G., et al. (2011). A $\beta$ oligomers induce glutamate release from hippocampal neurons. Curr. Alzheimer Res. 8, 552-562. doi: $10.2174 / 156720511796391917$

Butterfield, D. A., and Kanski, J. (2001). Brain protein oxidation in age-related neurodegenerative disorders that are associated with aggregated proteins. Mech. Ageing Dev. 122, 945-962. doi: 10.1016/s0047-6374(01)00249-4

Butterfield, D. A., and Stadtman, E. R. (1997). Protein oxidation processes in aging brain. Adv. Cell Aging Gerontol. 2, 161-191. doi: 10.1016/S15663124(08)60057-7

Butterfield, D. A., Reed, T., Perluigi, M., De Marco, C., Coccia, R., Cini, C., et al. (2006). Elevated protein-bound levels of the lipid peroxidation product, 4hydroxy-2-nonenal, in brain from persons with mild cognitive impairment. Neurosci. Lett. 397, 170-173. doi: 10.1016/j.neulet.2005.12.017

Caldeira, M. V., Salazar, I. L., Curcio, M., Canzoniero, L. M. T., and Duarte, C. B. (2014). Role of the ubiquitin-proteasome system in brain ischemia: friend or foe? Prog. Neurobiol. 112, 50-69. doi: 10.1016/j.pneurobio.2013.10.003

Calkins, M. J., Manczak, M., Mao, P., Shirendeb, U., and Reddy, P. H. (2011). Impaired mitochondrial biogenesis, defective axonal transport of mitochondria, abnormal mitochondrial dynamics and synaptic degeneration in a mouse model of Alzheimer's disease. Hum. Mol. Genet. 20, 4515-4529. doi: $10.1093 / \mathrm{hmg} / \mathrm{ddr} 381$

Carvalho, A. S. R., Torres, L. B., Persike, D. S., Fernandes, M. J. S., Amado, D., Naffah-Mazzacoratti, M. D. G., et al. (2011). Neuroprotective effect of pyruvate and oxaloacetate during pilocarpine induced status epilepticus in rats. Neurochem. Int. 58, 385-390. doi: 10.1016/j.neuint.2010.12.014

Castegna, A., Thongboonkerd, V., Klein, J. B., Lynn, B., Markesberyl, W. R., and Butterfield, D. A. (2003). Proteomic identification of nitrated proteins in Alzheimer's disease brain. J. Neurochem. 85, 1394-1401. doi: 10.1046/j.14714159.2003.01786.x

Castilho, R. F., Hansson, O., Ward, M. W., Budd, S. L., and Nicholls, D. G. (1998). Mitochondrial control of acute glutamate excitotoxicity in cultured cerebellar granule cells. J. Neurosci. 18, 10277-10286. doi: 10.1523/JNEUROSCI.18-2410277.1998

Castillo, P. E., Malenka, R. C., and Nicoll, R. A. (1997). Kainate receptors mediate a slow postsynaptic current in hippocampal CA3 neurons. Nature 388, 182-186. doi: $10.1038 / 40645$

Chen, P. E., Geballe, M. T., Stansfeld, P. J., Johnston, A. R., Yuan, H., Jacob, A. L., et al. (2005). Structural features of the glutamate binding site in recombinant NR1/NR2A N-methyl-D-aspartate receptors determined by site-directed mutagenesis and molecular modeling. Mol. Pharmacol. 67, 1470-1484. doi: $10.1124 / \mathrm{mol} .104 .008185$

Chen, S., Sayana, P., Zhang, X., and Le, W. (2013). Genetics of amyotrophic lateral sclerosis: an update. Mol. Neurodegener. 8:28. doi: 10.1186/1750-1326-8-28
Chen, Z., and Zhong, C. (2013). Decoding Alzheimer's disease from perturbed cerebral glucose metabolism: implications for diagnostic and therapeutic strategies. Prog. Neurobiol. 108, 21-43. doi: 10.1016/j.pneurobio.2013. 06.004

Cheng, Y.-R., Jiang, B.-Y., and Chen, C.-C. (2018). Acid-sensing ion channels: dual function proteins for chemo-sensing and mechano-sensing. J. Biomed. Sci. 25:46. doi: 10.1186/s12929-018-0448-y

Chever, O., Djukic, B., McCarthy, K. D., and Amzica, F. (2010). Implication of Kir4.1 channel in excess potassium clearance: an in vivo study on anesthetized glial-conditional Kir4.1 knock-out mice. J. Neurosci. 30, 15769-15777. doi: 10.1523/JNEUROSCI.2078-10.2010

Chittajallu, R., Vignes, M., Dev, K. K., Barnes, J. M., Collingridge, G. L., and Henley, J. M. (1996). Regulation of glutamate release by presynaptic kainate receptors in the hippocampus. Nature 379, 78-81. doi: 10.1038/379078a0

Choi, D. W., Koh, J. Y., and Peters, S. (1988). Pharmacology of glutamate neurotoxicity in cortical cell culture: attenuation by NMDA antagonists. J. Neurosci. 8, 185-196. doi: 10.1523/JNEUROSCI.08-01-00185.1988

Choi, D. W., Viseskul, V., Amirthanayagam, M., and Monyer, H. (1989). Aspartate neurotoxicity on cultured cortical neurons. J. Neurosci. Res. 23, 116-121. doi: $10.1002 /$ jnr. 490230115

Chung, Y. H., Joo, K. M., Nam, R. H., Cho, M. H., Kim, D. J., Lee, W. B., et al. (2005). Decreased expression of calretinin in the cerebral cortex and hippocampus of SOD1G93A transgenic mice. Brain Res. 1035, 105-109. doi: $10.1016 /$ j.brainres.2004.12.022

Clements, J. D., Lester, R. A., Tong, G., Jahr, C. E., and Westbrook, G. L. (1992). The time course of glutamate in the synaptic cleft. Science 258, 1498-1501. doi: $10.1126 /$ science. 1359647

Conn, P. J., and Pin, J. P. (1997). Pharmacology and functions of metabotropic glutamate receptors. Аnпu. Rev. Pharmacol. Toxicol. 37, 205-237. doi: 10.1146/annurev.pharmtox.37.1.205

Connolly, N. M. C., Düssmann, H., Anilkumar, U., Huber, H. J., and Prehn, J. H. M. (2014). Single-cell imaging of bioenergetic responses to neuronal excitotoxicity and oxygen and glucose deprivation. J. Neurosci. 34, 10192-10205. doi: 10.1523/JNEUROSCI.3127-13.2014

Connolly, N. M. C., and Prehn, J. H. M. (2015). The metabolic response to excitotoxicity-lessons from single-cell imaging. J. Bioenerg. Biomembr. 47, 75-88. doi: 10.1007/s10863-014-9578-4

Crino, P. B., Jin, H., Shumate, M. D., Robinson, M. B., Coulter, D. A., and BrooksKayal, A. R. (2002). Increased expression of the neuronal glutamate transporter (EAAT3/EAAC1) in hippocampal and neocortical epilepsy. Epilepsia 43, 211-218. doi: 10.1046/j.1528-1157.2002.35001.x

Cull-Candy, S., Brickley, S., and Farrant, M. (2001). NMDA receptor subunits: diversity, development and disease. Curr. Opin. Neurobiol. 11, 327-335. doi: 10.1016/s0959-4388(00)00215-4

Cunha, R. A. (2005). Neuroprotection by adenosine in the brain: from A1 receptor activation to A2A receptor blockade. Purinergic Signal. 1, 111-134. doi: 10.1007/s11302-005-0649-1

Cunha, C., Santos, C., Gomes, C., Fernandes, A., Correia, A. M., Sebastião, A. M., et al. (2018). Downregulated glia interplay and increased miRNA-155 as promising markers to track ALS at an early stage. Mol. Neurobiol. 55, 4207-4224. doi: 10.1007/s12035-017-0631-2

D'Ambrosio, R., Gordon, D. S., and Winn, H. R. (2002). Differential role of KIR channel and $\mathrm{Na}^{+} / \mathrm{K}^{+}$-pump in the regulation of extracellular $\mathrm{K}^{+}$in rat hippocampus. J. Neurophysiol. 87, 87-102. doi: 10.1152/jn.00240.2001

D’Orsi, B., Bonner, H., Tuffy, L. P., Düssmann, H., Woods, I., Courtney, M. J., et al. (2012). Calpains are downstream effectors of bax-dependent excitotoxic apoptosis. J. Neurosci. 32, 1847-1858. doi: 10.1523/JNEUROSCI.2345-11.2012

Damiano, M., Starkov, A. A., Petri, S., Kipiani, K., Kiaei, M., Mattiazzi, M., et al. (2006). Neural mitochondrial $\mathrm{Ca}^{2+}$ capacity impairment precedes the onset of motor symptoms in $\mathrm{G} 93 \mathrm{~A} \mathrm{Cu} / \mathrm{Zn}$-superoxide dismutase mutant mice. J. Neurochem. 96, 1349-1361. doi: 10.1111/j.1471-4159.2006.03619.x

Danbolt, N. C. (2001). Glutamate uptake. Prog. Neurobiol. 65, 1-105. doi: 10.1016/s0301-0082(00)00067-8

Das, A., Wallace, G. C., Holmes, C., McDowell, M. L., Smith, J. A., Marshall, J. D., et al. (2012). Hippocampal tissue of patients with refractory temporal lobe epilepsy is associated with astrocyte activation, inflammation, and altered expression of channels and receptors. Neuroscience 220, 237-246. doi: 10.1016/j.neuroscience.2012.06.002 
De Stefani, D., Raffaello, A., Teardo, E., Szabò, I., and Rizzuto, R. (2011). A forty-kilodalton protein of the inner membrane is the mitochondrial calcium uniporter. Nature 476, 336-340. doi: 10.1038/nature10230

Depp, C., Bas-Orth, C., Schroeder, L., Hellwig, A., and Bading, H. (2018). Synaptic activity protects neurons against calcium-mediated oxidation and contraction of mitochondria during excitotoxicity. Antioxid. Redox Signal. 29, 1109-1124. doi: 10.1089/ars.2017.7092

Descalzi, G., Gao, V., Steinman, M. Q., Suzuki, A., and Alberini, C. M. (2019). Lactate from astrocytes fuels learning-induced mRNA translation in excitatory and inhibitory neurons. Commun. Biol. 2:247. doi: 10.1038/s42003-019-0495-2

Devinsky, O., Vezzani, A., Najjar, S., De Lanerolle, N. C., and Rogawski, M. A. (2013). Glia and epilepsy: excitability and inflammation. Trends Neurosci. 36, 174-184. doi: 10.1016/j.tins.2012.11.008

Díaz, A., De Jesús, L., Mendieta, L., Calvillo, M., Espinosa, B., Zenteno, E., et al. (2010). The amyloid- $\beta 25-35$ injection into the CA1 region of the neonatal rat hippocampus impairs the long-term memory because of an increase of nitric oxide. Neurosci. Lett. 468, 151-155. doi: 10.1016/j.neulet.2009.10.087

Diaz, A., Mendieta, L., Zenteno, E., Guevara, J., and Limon, I. D. (2011). The role of NOS in the impairment of spatial memory and damaged neurons in rats injected with amyloid $\beta 25-35$ into the temporal cortex. Pharmacol. Biochem. Behav. 98, 67-75. doi: 10.1016/j.pbb.2010.12.005

Dick, O., and Bading, H. (2010). Synaptic activity and nuclear calcium signaling protect hippocampal neurons from death signal-associated nuclear translocation of FoxO3a induced by extrasynaptic N-methyl-Daspartate receptors. J. Biol. Chem. 285, 19354-19361. doi: 10.1074/jbc.m110. 127654

Dienel, G. A. (2017). The metabolic trinity, glucose-glycogen-lactate, links astrocytes and neurons in brain energetics, signaling, memory, and gene expression. Neurosci. Lett. 637, 18-25. doi: 10.1016/j.neulet.2015. 02.052

Djukic, B., Casper, K. B., Philpot, B. D., Chin, L.-S., and McCarthy, K. D. (2007). Conditional knock-out of Kir4.1 leads to glial membrane depolarization, inhibition of potassium and glutamate uptake, and enhanced short-term synaptic potentiation. J. Neurosci. 27, 11354-11365. doi: 10.1523/jneurosci. 0723-07.2007

Dong, X., Wang, Y., and Qin, Z. (2009). Molecular mechanisms of excitotoxicity and their relevance to pathogenesis of neurodegenerative diseases. Acta Pharmacol. Sin. 30, 379-387. doi: 10.1038/aps.2009.24

Doyle, K. P., Simon, R. P., and Stenzel-Poore, M. P. (2008). Mechanisms of ischemic brain damage. Neuropharmacology 55, 310-318. doi: 10.1016/j. neuropharm.2008.01.005

Du, H., Guo, L., Fang, F., Chen, D., Sosunov, A. A., McKhann, G. M., et al. (2008). Cyclophilin D deficiency attenuates mitochondrial and neuronal perturbation and ameliorates learning and memory in Alzheimer's disease. Nat. Med. 14, 1097-1105. doi: 10.1038/nm.1868

Du, H., Guo, L., Wu, X., Sosunov, A. A., McKhann, G. M., Chen, J. X., et al. (2014). Cyclophilin D deficiency rescues A $\beta$-impaired PKA/CREB signaling and alleviates synaptic degeneration. Biochim. Biophys. Acta 1842, 2517-2527. doi: 10.1016/j.bbadis.2013.03.004

Du, H., Guo, L., Zhang, W., Rydzewska, M., and Yan, S. (2011). Cyclophilin D deficiency improves mitochondrial function and learning/memory in aging Alzheimer disease mouse model. Neurobiol. Aging 32, 398-406. doi: 10.1016/j. neurobiolaging.2009.03.003

Dudek, F. E., and Rogawski, M. A. (2005). Regulation of brain water: is there a role for aquaporins in epilepsy? Epilepsy Curr. 5, 104-106. doi: 10.1111/j.1535-7511. 2005.05310.x

During, M. J., and Spencer, D. D. (1993). Extracellular hippocampal glutamate and spontaneous seizure in the conscious human brain. Lancet 341, 1607-1610. doi: 10.1016/0140-6736(93)90754-5

Dutta, R., and Trapp, B. D. (2011). Mechanisms of neuronal dysfunction and degeneration in multiple sclerosis. Prog. Neurobiol. 93, 1-12. doi: 10.1016/j. pneurobio.2010.09.005

Dzubay, J. A., and Jahr, C. E. (1999). The concentration of synaptically released glutamate outside of the climbing fiber-Purkinje cell synaptic cleft. J. Neurosci. 19, 5265-5274. doi: 10.1523/jneurosci.19-13-05265.1999

Edwards, J. P., Zhang, X., Frauwirth, K. A., and Mosser, D. M. (2006). Biochemical and functional characterization of three activated macrophage populations. J. Leukoc. Biol. 80, 1298-1307. doi: 10.1189/jlb.0406249
Ehlers, M. D., Zhang, S., Bernhardt, J. P., and Huganir, R. L. (1996). Inactivation of NMDA receptors by direct interaction of calmodulin with the NR1 subunit. Cell 84, 745-755. doi: 10.1016/s0092-8674(00)81052-1

Eid, T., Lee, T.-S. W., Thomas, M. J., Amiry-Moghaddam, M., Bjørnsen, L. P., Spencer, D. D., et al. (2005). Loss of perivascular aquaporin 4 may underlie deficient water and $\mathrm{K}^{+}$homeostasis in the human epileptogenic hippocampus. Proc. Natl. Acad. Sci. U S A 102, 1193-1198. doi: 10.1073/pnas.0409308102

Erreger, K., Dravid, S. M., Banke, T. G., Wyllie, D. J. A., and Traynelis, S. F. (2005). Subunit-specific gating controls rat NR1/NR2A and NR1/NR2B NMDA channel kinetics and synaptic signalling profiles. J. Physiol. 563, 345-358. doi: 10.1113/jphysiol.2004.080028

Ertekin-Taner, N. (2007). Genetics of Alzheimer's disease: a centennial review. Neurol. Clin. 25, 611-667. doi: 10.1016/j.ncl.2007.03.009

Fairman, W. A., and Amara, S. G. (1999). Functional diversity of excitatory amino acid transporters: ion channel and transport modes. Am. J. Physiol. 277, F481-F486. doi: 10.1152/ajprenal.1999.277.4.f481

Ferraguti, F., Crepaldi, L., and Nicoletti, F. (2008). Metabotropic glutamate 1 receptor: current concepts and perspectives. Pharmacol. Rev. 60, 536-581. doi: $10.1124 /$ pr.108.000166

Ferrari, R., Kapogiannis, D., Huey, E. D., and Momeni, P. (2011). FTD and ALS: a tale of two diseases. Curr. Alzheimer Res. 8, 273-294 doi: 10.2174/156720511795563700

Ferreira, I. L., Bajouco, L. M., Mota, S. I., Auberson, Y. P., Oliveira, C. R., and Rego, A. C. (2012). Amyloid $\beta$ peptide 1-42 disturbs intracellular calcium homeostasis through activation of GluN2B-containing N-methyl-d-aspartate receptors in cortical cultures. Cell Calcium 51, 95-106. doi: 10.1016/j.ceca.2011. 11.008

Ferrer, I. (2012). Defining Alzheimer as a common age-related neurodegenerative process not inevitably leading to dementia. Prog. Neurobiol. 97, 38-51. doi: 10.1016/j.pneurobio.2012.03.005

Fisher, R. S., Cross, J. H., French, J. A., Higurashi, N., Hirsch, E., Jansen, F. E., et al. (2017). Operational classification of seizure types by the international league against epilepsy: position paper of the ILAE commission for classification and terminology. Epilepsia 58, 522-530. doi: 10.1111/epi.13670

Floyd, R. A. (1999). Antioxidants, oxidative stress, and degenerative neurological disorders. Proc. Soc. Exp. Biol. Med. 222, 236-245. doi: 10.1046/j.1525-1373. 1999.d01-140.x

Fogarty, M. J., Mu, E. W. H., Noakes, P. G., Lavidis, N. A., and Bellingham, M. C. (2016). Marked changes in dendritic structure and spine density precede significant neuronal death in vulnerable cortical pyramidal neuron populations in the SOD1(G93A) mouse model of amyotrophic lateral sclerosis. Acta Neuropathol. Commun. 4:77. doi: 10.1186/s40478-016-0347-y

Frantseva, M. V., Velazquez, J. L., Hwang, P. A., and Carlen, P. L. (2000). Free radical production correlates with cell death in an in vitro model of epilepsy. Eur. J. Neurosci. 12, 1431-1439. doi: 10.1046/j.1460-9568.2000.00016.x

Freeman, B. A., and Crapo, J. D. (1982). Biology of disease: free radicals and tissue injury. Lab. Invest. 47, 412-426.

Fukuhara, T., Nishio, S., Ono, Y., Kawauchi, M., Asari, S., and Ohmoto, T. (1994). Induction of $\mathrm{Cu}, \mathrm{Zn}$-superoxide dismutase after cortical contusion injury during hypothermia. Brain Res. 657, 333-336. doi: 10.1016/00068993(94)90987-3

Giribaldi, F., Milanese, M., Bonifacino, T., Anna Rossi, P. I., Di Prisco, S., Pittaluga, A., et al. (2013). Group I metabotropic glutamate autoreceptors induce abnormal glutamate exocytosis in a mouse model of amyotrophic lateral sclerosis. Neuropharmacology 66, 253-263. doi: 10.1016/j.neuropharm.2012. 05.018

Goffin, K., Dedeurwaerdere, S., Van Laere, K., and Van Paesschen, W. (2008). Neuronuclear assessment of patients with epilepsy. Semin. Nucl. Med. 38, 227-239. doi: 10.1053/j.semnuclmed.2008.02.004

Gomes, C., Cunha, C., Nascimento, F., Ribeiro, J. A., Vaz, A. R., and Brites, D. (2019). Cortical neurotoxic astrocytes with early ALS pathology and miR-146a deficit replicate gliosis markers of symptomatic SOD1G93A mouse model. Mol. Neurobiol. 56, 2137-2158. doi: 10.1007/s12035-018-1220-8

Gonçalves-Ribeiro, J., Pina, C. C., Sebastião, A. M., and Vaz, S. H. (2019). Glutamate transporters in hippocampal LTD/LTP: not just prevention of excitotoxicity. Front. Cell. Neurosci. 13:357. doi: 10.3389/fncel.2019.00357

González-Hernández, T., García-Marín, V., Pérez-Delgado, M. M., GonzálezGonzález, M. L., Rancel-Torres, N., and González-Feria, L. (2000). Nitric oxide 
synthase expression in the cerebral cortex of patients with epilepsy. Epilepsia 41, 1259-1268. doi: 10.1111/j.1528-1157.2000.tb04603.x

Goss, J. R., Taffe, K. M., Kochanek, P. M., and DeKosky, S. T. (1997). The antioxidant enzymes glutathione peroxidase and catalase increase following traumatic brain injury in the rat. Exp. Neurol. 146, 291-294. doi: 10.1006/exnr. 1997.6515

Gottlieb, M., Wang, Y., and Teichberg, V. I. (2003). Blood-mediated scavenging of cerebrospinal fluid glutamate. J. Neurochem. 87, 119-126. doi: 10.1046/j.14714159.2003.01972.x

Gravel, M., Béland, L.-C., Soucy, G., Abdelhamid, E., Rahimian, R., Gravel, C., et al. (2016). IL-10 controls early microglial phenotypes and disease onset in ALS caused by misfolded superoxide dismutase 1. J. Neurosci. 36, 1031-1048. doi: 10.1523/JNEUROSCI.0854-15.2016

Griffiths, T., Evans, M. C., and Meldrum, B. S. (1983). Intracellular calcium accumulation in rat hippocampus during seizures induced by bicuculline or L-allylglycine. Neuroscience 10, 385-395. doi: 10.1016/0306-4522(83)90141-0

Grundke-Iqbal, I., Iqbal, K., Tung, Y. C., Quinlan, M., Wisniewski, H. M., and Binder, L. I. (1986). Abnormal phosphorylation of the microtubule-associated protein tau (tau) in Alzheimer cytoskeletal pathology. Proc. Natl. Acad. Sci. US A 83, 4913-4917. doi: 10.1073/pnas.83.13.4913

Guo, H., Camargo, L. M., Yeboah, F., Digan, M. E., Niu, H., Pan, Y., et al. (2017). A NMDA-receptor calcium influx assay sensitive to stimulation by glutamate and glycine/D-serine. Sci. Rep. 7:11608. doi: 10.1038/s41598-017$11947-x$

Guo, H., Lai, L., Butchbach, M. E. R., Stockinger, M. P., Shan, X., Bishop, G. A., et al. (2003). Increased expression of the glial glutamate transporter EAAT2 modulates excitotoxicity and delays the onset but not the outcome of ALS in mice. Hum. Mol. Genet. 12, 2519-2532. doi: 10.1093/hmg/ddg267

Hamano, H., Nabekura, J., Nishikawa, M., and Ogawa, T. (1996). Docosahexaenoic acid reduces GABA response in substantia nigra neuron of rat. J. Neurophysiol. 75, 1264-1270. doi: 10.1152/jn.1996.75.3.1264

Hansen, K. B., Yi, F., Perszyk, R. E., Menniti, F. S., and Traynelis, S. F. (2017)."NMDA receptors in the central nervous system," in NMDA Receptors, eds N. Burnashev and P. Szepetowski (New York, NY: Springer), 1-80.

Hardingham, G. E., and Bading, H. (2010). Synaptic versus extrasynaptic NMDA receptor signalling: implications for neurodegenerative disorders. Nat. Rev. Neurosci. 11, 682-696. doi: 10.1038/nrn2911

Hardingham, G. E., Fukunaga, Y., and Bading, H. (2002). Extrasynaptic NMDARs oppose synaptic NMDARs by triggering CREB shut-off and cell death pathways. Nat. Neurosci. 5, 405-414. doi: 10.1038/nn835

Harris, A. Z., and Pettit, D. L. (2007). Extrasynaptic and synaptic NMDA receptors form stable and uniform pools in rat hippocampal slices. J. Physiol. 584, 509-519. doi: 10.1113/jphysiol.2007.137679

Haughey, N. J., and Mattson, M. P. (2003). Alzheimer's amyloid $\beta$-peptide enhances ATP/gap junction-mediated calcium-wave propagation in astrocytes. Neuromolecular Med. 3, 173-180. doi: 10.1385/NMM:3:3:173

Henneberger, C., Papouin, T., Oliet, S. H. R., and Rusakov, D. A. (2010). Longterm potentiation depends on release of d-serine from astrocytes. Nature 463, 232-236. doi: $10.1038 /$ nature 08673

Hensley, K., Carney, J. M., Mattson, M. P., Aksenova, M., Harris, M., Wu, J. F., et al. (1994). A model for $\beta$-amyloid aggregation and neurotoxicity based on free radical generation by the peptide: relevance to Alzheimer disease. Proc. Natl. Acad. Sci. U S A 91, 3270-3274. doi: 10.1073/pnas.91.8.3270

Hensley, K., Hall, N., Subramaniam, R., Cole, P., Harris, M., Aksenov, M., et al. (1995). Brain regional correspondence between Alzheimer's disease histopathology and biomarkers of protein oxidation. J. Neurochem. 65, 2146-2156. doi: 10.1073/pnas.91.8.3270

Herman, M. A., and Jahr, C. E. (2007). Extracellular glutamate concentration in hippocampal slice. J. Neurosci. 27, 9736-9741. doi: 10.1523/JNEUROSCI.300907.2007

Hertz, L., Dringen, R., Schousboe, A., and Robinson, S. R. (1999). Astrocytes: glutamate producers for neurons. J. Neurosci. Res. 57, 417-428. doi: 10.1002/(sici)1097-4547(19990815)57:4<417::aid-jnr1 >3.0.co;2-n

Hewett, S. J., Uliasz, T. F., Vidwans, A. S., and Hewett, J. A. (2000). Cyclooxygenase-2 contributes to N-methyl-D-aspartate-mediated neuronal cell death in primary cortical cell culture. J. Pharmacol. Exp. Ther. 293, 417-425.

Honrath, B., Krabbendam, I. E., Culmsee, C., and Dolga, A. M. (2017). Small conductance $\mathrm{Ca}^{2+}$-activated $\mathrm{K}^{+}$channels in the plasma membrane, mitochondria and the ER: pharmacology and implications in neuronal diseases. Neurochem. Int. 109, 13-23. doi: 10.1016/j.neuint.2017.05.005

Hoogland, G., van Oort, R. J., Proper, E. A., Jansen, G. H., van Rijen, P. C., van Veelen, C. W., et al. (2004). Alternative splicing of glutamate transporter EAAT2 RNA in neocortex and hippocampus of temporal lobe epilepsy patients. Epilepsy Res. 59, 75-82. doi: 10.1016/j.eplepsyres.2004.03.003

Howland, J. G., Taepavarapruk, P., and Phillips, A. G. (2002). Glutamate receptordependent modulation of dopamine efflux in the nucleus accumbens by basolateral, but not central, nucleus of the amygdala in rats. J. Neurosci. 22, 1137-1145. doi: 10.1523/JNEUROSCI.22-03-01137.2002

Hu, S., Sheng, W. S., Ehrlich, L. C., Peterson, P. K., and Chao, C. C. (2000). Cytokine effects on glutamate uptake by human astrocytes. Neuroimmunomodulation 7, 153-159. doi: 10.1159/000026433

Huang, Y., Shen, W., Su, J., Cheng, B., Li, D., Liu, G., et al. (2017). Modulating the balance of synaptic and extrasynaptic NMDA receptors shows positive effects against amyloid- $\beta$-induced neurotoxicity. J. Alzheimers Dis. 57, 885-897. doi: $10.3233 /$ jad-161186

Hubbard, J. A., Szu, J. I., Yonan, J. M., and Binder, D. K. (2016). Regulation of astrocyte glutamate transporter-1 (GLT1) and aquaporin-4 (AQP4) expression in a model of epilepsy. Exp. Neurol. 283, 85-96. doi: 10.1016/j.expneurol.2016. 05.003

Huxtable, R. J. (1992). Physiological actions of taurine. Physiol. Rev. 72, 101-163. doi: 10.1152/physrev.1992.72.1.101

Ishii, K., Sasaki, M., Kitagaki, H., Yamaji, S., Sakamoto, S., Matsuda, K., et al. (1997). Reduction of cerebellar glucose metabolism in advanced Alzheimer's disease. J. Nucl. Med. 38, 925-928.

Jackman, N. A., Melchior, S. E., Hewett, J. A., and Hewett, S. J. (2012). Non-cell autonomous influence of the astrocyte system xc- on hypoglycaemic neuronal cell death. ASN Neuro 4:e00074. doi: 10.1042/an20110030

Jarrett, S. G., Liang, L.-P., Hellier, J. L., Staley, K. J., and Patel, M. (2008). Mitochondrial DNA damage and impaired base excision repair during epileptogenesis. Neurobiol. Dis. 30, 130-138. doi: 10.1016/j.nbd.2007.12.009

Jerónimo-Santos, A., Vaz, S. H., Parreira, S., Rapaz-Lérias, S., Caetano, A. P., BuéeScherrer, V., et al. (2015). Dysregulation of TrkB receptors and BDNF function by amyloid- $\beta$ peptide is mediated by calpain. Cereb. Cortex 25, 3107-3121. doi: $10.1093 /$ cercor/bhu105

Jia, M., Njapo, S. A. N., Rastogi, V., and Hedna, V. S. (2015). Taming glutamate excitotoxicity: strategic pathway modulation for neuroprotection. CNS Drugs 29, 153-162. doi: 10.1007/s40263-015-0225-3

Jiang, L. L., Zhu, B., Zhao, Y., Li, X., Liu, T., Pina-Crespo, J., et al. (2019). Membralin deficiency dysregulates astrocytic glutamate homeostasis leading to ALS-like impairment. J. Clin. Invest. 129, 3103-3120. doi: 10.1172/jci127695

Jonas, P. (2000). The time course of signaling at central glutamatergic synapses. Physiology 15, 83-89. doi: 10.1152/physiologyonline.2000.15.2.83

Jones, N. (2011). Stroke: disruption of the nNOS-PSD-95 complex is neuroprotective in models of cerebral ischemia. Nat. Rev. Neurol. 7:61. doi: 10.1038/nrneurol.2010.203

Kennedy, A. M., Frackowiak, R. S. J., Newman, S. K., Bloomfield, P. M., Seaward, J., Roques, P., et al. (1995). Deficits in cerebral glucose metabolism demonstrated by positron emission tomography in individuals at risk of familial Alzheimer's disease. Neurosci. Lett. 186, 17-20. doi: 10.1016/0304-3940(95)11270-7

Kia, A., McAvoy, K., Krishnamurthy, K., Trotti, D., and Pasinelli, P. (2018). Astrocytes expressing ALS-linked mutant FUS induce motor neuron death through release of tumor necrosis factor- $\alpha$. Glia 66, 1016-1033. doi: 10.1002/glia.23298

Kiernan, M. C., Vucic, S., Cheah, B. C., Turner, M. R., Eisen, A., Hardiman, O., et al. (2011). Amyotrophic lateral sclerosis. Lancet 377, 942-955 doi: 10.1016/S0140-6736(10)61156-7

Kobayashi, E., Nakano, M., Kubota, K., Himuro, N., Mizoguchi, S., Chikenji, T., et al. (2018). Activated forms of astrocytes with higher GLT-1 expression are associated with cognitive normal subjects with Alzheimer pathology in human brain. Sci. Rep. 8:1712. doi: 10.1038/s41598-018-19442-7

Koenigsknecht-Talboo, J., and Landreth, G. E. (2005). Microglial phagocytosis induced by fibrillar $\beta$-amyloid and IgGs are differentially regulated by proinflammatory cytokines. J. Neurosci. 25, 8240-8249. doi: 10.1523/JNEUROSCI.1808-05.2005

Kofuji, P., and Newman, E. A. (2004). Potassium buffering in the central nervous system. Neuroscience 129, 1045-1056. doi: 10.1016/j.neuroscience.2004.06.008 
Kojima, S., Nakamura, T., Nidaira, T., Nakamura, K., Ooashi, N., Ito, E., et al. (1999). Optical detection of synaptically induced glutamate transport in hippocampal slices. J. Neurosci. 19, 2580-2588. doi: 10.1523/JNEUROSCI.1907-02580.1999

Komine, O., and Yamanaka, K. (2015). Neuroinflammation in motor neuron disease. Nagoya J. Med. Sci. 77, 537-549.

Kong, Q., Chang, L. C., Takahashi, K., Liu, Q., Schulte, D. A., Lai, L., et al. (2014). Small-molecule activator of glutamate transporter EAAT2 translation provides neuroprotection. J. Clin. Invest. 124, 1255-1267. doi: 10.1172/jci66163

Kong, Q., Takahashi, K., Schulte, D., Stouffer, N., Lin, Y., and Lin, C. L. (2012). Increased glial glutamate transporter EAAT2 expression reduces epileptogenic processes following pilocarpine-induced status epilepticus. Neurobiol. Dis. 47, 145-154. doi: 10.1016/j.nbd.2012.03.032

Kovac, S., Abramov, A. Y., and Walker, M. C. (2013). Energy depletion in seizures: anaplerosis as a strategy for future therapies. Neuropharmacology 69, 96-104. doi: 10.1016/j.neuropharm.2012.05.012

Kovac, S., Domijan, A.-M., Walker, M. C., and Abramov, A. Y. (2012). Prolonged seizure activity impairs mitochondrial bioenergetics and induces cell death. J. Cell Sci. 125, 1796-1806. doi: 10.1242/jcs.099176

Kraig, R. P., Petito, C. K., Plum, F., and Pulsinelli, W. A. (1987). Hydrogen ions kill brain at concentrations reached in ischemia. J. Cereb. Blood Flow Metab. 7, 379-386. doi: $10.1038 / \mathrm{jcbfm} .1987 .80$

Kuchibhotla, K. V., Lattarulo, C. R., Hyman, B. T., and Bacskai, B. J. (2009). Synchronous hyperactivity and intercellular calcium waves in astrocytes in Alzheimer mice. Science 323, 1211-1215. doi: 10.1126/science.1169096

Kuner, T., and Schoepfer, R. (1996). Multiple structural elements determine subunit specificity of $\mathrm{Mg} 2+$ block in NMDA receptor channels. J. Neurosci. 16, 3549-3558. doi: 10.1523/JNEUROSCI.16-11-03549.1996

Kushnareva, Y. E., Wiley, S. E., Ward, M. W., Andreyev, A. Y., and Murphy, A. N. (2005). Excitotoxic injury to mitochondria isolated from cultured neurons. J. Biol. Chem. 280, 28894-28902. doi: 10.1074/jbc.m503090200

LaFerla, F. M., Green, K. N., and Oddo, S. (2007). Intracellular amyloid- $\beta$ in Alzheimer's disease. Nat. Rev. Neurosci. 8, 499-509. doi: 10.1038/nrn2168

Lancaster, B., and Adams, P. R. (1986). Calcium-dependent current generating the afterhyperpolarization of hippocampal neurons. J. Neurophysiol. 55, 1268-1282. doi: 10.1152/jn.1986.55.6.1268

Lee, D. J., Hsu, M. S., Seldin, M. M., Arellano, J. L., and Binder, D. K. (2012). Decreased expression of the glial water channel aquaporin-4 in the intrahippocampal kainic acid model of epileptogenesis. Exp. Neurol. 235, 246-255. doi: 10.1016/j.expneurol.2012.02.002

Leung, A. W. C., Varanyuwatana, P., and Halestrap, A. P. (2008). The mitochondrial phosphate carrier interacts with cyclophilin D and may play a key role in the permeability transition. J. Biol. Chem. 283, 26312-26323. doi: $10.1074 /$ jbc.m805235200

Lewerenz, J., Maher, P., and Methner, A. (2012). Regulation of xCT expression and system $\mathrm{x}_{\mathrm{c}}^{-}$function in neuronal cells. Amino Acids 42, 171-179. doi: 10.1007/s00726-011-0862-x

Li, K., Hala, T. J., Seetharam, S., Poulsen, D. J., Wright, M. C., and Lepore, A. C. (2015). GLT1 overexpression in SOD1(G93A) mouse cervical spinal cord does not preserve diaphragm function or extend disease. J. Neurol. 78, 12-23. doi: 10.1016/j.nbd.2015.03.010

Li, S., Jin, M., Koeglsperger, T., Shepardson, N., Shankar, G., and Selkoe, D. (2011). Soluble $A \beta$ oligomers inhibit long-term potentiation through a mechanism involving excessive activation of extrasynaptic NR2B-containing NMDA receptors. J. Neurosci. 31, 6627-6638. doi: 10.1523/JNEUROSCI.020311.2011

Li, M.-H., Leng, T.-D., Feng, X.-C., Yang, T., Simon, R. P., and Xiong, Z.-G. (2016). Modulation of acid-sensing ion channel la by intracellular $\mathrm{pH}$ and its role in ischemic stroke. J. Biol. Chem. 291, 18370-18383. doi: 10.1074/jbc.m115. 713636

Liang, L. P., Ho, Y. S., and Patel, M. (2000). Mitochondrial superoxide production in kainate-induced hippocampal damage. Neuroscience 101, 563-570. doi: 10.1016/s0306-4522(00)00397-3

Lieberman, D. N., and Mody, I. (1994). Regulation of NMDA channel function by endogenous $\mathrm{Ca}^{2+}$-dependent phosphatase. Nature 369, 235-239. doi: $10.1038 / 369235 \mathrm{a} 0$

Lin, C. L., Bristol, L. A., Jin, L., Dykes-Hoberg, M., Crawford, T., Clawson, L., et al. (1998). Aberrant RNA processing in a neurodegenerative disease: the cause for absent EAAT2, a glutamate transporter, in amyotrophic lateral sclerosis. Neuron 20, 589-602. doi: 10.1016/s0896-6273(00)80997-6

Lipton, S. A. (2008). NMDA receptor activity regulates transcription of antioxidant pathways. Nat. Neurosci. 11, 381-382. doi: 10.1038/nn0408-381

Lipton, S. A., Choi, Y. B., Pan, Z. H., Lei, S. Z., Chen, H. S., Sucher, N. J., et al. (1993). A redox-based mechanism for the neuroprotective and neurodestructive effects of nitric oxide and related nitroso-compounds. Nature 364, 626-632. doi: 10.1038/364626a0

Liu, B., and Hong, J.-S. (2003). Role of microglia in inflammation-mediated neurodegenerative diseases: mechanisms and strategies for therapeutic intervention. J. Pharmacol. Exp. Ther. 304, 1-7. doi: 10.1124/jpet.102.035048

Liu, B., Niu, L., Shen, M.-Z., Gao, L., Wang, C., Li, J., et al. (2014). Decreased astroglial monocarboxylate transporter 4 expression in temporal lobe epilepsy. Mol. Neurobiol. 50, 327-338. doi: 10.1007/s12035-013-8619-z

Lo, M., Wang, Y.-Z., and Gout, P. W. (2008). The $\mathrm{x}_{\mathrm{c}}^{-}$cystine/glutamate antiporter: a potential target for therapy of cancer and other diseases. J. Cell. Physiol. 215, 593-602. doi: 10.1002/jcp.21366

Lucca, G., Comim, C. M., Valvassori, S. S., Réus, G. Z., Vuolo, F., Petronilho, F., et al. (2009). Effects of chronic mild stress on the oxidative parameters in the rat brain. Neurochem. Int. 54, 358-362. doi: 10.1016/j.neuint.2009.01.001

Luetjens, C. M., Bui, N. T., Sengpiel, B., Münstermann, G., Poppe, M., Krohn, A. J., et al. (2000). Delayed mitochondrial dysfunction in excitotoxic neuron death: cytochrome $\mathrm{c}$ release and a secondary increase in superoxide production. J. Neurosci. 20, 5715-5723. doi: 10.1523/JNEUROSCI.20-15-05715.2000

Lutgen, V., Resch, J., Qualmann, K., Raddatz, N. J., Panhans, C., Olander, E. M., et al. (2014). Behavioral assessment of acute inhibition of system xc- in rats. Psychopharmacology 231, 4637-4647. doi: 10.1007/s00213-014-3612-4

Mächler, P., Wyss, M. T., Elsayed, M., Stobart, J., Gutierrez, R., von FaberCastell, A., et al. (2016). in vivo evidence for a lactate gradient from astrocytes to neurons. Cell Metab. 23, 94-102. doi: 10.1016/j.cmet.2015.10.010

Madison, D. V., and Nicoll, R. A. (1984). Control of the repetitive discharge of rat CA 1 pyramidal neurones in vitro. J. Physiol. 354, 319-331. doi: 10.1113/jphysiol.1984.sp015378

Magistretti, P. J., and Allaman, I. (2015). A cellular perspective on brain energy metabolism and functional imaging. Neuron 86, 883-901. doi: 10.1016/j. neuron.2015.03.035

Magnusson, K. R., Koerner, J. F., Larson, A. A., Smullin, D. H., Skilling, S. R., and Beitz, A. J. (1991). NMDA-, kainate- and quisqualate-stimulated release of taurine from electrophysiologically monitored rat hippocampal slices. Brain Res. 549, 1-8. doi: 10.1016/0006-8993(91)90592-j

Manczak, M., Anekonda, T. S., Henson, E., Park, B. S., Quinn, J., and Reddy, P. H. (2006). Mitochondria are a direct site of $A \beta$ accumulation in Alzheimer's disease neurons: implications for free radical generation and oxidative damage in disease progression. Hum. Mol. Genet. 15, 1437-1449. doi: $10.1093 / \mathrm{hmg} / \mathrm{ddl} 066$

Maneshi, M. M., Maki, B., Gnanasambandam, R., Belin, S., Popescu, G. K., Sachs, F., et al. (2017). Mechanical stress activates NMDA receptors in the absence of agonists. Sci. Rep. 7:39610. doi: 10.1038/srep39610

Marcaida, G., Kosenko, E., Miñana, M. D., Grisolía, S., and Felipo, V. (1996). Glutamate induces a calcineurin-mediated dephosphorylation of $\mathrm{Na}^{+}, \mathrm{K}^{+}$. ATPase that results in its activation in cerebellar neurons in culture. J. Neurochem. 66, 99-104. doi: 10.1046/j.1471-4159.1996.66010099.x

Mark, L. P., Prost, R. W., Ulmer, J. L., Smith, M. M., Daniels, D. L., Strottmann, J. M., et al. (2001). Pictorial review of glutamate excitotoxicity: fundamental concepts for neuroimaging. Am. J. Neuroradiol. 22, 1813-1824.

Martin, L. J., Liu, Z., Chen, K., Price, A. C., Pan, Y., Swaby, J. A., et al. (2007), Motor neuron degeneration in amyotrophic lateral sclerosis mutant superoxide dismutase-1 transgenic mice: mechanisms of mitochondriopathy and cell death. J. Comp. Neurol. 500, 20-46. doi: 10.1002/cne.21160

Martineau, M., Shi, T., Puyal, J., Knolhoff, A. M., Dulong, J., Gasnier, B., et al. (2013). Storage and uptake of D-serine into astrocytic synaptic-like vesicles specify gliotransmission. J. Neurosci. 33, 3413-3423. doi: 10.1523/jneurosci. $3497-12.2013$

Matsuyama, T., Shimizu, S., Nakamura, H., Michishita, H., Tagaya, M., and Sugita, M. (1994). Effects of recombinant superoxide dismutase on manganese superoxide dismutase gene expression in gerbil hippocampus after ischemia. Stroke 25, 1417-1423; discussion 1424. doi: 10.1161/01.str.25. 7.1417 
Mattiazzi, M., D’Aurelio, M., Gajewski, C. D., Martushova, K., Kiaei, M., Beal, M. F., et al. (2002). Mutated human SOD1 causes dysfunction of oxidative phosphorylation in mitochondria of transgenic mice. J. Biol. Chem. 277, 29626-29633. doi: 10.1074/jbc.m203065200

Mattson, M. P. (2013). Excitation BolsTORs motor neurons in ALS mice. Neuron 80, 1-3. doi: 10.1016/j.neuron.2013.09.017

McBain, C. J., and Mayer, M. L. (1994). N-methyl-D-aspartic acid receptor structure and function. Physiol. Rev. 74, 723-760. doi: 10.1152/physrev.1994. 74.3.723

McGown, A., McDearmid, J. R., Panagiotaki, N., Tong, H., Al Mashhadi, S., Redhead, N., et al. (2013). Early interneuron dysfunction in ALS: insights from a mutant sod1 zebrafish model. Ann. Neurol. 73, 246-258. doi: 10.1002/ana. 23780

Mehta, A., Prabhakar, M., Kumar, P., Deshmukh, R., and Sharma, P. L. (2013). Excitotoxicity: bridge to various triggers in neurodegenerative disorders. Eur. J. Pharmacol. 698, 6-18. doi: 10.1016/j.ejphar.2012.10.032

Menzies, F. M., Ince, P. G., and Shaw, P. J. (2002). Mitochondrial involvement in amyotrophic lateral sclerosis. Neurochem. Int. 40, 543-551. doi: 10.1016/s01970186(01)00125-5

Merlini, M., Meyer, E. P., and Nitsch, A. U. R. M. (2011). Vascular $\beta$-amyloid and early astrocyte alterations impair cerebrovascular function and cerebral metabolism in transgenic arcA $\beta$ mice. Acta Neuropathol. 122, 293-311. doi: 10.1007/s00401-011-0834-y

Mesci, P., Zaïdi, S., Lobsiger, C. S., Millecamps, S., Escartin, C., Seilhean, D., et al. (2015). System xC- is a mediator of microglial function and its deletion slows symptoms in amyotrophic lateral sclerosis mice. Brain 138, 53-68. doi: 10.1093/brain/awu312

Mikami, Y., Kanemaru, K., Okubo, Y., Nakaune, T., Suzuki, J., Shibata, K., et al. (2016). Nitric oxide-induced activation of the type 1 ryanodine receptor is critical for epileptic seizure-induced neuronal cell death. EBioMedicine 11, 253-261. doi: 10.1016/j.ebiom.2016.08.020

Milanese, M., Bonifacino, T., Fedele, E., Rebosio, C., Cattaneo, L., Benfenati, F., et al. (2015). Exocytosis regulates trafficking of GABA and glycine heterotransporters in spinal cord glutamatergic synapses: a mechanism for the excessive heterotransporter-induced release of glutamate in experimental amyotrophic lateral sclerosis. Neurobiol. Dis. 74, 314-324. doi: 10.1016/j.nbd. 2014.12.004

Minciacchi, D., Kassa, R. M., Del Tongo, C., Mariotti, R., and Bentivoglio, M. (2009). Voronoi-based spatial analysis reveals selective interneuron changes in the cortex of FALS mice. Exp. Neurol. 215, 77-86. doi: 10.1016/j.expneurol. 2008.09.005

Mishra, V., Shuai, B., Kodali, M., Shetty, G. A., Hattiangady, B., Rao, X., et al. (2015). Resveratrol treatment after status epilepticus restrains neurodegeneration and abnormal neurogenesis with suppression of oxidative stress and inflammation. Sci. Rep. 5:17807. doi: 10.1038/srep17807

Mosconi, L., Pupi, A., and De Leon, M. J. (2009). Brain glucose hypometabolism and oxidative stress in preclinical Alzheimer's disease. Ann. N Y Acad. Sci. 1147, 180-195. doi: 10.1196/annals.1427.007

Mulholland, P. J., Luong, N. T., Woodward, J. J., and Chandler, L. J. (2008). Brain-derived neurotrophic factor activation of extracellular signalregulated kinase is autonomous from the dominant extrasynaptic NMDA receptor extracellular signal-regulated kinase shutoff pathway. Neuroscience 151, 419-427. doi: 10.1016/j.neuroscience.2007.11.001

Mülsch, A., Busse, R., Mordvintcev, P. I., Vanin, A. F., Nielsen, E. O., ScheelKrüger, J., et al. (1994). Nitric oxide promotes seizure activity in kainate-treated rats. Neuroreport 5, 2325-2328. doi: 10.1097/00001756-199411000-00029

Murphy, E. J., Behrmann, D., Bates, C. M., and Horrocks, L. A. (1994). Lipid alterations following impact spinal cord injury in the rat. Mol. Chem. Neuropathol. 23, 13-26. doi: 10.1007/bf02858504

Murphy-Royal, C., Dupuis, J. P., Varela, J. A., Panatier, A., Pinson, B., Baufreton, J., et al. (2015). Surface diffusion of astrocytic glutamate transporters shapes synaptic transmission. Nat. Neurosci. 18, 219-226. doi: 10.1038/nn.3901

Mutch, W. A., and Hansen, A. J. (1984). Extracellular pH changes during spreading depression and cerebral ischemia: mechanisms of brain $\mathrm{pH}$ regulation. J. Cereb. Blood Flow Metab. 4, 17-27. doi: 10.1038/jcbfm.1984.3

Newman, L. A., Korol, D. L., and Gold, P. E. (2011). Lactate produced by glycogenolysis in astrocytes regulates memory processing. PLoS One 6:e28427. doi: 10.1371 /journal.pone. 0028427
Nicholls, D. G. (2004). Mitochondrial dysfunction and glutamate excitotoxicity studied in primary neuronal cultures. Curr. Mol. Med. 4, 149-177. doi: 10.2174/1566524043479239

Nicholls, D. G., and Budd, S. L. (2000). Mitochondria and neuronal survival. Physiol. Rev. 80, 315-360. doi: 10.1152/physrev.2000.80.1.315

Nikodemova, M., Small, A. L., Smith, S. M. C., Mitchell, G. S., and Watters, J. J. (2014). Spinal but not cortical microglia acquire an atypical phenotype with high VEGF, galectin-3 and osteopontin, and blunted inflammatory responses in ALS rats. Neurobiol. Dis. 69, 43-53. doi: 10.1016/j.nbd.2013.11.009

Nikolic, L., Nobili, P., Shen, W., and Audinat, E. (2019). Role of astrocyte purinergic signaling in epilepsy. Glia doi: 10.1002/glia.23747 [Epub ahead of print].

Norenberg, M. D., and Martinez-Hernandez, A. (1979). Fine structural localization of glutamine synthetase in astrocytes of rat brain. Brain Res. 161, 303-310. doi: 10.1016/0006-8993(79)90071-4

O'Byrne, M. B., and Tipton, K. F. (2000). Taurine-induced attenuation of MPP ${ }^{+}$ neurotoxicity in vitro. J. Neurochem. 74, 2087-2093. doi: 10.1046/j.1471-4159. 2000.0742087.x

Ohtsuki, T., Matsumoto, M., Suzuki, K., Taniguchi, N., and Kamada, T. (1993). Effect of transient forebrain ischemia on superoxide dismutases in gerbil hippocampus. Brain Res. 620, 305-309. doi: 10.1016/0006-8993(93)90171-i

Olabarria, M., Noristani, H. N., Verkhratsky, A., and Rodríguez, J. J. (2011). Age-dependent decrease in glutamine synthetase expression in the hippocampal astroglia of the triple transgenic Alzheimer's disease mouse model: mechanism for deficient glutamatergic transmission? Mol. Neurodegener. 6:55. doi: 10.1186/1750-1326-6-55

Olney, J. W. (1969). Brain lesions, obesity, and other disturbances in mice treated with monosodium glutamate. Science 164, 719-721. doi: 10.1126/science.164 3880.719

Ottersen, O. P., Zhang, N., and Walberg, F. (1992). Metabolic compartmentation of glutamate and glutamine: morphological evidence obtained by quantitative immunocytochemistry in rat cerebellum. Neuroscience 46, 519-534. doi: 10.1016/0306-4522(92)90141-n

Pál, B. (2018). Involvement of extrasynaptic glutamate in physiological and pathophysiological changes of neuronal excitability. Cell. Mol. Life Sci. 75, 2917-2949. doi: 10.1007/s00018-018-2837-5

Palmer, A. M., Marion, D. W., Botscheller, M. L., Bowen, D. M., and DeKosky, S. T. (1994). Increased transmitter amino acid concentration in human ventricular CSF after brain trauma. Neuroreport 6, 153-156. doi: 10.1097/00001756199412300-00039

Papouin, T., Ladépêche, L., Ruel, J., Sacchi, S., Labasque, M., Hanini, M., et al. (2012). Synaptic and extrasynaptic NMDA receptors are gated by different endogenous coagonists. Cell 150, 633-646. doi: 10.1016/j.cell.2012.06.029

Parsons, M. P., and Raymond, L. A. (2014). Extrasynaptic NMDA receptor involvement in central nervous system disorders. Neuron 82, 279-293. doi: 10.1016/j.neuron.2014.03.030

Pasinelli, P., Houseweart, M. K., Brown, R. H., and Cleveland, D. W. (2000). Caspase- 1 and -3 are sequentially activated in motor neuron death in $\mathrm{Cu}, \mathrm{Zn}$ superoxide dismutase-mediated familial amyotrophic lateral sclerosis. Proc. Natl. Acad. Sci. U S A 97, 13901-13906. doi: 10.1073/pnas.240305897

Patel, M., Day, B. J., Crapo, J. D., Fridovich, I., and McNamara, J. O. (1996). Requirement for superoxide in excitotoxic cell death. Neuron 16, 345-355. doi: 10.1016/s0896-6273(00)80052-5

Patneau, D. K., and Mayer, M. L. (1990). Structure-activity relationships for amino acid transmitter candidates acting at N-methyl-D-aspartate and quisqualate receptors. J. Neurosci. 10, 2385-2399. doi: 10.1523/jneurosci.10-07-02 385.1990

Patricio-Martínez, A., Sánchez-Zavaleta, R., Angulo-Cruz, I., GutierrezPraxedis, L., Ramírez, E., Martínez-García, I., et al. (2019). The acute activation of the $\mathrm{CB} 1$ receptor in the hippocampus decreases neurotoxicity and prevents spatial memory impairment in rats lesioned with $\beta$-amyloid 25-35. Neuroscience 416, 239-254. doi: 10.1016/j.neuroscience.2019.08.001

Pauletti, A., Terrone, G., Shekh-Ahmad, T., Salamone, A., Ravizza, T., Rizzi, M. et al. (2019). Targeting oxidative stress improves disease outcomes in a rat model of acquired epilepsy. Brain 142:e39. doi: 10.1093/brain/awz130

Pazdernik, T. L., Layton, M., Nelson, S. R., and Samson, F. E. (1992). The osmotic/calcium stress theory of brain damage: are free radicals involved? Neurochem. Res. 17, 11-21. doi: 10.1007/bf00966860 
Pellegrini-Giampietro, D. E., Cherici, G., Alesiani, M., Carla, V., and Moroni, F. (1990). Excitatory amino acid release and free radical formation may cooperate in the genesis of ischemia-induced neuronal damage. J. Neurosci. 10, 1035-1041. doi: 10.1523/jneurosci.10-03-01035.1990

Peterson, A. R., and Binder, D. K. (2019). Regulation of synaptosomal GLT-1 and GLAST during epileptogenesis. Neuroscience 411, 185-201. doi: 10.1016/j. neuroscience.2019.05.048

Petkova, Z., Tchekalarova, J., Pechlivanova, D., Moyanova, S., Kortenska, L., Mitreva, R., et al. (2014). Treatment with melatonin after status epilepticus attenuates seizure activity and neuronal damage but does not prevent the disturbance in diurnal rhythms and behavioral alterations in spontaneously hypertensive rats in kainate model of temporal lobe epilepsy. Epilepsy Behav. 31, 198-208. doi: 10.1016/j.yebeh.2013.12.013

Petr, G. T., Sun, Y., Frederick, N. M., Zhou, Y., Dhamne, S. C., Hameed, M. Q., et al. (2015). Conditional deletion of the glutamate transporter GLT-1 reveals that astrocytic GLT-1 protects against fatal epilepsy while neuronal GLT-1 contributes significantly to glutamate uptake into synaptosomes. J. Neurosci. 35, 5187-5201. doi: 10.1523/jneurosci.4255-14.2015

Phillis, J. W., and Wu, P. H. (1981). The role of adenosine and its nucleotides in central synaptic transmission. Prog. Neurobiol. 16, 187-239. doi: 10.1016/03010082(81)90014-9

Pinto, S., Cunha, C., Barbosa, M., Vaz, A. R., and Brites, D. (2017). Exosomes from NSC-34 cells transfected with hSOD1-G93A are enriched in miR-124 and drive alterations in microglia phenotype. Front. Neurosci. 11:273. doi: 10.3389/fnins. 2017.00273

Pittau, F., Grouiller, F., Spinelli, L., Seeck, M., Michel, C. M., and Vulliemoz, S. (2014). The role of functional neuroimaging in pre-surgical epilepsy evaluation. Front. Neurol. 5:31. doi: 10.3389/fneur.2014.00031

Politi, D. M., and Rogawski, M. A. (1991). Glyburide-sensitive $\mathrm{K}^{+}$channels in cultured rat hippocampal neurons: activation by cromakalim and energydepleting conditions. Mol. Pharmacol. 40, 308-315.

Popova, I., Malkov, A., Ivanov, A. I., Samokhina, E., Buldakova, S., Gubkina, O., et al. (2017). Metabolic correction by pyruvate halts acquired epilepsy in multiple rodent models. Neurobiol. Dis. 106, 244-254. doi: 10.1016/j.nbd.2017. 07.012

Prentice, H., Modi, J. P., and Wu, J.-Y. (2015). Mechanisms of neuronal protection against excitotoxicity, endoplasmic reticulum stress and mitochondrial dysfunction in stroke and neurodegenerative diseases. Oxid. Med. Cell. Longev. 2015:964518. doi: 10.1155/2015/964518

Proper, E. A., Hoogland, G., Kappen, S. M., Jansen, G. H., Rensen, M. G., Schrama, L. H., et al. (2002). Distribution of glutamate transporters in the hippocampus of patients with pharmaco-resistant temporal lobe epilepsy. Brain 125, 32-43. doi: 10.1093/brain/awf001

Qiang, M., Dong, X., Zha, Z., Zuo, X.-K., Song, X.-L., Zhao, L., et al. (2018). Selection of an ASIC1a-blocking combinatorial antibody that protects cells from ischemic death. Proc. Natl. Acad. Sci. U S A 115, E7469-E7477. doi: 10.1073/pnas. 1807233115

Qin, S., Colin, C., Hinners, I., Gervais, A., Cheret, C., and Mallat, M. (2006). System $\mathrm{X}_{\mathrm{c}}^{-}$and apolipoprotein $\mathrm{E}$ expressed by microglia have opposite effects on the neurotoxicity of amyloid- $\beta$ peptide 1-40. J. Neurosci. 26, 3345-3356. doi: 10.1523/jneurosci.5186-05.2006

Qiu, J., Tan, Y.-W., Hagenston, A. M., Martel, M.-A., Kneisel, N., Skehel, P. A., et al. (2013). Mitochondrial calcium uniporter Mcu controls excitotoxicity and is transcriptionally repressed by neuroprotective nuclear calcium signals. Nat. Commun. 4:2034. doi: 10.1038/ncomms3034

Rahimi, N., Hassanipour, M., Yarmohammadi, F., Faghir-Ghanesefat, H., Pourshadi, N., Bahramnejad, E., et al. (2019). Nitric oxide and glutamate are contributors of anti-seizure activity of rubidium chloride: a comparison with lithium. Neurosci. Lett. 708:134349. doi: 10.1016/j.neulet.2019.134349

Raiteri, L., Paolucci, E., Prisco, S., Raiteri, M., and Bonanno, G. (2003). Activation of a glycine transporter on spinal cord neurons causes enhanced glutamate release in a mouse model of amyotrophic lateral sclerosis. Br. J. Pharmacol. 138, 1021-1025. doi: 10.1038/sj.bjp.0705142

Rakhade, S. N., and Loeb, J. A. (2008). Focal reduction of neuronal glutamate transporters in human neocortical epilepsy. Epilepsia 49, 226-236. doi: 10.1111/j.1528-1167.2007.01310.x

Ralay Ranaivo, H., Craft, J. M., Hu, W., Guo, L., Wing, L. K., Van Eldik, L. J., et al. (2006). Glia as a therapeutic target: selective suppression of human amyloid- $\beta$-induced upregulation of brain proinflammatory cytokine production attenuates neurodegeneration. J. Neurosci. 26, 662-670. doi: 10.1523/jneurosci.4652-05.2006

Ransom, C. B., Ransom, B. R., and Sontheimer, H. (2000). Activity-dependent extracellular $\mathrm{K}^{+}$accumulation in rat optic nerve: the role of glial and axonal $\mathrm{Na}^{+}$pumps. J. Physiol. 522, 427-442. doi: 10.1111/j.1469-7793.2000. 00427.x

Reiner, A., and Levitz, J. (2018). Glutamatergic signaling in the central nervous system: ionotropic and metabotropic receptors in concert. Neuron 98, 1080-1098. doi: 10.1016/j.neuron.2018.05.018

Reynolds, A., Laurie, C., Mosley, R. L., and Gendelman, H. E. (2007). Oxidative stress and the pathogenesis of neurodegenerative disorders. Int. Rev. Neurobiol. 82, 297-325. doi: 10.1016/S0074-7742(07)82016-2

Richter, C., and Kass, G. E. (1991). Oxidative stress in mitochondria: its relationship to cellular $\mathrm{Ca}^{2+}$ homeostasis, cell death, proliferation, and differentiation. Chem. Biol. Interact. 77, 1-23. doi: 10.1016/00092797(91)90002-o

Riepe, M., Hori, N., Ludolph, A. C., Carpenter, D. O., Spencer, P. S., and Allen, C. N. (1992). Inhibition of energy metabolism by 3-nitropropionic acid activates ATP-sensitive potassium channels. Brain Res. 586, 61-66. doi: 10.1016/0006-8993(92)91371-k

Rodríguez-Arellano, J. J., Parpura, V., Zorec, R., and Verkhratsky, A. (2016). Astrocytes in physiological aging and Alzheimer's disease. Neuroscience 323, 170-182. doi: 10.1016/j.neuroscience.2015.01.007

Rönicke, R., Mikhaylova, M., Rönicke, S., Meinhardt, J., Schröder, U. H., Fändrich, M., et al. (2011). Early neuronal dysfunction by amyloid $\beta$ oligomers depends on activation of NR2B-containing NMDA receptors. Neurobiol. Aging 32, 2219-2228. doi: 10.1016/j.neurobiolaging.2010.01.011

Rose, J., Brian, C., Woods, J., Pappa, A., Panayiotidis, M. I., Powers, R., et al. (2017). Mitochondrial dysfunction in glial cells: implications for neuronal homeostasis and survival. Toxicology 391, 109-115. doi: 10.1016/j.tox.2017.06.011

Rossi, D., Brambilla, L., Valori, C. F., Roncoroni, C., Crugnola, A., Yokota, T., et al. (2008). Focal degeneration of astrocytes in amyotrophic lateral sclerosis. Cell Death Differ. 15, 1691-1700. doi: 10.1038/cdd.2008.99

Rossi, D. J., Oshima, T., and Attwell, D. (2000). Glutamate release in severe brain ischaemia is mainly by reversed uptake. Nature 403, 316-321. doi: $10.1038 / 35002090$

Rothstein, J. D., Dykes-Hoberg, M., Pardo, C. A., Bristol, L. A., Jin, L., Kuncl, R. W., et al. (1996). Knockout of glutamate transporters reveals a major role for astroglial transport in excitotoxicity and clearance of glutamate. Neuron 16, 675-686. doi: 10.1016/s0896-6273(00)80086-0

Rothstein, J. D., Patel, S., Regan, M. R., Haenggeli, C., Huang, Y. H., Bergles, D. E., et al. (2005). $\beta$-lactam antibiotics offer neuroprotection by increasing glutamate transporter expression. Nature 433, 73-77. doi: 10.1038/nature03180

Rowley, S., Liang, L.-P., Fulton, R., Shimizu, T., Day, B., and Patel, M. (2015). Mitochondrial respiration deficits driven by reactive oxygen species in experimental temporal lobe epilepsy. Neurobiol. Dis. 75, 151-158. doi: 10.1016/j.nbd.2014.12.025

Rutecki, P. A., Sayin, U., Yang, Y., and Hadar, E. (2002). Determinants of ictal epileptiform patterns in the hippocampal slice. Epilepsia 43, 179-183. doi: 10.1046/j.1528-1157.43.s.5.34.x

Ryan, K., Backos, D. S., Reigan, P., and Patel, M. (2012). Post-translational oxidative modification and inactivation of mitochondrial complex I in epileptogenesis. J. Neurosci. 32, 11250-11258. doi: 10.1523/jneurosci.090712.2012

Saba, L., Viscomi, M. T., Caioli, S., Pignataro, A., Bisicchia, E., Pieri, M., et al. (2016). Altered functionality, morphology and vesicular glutamate transporter expression of cortical motor neurons from a presymptomatic mouse model of amyotrophic lateral sclerosis. Cereb. Cortex 26, 1512-1528. doi: 10.1093/cercor/bhu317

Sah, P. (1996). $\mathrm{Ca}^{2+}$-activated $\mathrm{K}^{+}$currents in neurones: types, physiological roles and modulation. Trends Neurosci. 19, 150-154. doi: 10.1016/s01662236(96)80026-9

Samson, A. J., Robertson, G., Zagnoni, M., and Connolly, C. N. (2016). Neuronal networks provide rapid neuroprotection against spreading toxicity. Sci. Rep. 6:33746. doi: $10.1038 /$ srep33746

Sapolsky, R. M. (2001). Cellular defenses against excitotoxic insults. J. Neurochem. 76, 1601-1611. doi: 10.1046/j.1471-4159.2001.00203.x 
Sarac, S., Afzal, S., Broholm, H., Madsen, F. F., Ploug, T., and Laursen, H. (2009). Excitatory amino acid transporters EAAT-1 and EAAT-2 in temporal lobe and hippocampus in intractable temporal lobe epilepsy. APMIS 117, 291-301. doi: 10.1111/j.1600-0463.2009.02443.x

Sasaki, S., Komori, T., and Iwata, M. (2000). Excitatory amino acid transporter 1 and 2 immunoreactivity in the spinal cord in amyotrophic lateral sclerosis. Acta Neuropathol. 100, 138-144. doi: 10.1007/s004019900159

Sato, H., Kuriyama-Matsumura, K., Hashimoto, T., Sasaki, H., Wang, H., Ishii, T., et al. (2001). Effect of oxygen on induction of the cystine transporter by bacterial lipopolysaccharide in mouse peritoneal macrophages. J. Biol. Chem. 276, 10407-10412. doi: 10.1074/jbc.m007216200

Sato, H., Tamba, M., Ishii, T., and Bannai, S. (1999). Cloning and expression of a plasma membrane cystine/glutamate exchange transporter composed of two distinct proteins. J. Biol. Chem. 274, 11455-11458. doi: 10.1074/jbc.274.17. 11455

Sato, H., Tamba, M., Okuno, S., Sato, K., Keino-Masu, K., Masu, M., et al. (2002). Distribution of cystine/glutamate exchange transporter, system $\mathrm{x}_{\mathrm{c}}^{-}$, in the mouse brain. J. Neurosci. 22, 8028-8033. doi: 10.1523/jneurosci.22-18-08 028.2002

Schafe, G. E., Atkins, C. M., Swank, M. W., Bauer, E. P., Sweatt, J. D., and Ledoux, J. E. (2000). Activation of ERK/MAP kinase in the amygdala is required for memory consolidation of Pavlovian fear conditioning. J. Neurosci. 20, 8177-8187. doi: 10.1523/jneurosci.20-21-08177.2000

Scheuner, D., Eckman, C., Jensen, M., Song, X., Citron, M., Suzuki, N., et al. (1996). Secreted amyloid $\beta$-protein similar to that in the senile plaques of Alzheimer's disease is increased in vivo by the presenilin 1 and 2 and APP mutations linked to familial Alzheimer's disease. Nat. Med. 2, 864-870. doi: 10.1038/nm0896-864

Schor, N. F. (1988). Inactivation of mammalian brain glutamine synthetase by oxygen radicals. Brain Res. 456, 17-21. doi: 10.1016/0006-8993(88)90341-1

Schousboe, A., Westergaard, N., Waagepetersen, H. S., Larsson, O. M., Bakken, I. J., and Sonnewald, U. (1997). Trafficking between glia and neurons of TCA cycle intermediates and related metabolites. Glia 21, 99-105. doi: 10.1002/(sici)1098-1136(199709)21:1<99::aid-glia11 >3.0.co;2-w

Schurr, A. (2014). Cerebral glycolysis: a century of persistent misunderstanding and misconception. Front. Neurosci. 8:360. doi: 10.3389/fnins.2014.00360

Scimemi, A., Meabon, J. S., Woltjer, R. L., Sullivan, J. M., Diamond, J. S., and Cook, D. G. (2013). Amyloid- $\beta 1-42$ slows clearance of synaptically released glutamate by mislocalizing astrocytic GLT-1. J. Neurosci. 33, 5312-5318. doi: 10.1523/JNEUROSCI.5274-12.2013

Seifert, G., Carmignoto, G., and Steinhäuser, C. (2010). Astrocyte dysfunction in epilepsy. Brain Res. Rev. 63, 212-221. doi: 10.1016/j.brainresrev.2009.10.004

Selvaraj, B. T., Livesey, M. R., Zhao, C., Gregory, J. M., James, O. T., Cleary, E. M., et al. (2018). C9ORF72 repeat expansion causes vulnerability of motor neurons to $\mathrm{Ca}^{2+}$-permeable AMPA receptor-mediated excitotoxicity. Nat. Commun. 9:347. doi: 10.1038/s41467-017-02729-0

Sha, L., Wang, X., Li, J., Shi, X., Wu, L., Shen, Y., et al. (2017). Pharmacologic inhibition of Hsp90 to prevent GLT-1 degradation as an effective therapy for epilepsy. J. Exp. Med. 214, 547-563. doi: 10.1084/jem.20160667

Sheffield, L. G., Marquis, J. G., and Berman, N. E. J. (2000). Regional distribution of cortical microglia parallels that of neurofibrillary tangles in Alzheimer's disease. Neurosci. Lett. 285, 165-168. doi: 10.1016/s0304-3940(00)01037-5

Shibuya, K., Park, S. B., Geevasinga, N., Menon, P., Howells, J., Simon, N. G., et al. (2016). Motor cortical function determines prognosis in sporadic ALS. Neurology 87, 513-520. doi: 10.1212/wnl.0000000000002912

Shih, A. Y., Erb, H., Sun, X., Toda, S., Kalivas, P. W., and Murphy, T. H. (2006). Cystine/glutamate exchange modulates glutathione supply for neuroprotection from oxidative stress and cell proliferation. J. Neurosci. 26, 10514-10523. doi: 10.1523/jneurosci.3178-06.2006

Siemkowicz, E., and Hansen, A. J. (1981). Brain extracellular ion composition and EEG activity following 10 minutes ischemia in normo- and hyperglycemic rats. Stroke 12, 236-240. doi: 10.1161/01.str.12.2.236

Simon, R. P., Niro, M., and Gwinn, R. (1993). Brain acidosis induced by hypercarbic ventilation attenuates focal ischemic injury. J. Pharmacol. Exp. Ther. 267, 1428-1431.

Simpson, J. E., Ince, P. G., Lace, G., Forster, G., Shaw, P. J., Matthews, F., et al. (2010). Astrocyte phenotype in relation to Alzheimer-type pathology in the ageing brain. Neurobiol. Aging 31, 578-590. doi: 10.1016/j.neurobiolaging.2008. 05.015
Singh, A., and Trevick, S. (2016). The epidemiology of global epilepsy. Neurol. Clin. 34, 837-847. doi: 10.1016/j.ncl.2016.06.015

Sloviter, R. S., Dichter, M. A., Rachinsky, T. L., Dean, E., Goodman, J. H., Sollas, A. L., et al. (1996). Basal expression and induction of glutamate decarboxylase and GABA in excitatory granule cells of the rat and monkey hippocampal dentate gyrus. J. Comp. Neurol. 373, 593-618. doi: 10.1002/(sici)1096-9861(19960930)373:4<593::aid-cne8>3.0.co;2-X

Smith, C. D., Carney, J. M., Starke-Reed, P. E., Oliver, C. N., Stadtman, E. R., Floyd, R. A., et al. (1991). Excess brain protein oxidation and enzyme dysfunction in normal aging and in Alzheimer disease. Proc. Natl. Acad. Sci. U S A 88, 10540-10543. doi: 10.1073/pnas.88.23.10540

Sokal, D. M., Mason, R., and Parker, T. L. (2000). Multi-neuronal recordings reveal a differential effect of thapsigargin on bicuculline- or gabazineinduced epileptiform excitability in rat hippocampal neuronal networks. Neuropharmacology 39, 2408-2417. doi: 10.1016/s0028-3908(00)00095-2

Soukupová, M., Binaschi, A., Falcicchia, C., Zucchini, S., Roncon, P., Palma, E., et al. (2014). Impairment of GABA release in the hippocampus at the time of the first spontaneous seizure in the pilocarpine model of temporal lobe epilepsy. Exp. Neurol. 257, 39-49. doi: 10.1016/j.expneurol.2014.04.014

Stavrovskaya, I. G., and Kristal, B. S. (2005). The powerhouse takes control of the cell: is the mitochondrial permeability transition a viable therapeutic target against neuronal dysfunction and death? Free Radic. Biol. Med. 38, 687-697. doi: 10.1016/j.freeradbiomed.2004.11.032

Steinhäuser, C., Grunnet, M., and Carmignoto, G. (2016). Crucial role of astrocytes in temporal lobe epilepsy. Neuroscience 323, 157-169. doi: 10.1016/j. neuroscience.2014.12.047

Stephens, B., Guiloff, R. J., Navarrete, R., Newman, P., Nikhar, N., and Lewis, P. (2006). Widespread loss of neuronal populations in the spinal ventral horn in sporadic motor neuron disease. A morphometric study. J. Neurol. Sci. 244, 41-58. doi: 10.1016/j.jns.2005.12.003

Stobart, J. L., and Anderson, C. M. (2013). Multifunctional role of astrocytes as gatekeepers of neuronal energy supply. Front. Cell. Neurosci. 7:38. doi: 10.3389/fncel.2013.00038

Sultan, S., Li, L., Moss, J., Petrelli, F., Cassé, F., Gebara, E., et al. (2015). Synaptic integration of adult-born hippocampal neurons is locally controlled by astrocytes. Neuron 88, 957-972. doi: 10.1016/j.neuron.2015.10.037

Surin, A. M., Gorbacheva, L. R., Savinkova, I. G., Sharipov, R. R., Khodorov, B. I., and Pinelis, V. G. (2014). Study on ATP concentration changes in cytosol of individual cultured neurons during glutamate-induced deregulation of calcium homeostasis. Biochemistry 79, 146-157. doi: 10.1134/s0006297914020084

Susarla, B. T., and Robinson, M. B. (2008). Internalization and degradation of the glutamate transporter GLT-1 in response to phorbol ester. Neurochem. Int. 52, 709-722. doi: 10.1016/j.neuint.2007.08.020

Suzuki, A., Stern, S. A., Bozdagi, O., Huntley, G. W., Walker, R. H., Magistretti, P. J., et al. (2011). Astrocyte-neuron lactate transport is required for long-term memory formation. Cell 144, 810-823. doi: 10.1016/j.cell.2011. 02.018

Talantova, M., Sanz-Blasco, S., Zhang, X., Xia, P., Waseem, M., and Okamoto, S. (2013). A $\beta$ induces astrocytic glutamate release, extrasynaptic NMDA receptor activation, and synaptic loss. Proc. Natl. Acad. Sci. U S A 110, E2518-E2527. doi: 10.1073/pnas.1306832110

Tanaka, K., Watase, K., Manabe, T., Yamada, K., Watanabe, M., Takahashi, K., et al. (1997). Epilepsy and exacerbation of brain injury in mice lacking the glutamate transporter GLT-1. Science 276, 1699-1702. doi: 10.1126/science. 276.5319.1699

Tang, C. M., Dichter, M., and Morad, M. (1990). Modulation of the N-methylD-aspartate channel by extracellular H+. Proc. Natl. Acad. Sci. U S A 87, 6445-6449. doi: 10.1073/pnas.87.16.6445

Tanqueiro, S. R., Ramalho, R. M., Rodrigues, T. M., Lopes, L. V., Sebastião, A. M., and Diógenes, M. J. (2018). Inhibition of NMDA receptors prevents the loss of BDNF function induced by amyloid $\beta$. Front. Pharmacol. 9:237. doi: 10.3389/fphar.2018.00237

Taylor, J. M., Main, B. S., and Crack, P. J. (2013). Neuroinflammation and oxidative stress: co-conspirators in the pathology of Parkinson's disease. Neurochem. Int. 62, 803-819. doi: 10.1016/j.neuint.2012.12.016

Texidó, L., Martín-Satué, M., Alberdi, E., Solsona, C., and Matute, C. (2011). Amyloid $\beta$ peptide oligomers directly activate NMDA receptors. Cell Calcium 49, 184-190. doi: 10.1016/j.ceca.2011.02.001 
Thielsen, K. D., Moser, J. M., Schmitt-John, T., Jensen, M. S., Jensen, K., and Holm, M. M. (2013). The Wobbler mouse model of amyotrophic lateral sclerosis (ALS) displays hippocampal hyperexcitability and reduced number of interneurons, but no presynaptic vesicle release impairments. PLoS One 8:e82767. doi: 10.1371/journal.pone.0082767

Thorn, T. L., He, Y., Jackman, N. A., Lobner, D., Hewett, J. A., and Hewett, S. J. (2015). A cytotoxic, co-operative interaction between energy deprivation and glutamate release from system xc-mediates aglycemic neuronal cell death. ASN Neuro 7:1759091415614301. doi: 10.1177/1759091415614301

Tombaugh, G. C., and Sapolsky, R. M. (1990). Mild acidosis protects hippocampal neurons from injury induced by oxygen and glucose deprivation. Brain Res. 506, 343-345. doi: 10.1016/0006-8993(90)91277-n

Tong, J., Huang, C., Bi, F., Wu, Q., Huang, B., Liu, X., et al. (2013). Expression of ALS-linked TDP-43 mutant in astrocytes causes non-cell-autonomous motor neuron death in rats. EMBO J. 32, 1917-1926. doi: 10.1038/emboj. 2013.122

Torp, R., Andiné, P., Hagberg, H., Karagülle, T., Blackstad, T. W., and Ottersen, O. P. (1991). Cellular and subcellular redistribution of glutamate-, glutamine- and taurine-like immunoreactivities during forebrain ischemia: a semiquantitative electron microscopic study in rat hippocampus. Neuroscience 41, 433-447. doi: 10.1016/0306-4522(91)90339-p

Trapp, S., and Ballanyi, K. (1995). KATP channel mediation of anoxia-induced outward current in rat dorsal vagal neurons in vitro. J. Physiol. 487, 37-50. doi: 10.1113/jphysiol.1995.sp020859

Trussell, L. O., and Fischbach, G. D. (1989). Glutamate receptor desensitization and its role in synaptic transmission. Neuron 3, 209-218. doi: 10.1016/08966273(89)90034-2

Van Damme, P., Bogaert, E., Dewil, M., Hersmus, N., Kiraly, D., Scheveneels, W., et al. (2007). Astrocytes regulate GluR2 expression in motor neurons and their vulnerability to excitotoxicity. Proc. Natl. Acad. Sci. U S A 104, 14825-14830. doi: 10.1073/pnas.0705046104

Van Damme, P., Braeken, D., Callewaert, G., Robberecht, W., and Van Den Bosch, L. (2005). GluR2 deficiency accelerates motor neuron degeneration in a mouse model of amyotrophic lateral sclerosis. J. Neuropathol. Exp. Neurol. 64, 605-612. doi: 10.1097/01.jnen.0000171647.09589.07

van den Berg, C. J., and Garfinkel, D. (1971). A simulation study of brain compartments. Metabolism of glutamate and related substances in mouse brain. Biochem. J. 123, 211-218. doi: 10.1042/bj1230211

Vergun, O., Keelan, J., Khodorov, B. I., and Duchen, M. R. (1999). Glutamate-induced mitochondrial depolarisation and perturbation of calcium homeostasis in cultured rat hippocampal neurones. J. Physiol. 519, 451-466. doi: 10.1111/j.1469-7793.1999.0451m.x

Vesce, S., Kirk, L., and Nicholls, D. G. (2004). Relationships between superoxide levels and delayed calcium deregulation in cultured cerebellar granule cells exposed continuously to glutamate. J. Neurochem. 90, 683-693. doi: 10.1111/j. 1471-4159.2004.02516.x

Vincent, P., and Mulle, C. (2009). Kainate receptors in epilepsy and excitotoxicity. Neuroscience 158, 309-323. doi: 10.1016/j.neuroscience.2008.02.066

Vucic, S., and Kiernan, M. C. (2006). Axonal excitability properties in amyotrophic lateral sclerosis. Clin. Neurophysiol. 117, 1458-1466. doi: 10.1016/j.clinph.2006. 04.016

Vucic, S., and Kiernan, M. C. (2013). Utility of transcranial magnetic stimulation in delineating amyotrophic lateral sclerosis pathophysiology. Handb. Clin. Neurol. 116, 561-575. doi: 10.1016/b978-0-444-53497-2.00045-0

Vyklický, L. (1993). Calcium-mediated modulation of N-methyl-D-aspartate (NMDA) responses in cultured rat hippocampal neurones. J. Physiol. 470, 575-600. doi: 10.1113/jphysiol.1993.sp019876

Wagle-Shukla, A., Ni, Z., Gunraj, C. A., Bahl, N., and Chen, R. (2009). Effects of short interval intracortical inhibition and intracortical facilitation on short interval intracortical facilitation in human primary motor cortex. J. Physiol. 587, 5665-5678. doi: 10.1113/jphysiol.2009.181446

Walczyk, T., and Wick, J. Y. (2017). The ketogenic diet: making a comeback. Consult. Pharm. 32, 388-396. doi: 10.4140/tcp.n.2017.388

Waldmann, R., Champigny, G., Bassilana, F., Heurteaux, C., and Lazdunski, M. (1997). A proton-gated cation channel involved in acid-sensing. Nature 386, 173-177. doi: 10.1038/386173a0

Walsh, D. M., Klyubin, I., Fadeeva, J. V., Cullen, W. K., Anwyl, R., Wolfe, M. S., et al. (2002). Naturally secreted oligomers of amyloid $\beta$ protein potently inhibit hippocampal long-term potentiation in vivo. Nature 416, 535-539. doi: $10.1038 / 416535$ a

Walz, W. (2000). Role of astrocytes in the clearance of excess extracellular potassium. Neurochem. Int. 36, 291-300. doi: 10.1016/s0197-0186(99)00137-0

Wang, C., Xie, N., Wang, Y., Li, Y., Ge, X., and Wang, M. (2015). Role of the mitochondrial calcium uniporter in rat hippocampal neuronal death after pilocarpine-induced status epilepticus. Neurochem. Res. 40, 1739-1746. doi: 10.1007/s11064-015-1657-3

Wang, X., Wang, W., Li, L., Perry, G., Lee, H. G., and Zhu, X. (2014). Oxidative stress and mitochondrial dysfunction in Alzheimer's disease. Biochim. Biophys. Acta 1842, 1240-1247. doi: 10.1016/j.bbadis.2013.10.015

Ward, M. W., Huber, H. J., Weisová, P., Düssmann, H., Nicholls, D. G., and Prehn, J. H. M. (2007). Mitochondrial and plasma membrane potential of cultured cerebellar neurons during glutamate-induced necrosis, apoptosis, and tolerance. J. Neurosci. 27, 8238-8249. doi: 10.1523/JNEUROSCI.198407.2007

Ward, M. W., Rego, A. C., Frenguelli, B. G., and Nicholls, D. G. (2000). Mitochondrial membrane potential and glutamate excitotoxicity in cultured cerebellar granule cells. J. Neurosci. 20, 7208-7219. doi: 10.1523/jneurosci.2019-07208.2000

Warr, O., Takahashi, M., and Attwell, D. (1999). Modulation of extracellular glutamate concentration in rat brain slices by cystine-glutamate exchange. J. Physiol. 514, 783-793. doi: 10.1111/j.1469-7793.1999.783ad.x

Wasterlain, C. G., Thompson, K. W., Suchomelova, L., and Niquet, J. (2010). Brain energy metabolism during experimental neonatal seizures. Neurochem. Res. 35 , 2193-2198. doi: 10.1007/s11064-010-0339-4

Watkins, J. C., and Evans, R. H. (1981). Excitatory amino acid transmitters. Annu. Rev. Pharmacol. Toxicol. 21, 165-204. doi: 10.1146/annurev.pa.21.040181. 001121

Weisová, P., Concannon, C. G., Devocelle, M., Prehn, J. H. M., and Ward, M. W. (2009). Regulation of glucose transporter 3 surface expression by the AMP-activated protein kinase mediates tolerance to glutamate excitation in neurons. J. Neurosci. 29, 2997-3008. doi: 10.1523/jneurosci.0354-09.2009

Westergaard, N., Banke, T. U. E., Wahl, P., Sonnewaldt, U., and Schousboe, A. (1995). Citrate modulates the regulation by $\mathrm{Zn}^{2+}$ of N-methyl-D-aspartate receptor-mediated channel current and neurotransmitter release. Proc. Natl. Acad. Sci. U S A 92, 3367-3370. doi: 10.1073/pnas.92.8.3367

Whitesell, L., and Lindquist, S. L. (2005). HSP90 and the chaperoning of cancer. Nat. Rev. Cancer 5, 761-772. doi: 10.1038/nrc1716

Williams, S., Hamil, N., Abramov, A. Y., Walker, M. C., and Kovac, S. (2015). Status epilepticus results in persistent overproduction of reactive oxygen species, inhibition of which is neuroprotective. Neuroscience 303, 160-165. doi: 10.1016/j.neuroscience.2015.07.005

Winkler, P., Luhmann, H. J., and Kilb, W. (2019). Taurine potentiates the anticonvulsive effect of the GABAA agonist muscimol and pentobarbital in the immature mouse hippocampus. Epilepsia 60, 464-474. doi: 10.1111/epi.14651

Witgert, M., Salamone, A. R., Strutt, A. M., Jawaid, A., Massman, P. J., Bradshaw, M., et al. (2010). Frontal-lobe mediated behavioral dysfunction in amyotrophic lateral sclerosis. Eur. J. Neurol. 17, 103-110. doi: 10.1111/j.14681331.2009.02801.x

Wolosker, H., Balu, D. T., and Coyle, J. T. (2016). The rise and fall of the dserine-mediated gliotransmission hypothesis. Trends Neurosci. 39, 712-721. doi: 10.1016/j.tins.2016.09.007

Wright, A., and Vissel, B. (2012). The essential role of AMPA receptor GluR2 subunit RNA editing in the normal and diseased brain. Front. Mol. Neurosci. 5:34. doi: 10.3389/fnmol.2012.00034

Wu, H. Y., and Lynch, D. R. (2006). Calpain and synaptic function. Mol. Neurobiol. 33, 215-236. doi: 10.1385/mn:33:3:215

Yamamoto, M., Kiyota, T., Walsh, S. M., Liu, J., Kipnis, J., and Ikezu, T. (2008). Cytokine-mediated inhibition of fibrillar amyloid- $\beta$ peptide degradation by human mononuclear phagocytes. J. Immunol. 181, 3877-3886. doi: 10.4049/jimmunol.181.6.3877

Yan, X., Shi, Z. F., Xu, L. X., Li, J. X., Wu, M., Wang, X. X., et al. (2017). Glutamate impairs mitochondria aerobic respiration capacity and enhances glycolysis in cultured rat astrocytes. Biomed. Environ. Sci. 30, 44-51. doi: 10.3967/bes 2017.005

Yao, J., Irwin, R. W., Zhao, L., Nilsen, J., Hamilton, R. T., and Brinton, R. D. (2009). Mitochondrial bioenergetic deficit precedes Alzheimer's pathology in 
female mouse model of Alzheimer's disease. Proc. Natl. Acad. Sci. U S A 106, 14670-14675. doi: 10.1073/pnas.0903563106

Yao, K., and $\mathrm{Zu}$, H. B. (2020). Microglial polarization: novel therapeutic mechanism against Alzheimer's disease. Inflammopharmacology 28, 95-110. doi: 10.1007/s10787-019-00613-5

Yenari, M. A., Giffard, R. G., Sapolsky, R. M., and Steinberg, G. K. (1999). The neuroprotective potential of heat shock protein 70 (HSP70). Mol. Med. Today 5, 525-531. doi: 10.1016/s1357-4310(99)01599-3

Zarei, S., Carr, K., Reiley, L., Diaz, K., Guerra, O., Altamirano, P., et al. (2015). A comprehensive review of amyotrophic lateral sclerosis. Surg. Neurol. Int. 6:171. doi: 10.4103/2152-7806.169561

Zeng, L. H., Bero, A. W., Zhang, B., Holtzman, D. M., and Wong, M. (2010). Modulation of astrocyte glutamate transporters decreases seizures in a mouse model of tuberous sclerosis complex. Neurobiol. Dis. 37, 764-771. doi: 10.1016/j.nbd.2009.12.020

Zhang, S., Sun, P., Sun, Z., Zhang, J., Zhou, J., and Gu, Y. (2013). Cortical GABAergic neurons are more severely impaired by alkalosis than acidosis. BMC Neurol. 13:192. doi: 10.1186/1471-2377-13-192

Zhao, W., Beers, D. R., and Appel, S. H. (2013). Immune-mediated mechanisms in the pathoprogression of amyotrophic lateral sclerosis. J. Neuroimmune Pharmacol. 8, 888-899. doi: 10.1007/s11481-013-9489-x

Zhou, X., Chen, Z., Yun, W., Ren, J., Li, C., Program, N., et al. (2015). Revisiting the function of extrasynaptic NMDA receptor in excitotoxicity. Neuroscientist 21, 337-344. doi: 10.1177/1073858414548724
Zhou, X., Ding, Q., Chen, Z., Yun, H., and Wang, H. (2013). Involvement of the GluN2A and GluN2B subunits in synaptic and extrasynaptic N-methyl-D-aspartate receptor function and neuronal excitotoxicity. J. Biol. Chem. 288, 24151-24159. doi: 10.1074/jbc.m113. 482000

Zhou, L., Li, F., Xu, H.-B., Luo, C.-X., Wu, H.-Y., Zhu, M.-M., et al. (2010). Treatment of cerebral ischemia by disrupting ischemia-induced interaction of nNOS with PSD-95. Nat. Med. 16, 1439-1443. doi: 10.1038/ nm. 2245

Zivin, J. A., and Choi, D. W. (1991). Stroke therapy. Sci. Am. 265, 56-65. doi: 10.1038/scientificamerican0791-56

Conflict of Interest: The authors declare that the research was conducted in the absence of any commercial or financial relationships that could be construed as a potential conflict of interest.

Copyright (C) 2020 Armada-Moreira, Gomes, Pina, Savchak, Gonçalves-Ribeiro, Rei, Pinto, Morais, Martins, Ribeiro, Sebastião, Crunelli and Vaz. This is an open-access article distributed under the terms of the Creative Commons Attribution License (CC BY). The use, distribution or reproduction in other forums is permitted, provided the original author(s) and the copyright owner(s) are credited and that the original publication in this journal is cited, in accordance with accepted academic practice. No use, distribution or reproduction is permitted which does not comply with these terms. 